




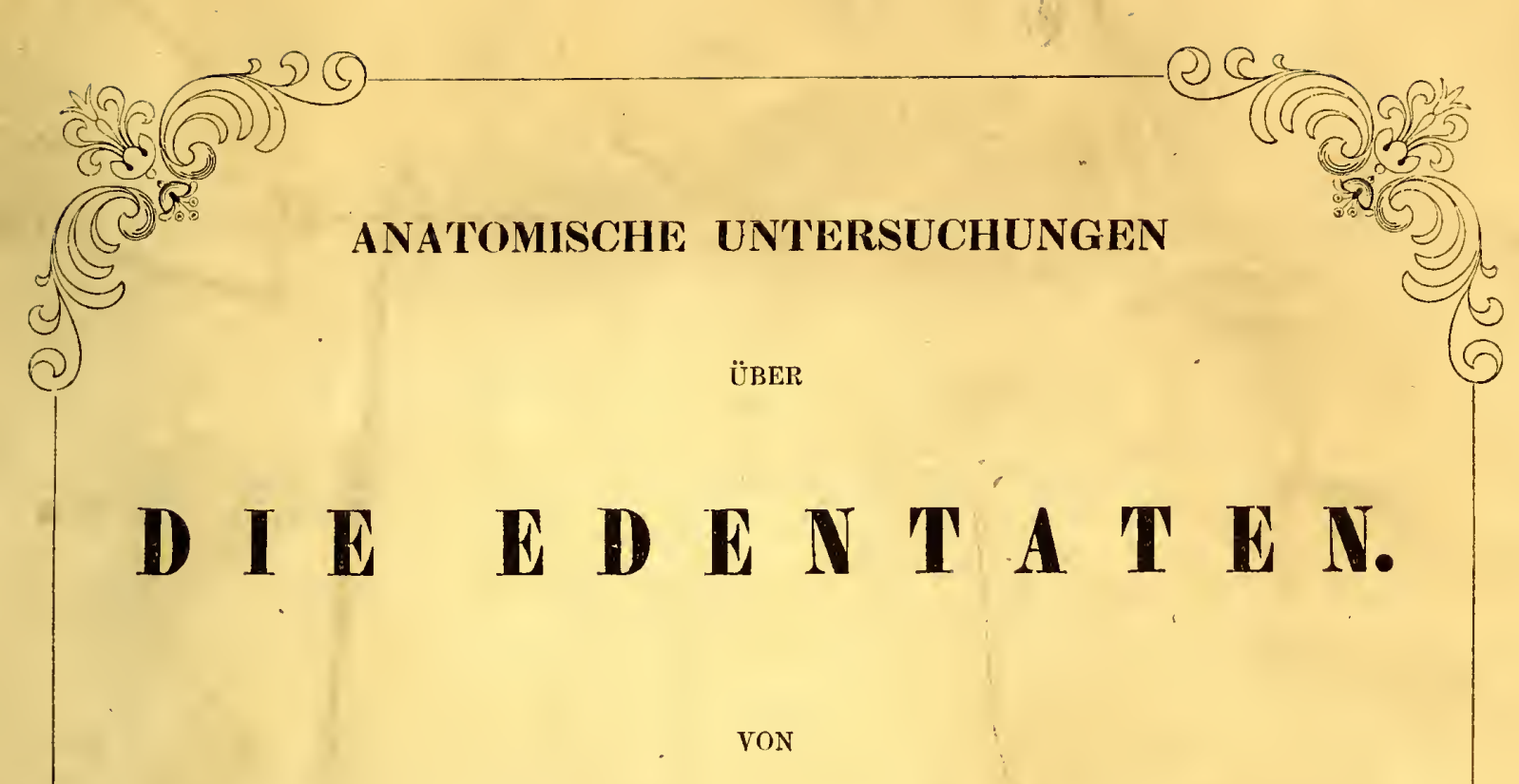

WILHELM voN RAPP,

RITTER DES ORDENS DER WÜRTTEMBERGISCHEN KRONE, PROFFGSOR DER MEDICIN IN TÜBINGEN.

MIT ZEHEN STEINDRUCKTAEELN.

ZWEITE VERBESSERTE UYID VERIIEIIRTE AUFLAGE.

9

T Ü B I N GE E ,

VERLAG UND DRUCK VON LUDWIG FRIEDRICH FUES. 1852. 


\section{ANATOMISCHE UNTERSUCHUNGEN}

ÜBER

\section{$\begin{array}{llllllllllll}\text { D } & \text { I } & \mathbf{E} & \mathbf{E} & \mathbf{D} & \mathbf{E} & \mathbf{N} & \mathbf{T} & \mathbf{A} & \mathbf{T} & \mathbf{E} & \mathbf{N}\end{array}$}

VON

\section{WILHELM, vON RAPP,}

RITTER DES ORDENS DER WÜRTTEMBERGISCHEN KRONE, PROFESSOR DER MEDICIN IN TÜBINGEX.

MIT ZEHEN STEINIRUCKTAFELN.

ZWEITE VERBESSERTE UYD VERUEURTE IUFLIGE.

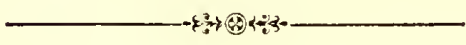

\section{T Ü B I N G E N,}

VERLAG UND DRUCK VON LUDWIG FRIEDRICH FUES.

1852. 


\section{Vorrede zur zweiten Auflage.}

Seit dem Erscheinen der ersten Auflage dieser Schrift im Jahr 1843 erhielt ich reiches Material zu neuen Untersuchungen über die Zoologie und vergleichende Anatomie der Edentaten.

Von dem seltenen Riesengürtelthier untersuchte ich drei Skelete, wovon eines der königlichen Naturalien-Sammlung in Stuttgart gehört; ferner erhielt ich die vollständige Haut dieses Thiers; auch stellte ich neue Untersuchungen an über die Ameisenfresser, von denen unsere Sammlung jetzt sieben Skelete besitzt. Sowohl zur anatomischen Untersuchung dieser Thiere, als auch der Gürtelthiere und Schuppenthiere erhielt ich wohlerhaltene Exemplare in Weingeist. Auch zur Untersuchung der pflanzenfressenden Edentaten fehlte es mir nicht an neuem Material.

Der Text wurde mit Benützung der neuesten Literatur, durch welche vorzugsweise der zoologische Theil wesentliche Ergänzungen und Verbesserungen erhielt, neu bearbeitet. Von den Abbildungen wurden einige durch neue ersetzt; einige kamen hinzu, die in der ersten Auflage sich nicht finden; andere wurden beibchalten. Die letzte Tafel der ersten Auflage über die Schlagadern von Stenops wurde weggelassen, da ihre Ausführung einiges zu wïnschen übrig liess und da sie zu der Anatomie der Edentaten nicht gehört.

Tübingen, den 1. Dezember 1851.

Happ. 


\section{In ha t.}

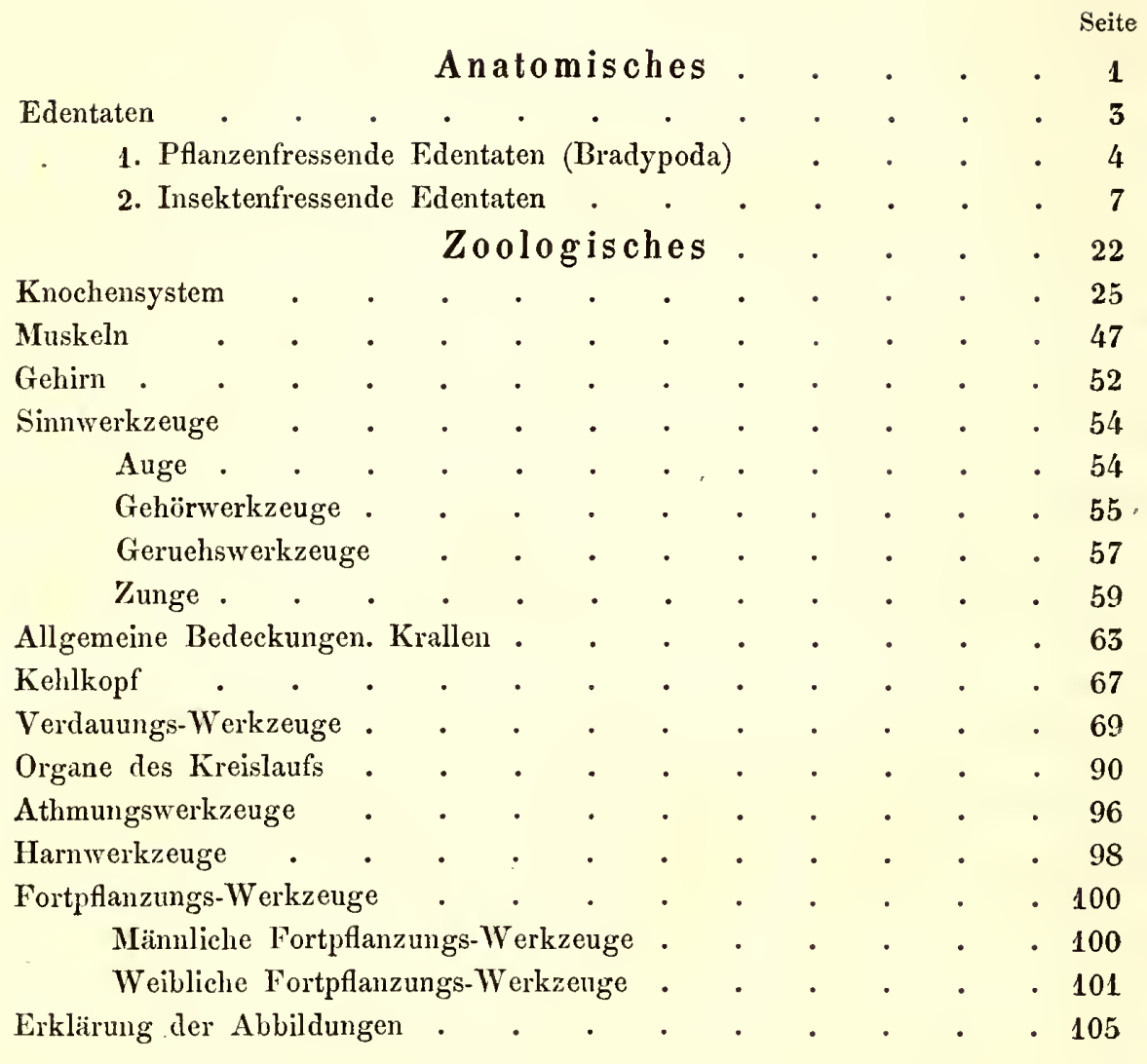


ZOOLOGISCHES. 



\section{E d e nt a t e}

Die Säugthiere, welche die Ordunng der Edentaten zusammensetzen, stimmen mit einander überein durch den Mangel der Schneidezälne, und durch grosse Nägel, die entweder zun Klettern oder zum Graben bestimmt sind. In Beziehung auf die Zähne zeigen diese Thiere unter einander grosse Verschiedenlueiten; einigen fehlen die Zähne ganz (Manis, Myrmecophaga), andere haben blos Backenzähine (Orycteropus, Chlamyphorus, Gürtelthiere). Bei einem Gürtelthier (Dasypus sexcinctus) kommt sogar oben auf jeder Seite ein Schneidezalın vor, dem zwei Zahne im Unterkiefer entsprechell. Diese Schneidezähne sind aber nicht vorne im Munde, sondern, seitlich angebracht, in einer geraden Linie mit den Backenzähnen. Choloepus hat Eckzähne und Backenzähne. Die Zahl der Zälne ist meist nicht gross. doch bei Priodontes, Fr. Cuv. (Dasypus gigas) ist die Zahl der Backenzähne selır beträchtlich.

Die Faulthiere oder pilanzenfressenden Edentaten haben durch ihre kurzen Maxillen und die abgerundete Gestalt des Kopfs, durch die Lage der beiden Milchdrüsen an der Brust, durch die Gestalt der Gebärmutter Aehnlichkeit mit den Affen, zu welchen sie sogar von Wagler und Andern gestellt worden sind; aber die Faulhiere stimmen in ihrem innern Bau in vielfacher Hinsicht mil den übrigen Edentaten überein, wie aus der anatomischen Darstellung der einzelnen Organe ausführlich gezeigt werden wird, und das fossile Megatherium bildet ein Zwischenglied zwischen den Taulthieren und den Gürtelthieren.

Die Monotremen (Schnabelthier, Echidna), welche sonst zu den Edentaten gezählt wurden, haben mehr Verwandtschaft mit den Bentelthieren, doch kommt ihnen so viel Eigenthünliches zu, dass sie am passendsten als eine eigene Ordnung der Säugthiere aufgestellt werden.

Wir theilen die Edentaten in pflanzenfressende und insektenfressende. 


\section{Pflanzenfressende Edentaten (Bradypoda).}

Cylindrische Backenzälne. Der Kopf kurz, fast rund. Die Zunge kurz. Der Magen ist zusammengesetzl, fast wie bei den Wiederkäuern. Der Schwanz sehr kurz oder fehlt fast ganz.

Diese Thiere nähren sich ausschliesslich von Baumblättern und halten sich beständig auf den Bäumen auf, bewegen sich äusserst langsam, auf dem Boden treten sie mit dem äussern Fussrande auf.

Das fossile Megatherium bildet die Verbindung zwischen den pflanzenfressenden und den insektenfressenden Edentaten. Der Gestalt des Kopfs nach nähert es sich am meisten den Faulthieren, durch den Bau der Extremitäten hat es mehr Aehnlichkeit mit den übrigen Edentaten.

\section{CHOLOEPUS, Illig. Wagn. Gray.}

Bradypus, Fr. Cuv.

Oben wie unten ein sehr langer, spitziger Eckzahn, oben vier, unten drei Backenzälne. An den vordern Füssen zwei, an den lintern drei Nägel.

\section{Cholocpus didactylus (das zweizehige Faulthier, der Unau).}

(Griffirir, Animal Kingdom. Tom. III. Fig.)

Braun grau, die Haare selır lang, kein Schwanz.

In Brasilien und Guiana.

Das junge Thier hat weiche, hellbraune, seidenartige Haare. Erreicht eine Länge von 23 Zoll.

\section{B R A D Y P U S, lllig.}

Acheus, Fr. Cuv.

Oben fünf Backenzähne, unten vier. Keine andern Zälhne. An den vordern Füssen wie an den hintern drei Nägel. Ein kurzer Schwanz. 
1. Bradypus tridactylus, Linn.

Bradypus Aï, Wagl. Bradypus pallidus, Wagn. Arctopithecus fiaccidus, Gray.

(Max. Prinz von Neu-Wied, Abbildungen zur Naturgeschichte von Brasilien.)

Graubraun, die Stirne gelblichweiss, vom Auge erstreckt sich eine schwarzbraune Linie nach aussen und unten. Die vordere Seite des Halses von der Farbe des Rückens.

In Brasilien.

Hat eine Länge von 17 bis $18 \mathrm{Zoll}$.

2. Bradypus torquatus, Illig.

(Max. Prinz von Neu-Wied, Abbildungen zur Naturgeschichte von Brasilien. Sechste Lieferung.)

Das Gesicht und der Hals mit schwarzen, sehr kurzen Haaren bedeckt. Der obere Theil des Rückens hat einen breiten schwarzen Fleck mit langen Haaren, auch um den Hals herum zieht sich ein Streifen schwarzer Haare.

J. GRAY ${ }^{1}$ ) bildet für diese Art, die er als Bradypus crinitus bezeichnet, und für eine andere, von welcher ihm aber nur das Skelet bekannt ist (Bradypus affinis, Gray), ein eigenes Genus, welches sieh von seinem Genus Arctopithecus dadurch unterscheidet, dass bei ersterem die absteigenden Flügelfortsätze (Processus pterygoidei) des Keilbeins blasenförmig aufgetrieben sind. Nur bei Choloepus zeigt sieh anch diese Auftreibung.

In Brasilien, Pern.

Ist etwas grösser als Brallypus tridactylus.

\section{Bradypus cuculliger, Wagl.}

Bradypus gularis, Rüppel.

(Museum Senchenberg. Dritter Band, neunte Tafel.)

Die Stirne, die Wangen und die Kehle mit kurzen, gelblichen Haaren bedeckt. Vom Oberkopf zieht sich an den Seiten des Halses ein schieferblauer Streifen vor der Schulter herunter. Nach der Länge der Wirbelsänle verlauft

1) Proceedings of the zoological Society of London. 1849. 
ein schwarzer Streifen. Auf dem Rücken ein gelber Fleck beim Männchen. Rücken und Füsse gelblich grau mit dunkleren Flecken.

In Guiana.

Diese Art wurde früher von Bradypus tridactylus nicht unterschieden, und die anatomischen Untersuchungen, die bisher von Bradypus tridactylus angeführt wurden, mögen grossentheils an Bradypus cuculliger angestellt worden sein.

\section{Bradypus infuscatus, Wagl.}

Russbraun. Stirn und Schläfengegend gelblichweiss. Die Augen von einem dunkelbraumen Streifen eingefasst, der sich als breitere Binde abwärts gegen den Winkel des Unterkiefers zieht. Auf dem Rücken weissliche Flecken; beim Männchen ein gelber Fleck auf dem Rücken ').

Im nordwestlichen Brasilien; in Pern.

Unter der Benemung Arctopithecus marmoratus führt $\mathrm{G}_{\mathrm{RAY}}{ }^{2}$ ) ein Faulthier aus Brasilien an, von graubrauner Farbe; der Rücken und die äussere Seite der Arme weissgefleckt, nach der Länge des Rückens ein schwarzer Streifen. Der Winkel des Unlerkiefers verlängert, schmal, zugespitzt. Nach A. Wagner ist dieses das Weibchen Bradypus cuculliger ${ }^{5}$ ). Als Arctopithecus Blainvillii stellt GrAX eine Art aus dem tropischen Amerika auf, welehe in den äussern Merkmalen nieht verschieden sei von Arctopithecus marmoratus, aber durch die Gestalt des Schädels abweiche. Die Stirngegend ist nemlieh stark aufgetrieben, über der Augenhöhle wie geschwollen; der Unterkiefer hat vorne am obern Rande eine schwache Hervorragung. Diese Art scheint von Arctopithecus marmoratus, Grax, (Bradypus cuculliger) nicht verschieden zu sein.

1) WAfLer, uiber Bradypus. Isis 1831. S. 605. A. Wagnen in den Supplementen zu Scmetebrs Sängthieren. Vicrte Abtheilung. S. 1/8.

2) Proceedings of the zoological Socicty of London. $18 \%$

3) Bemerkungen iber den dermaligen Stand unscrer Kcnntniss der Faulthier-Arten. In den Münchmer gelehrten Anzeigen. Nro 9. 1850. 


\section{Insektenfressende Edentaten.}

Die Kiefer sind verlängert; die Nägel stark, zam Graben tauglich. Einige dieser Thiere laben Backenzähne, andern fehlen die Zähne ganz. Diese Edentaten nähren sich hauptsächlich von Ameisen und Termiten, einige auch vom Fleisch crepirter Thiere.

1) Mit Backenzähnen.

DASYPUS, Linn. (GÜRTELTHIER, TATU.)

Der Kopf, der Leib, oft auch der Schwanz, mit einem Panzer bedeckt, der aus regelmässigen, in der Haut liegenden kleinen Knochentafeln gebildet wird. Die Zunge kann nicht weit herausgestreckt werden. Nur Backenzähne (bei einer Art auch seitlich gestellte Schneidezähne). Die Nägel gross, wenig gekrümmt, an den vordern Füssen grösser als an den hintern.

Diese Thiere graben sich Höhlen in die Erde, und leben von Insekten und Würmern, auch vom Fleisch crepirter Thiere.

Die Gürtelthiere bringen mehrere Junge auf einmal zur Welt.

Erstes Subgenus:

Dasypus, Fr. Cur.

Auf jeder Seite trägt der Zwischenkieferknochen einen Zahn (Schneidezalı), ihm entsprechen im Unterkiefer zwei Zähne (Schneidezähne). Oben und unten Backenzähne (siehe die $\Lambda$ bbildung). An den vordern wie an den hintern Füssen fünf Zehen.

\section{Dasypus sexcinctus, Linn.}

Dasypus setosus, Max. Prinz von Neu-Wied. (Geofroy Saint-Hilaire, Hist. naturelle des mammifères. Tom. II.)

In Brasilien und Paraguay. 


\section{Zweites Subgenus:}

Tatusia, Fr. Cuv.

Walzenförmige Backenzähne. Andere Zähne finden sich nicht. Vier oder fünf Zehen an den vordern Füssen, an den hintern fünf.

\section{Dasypus (Tatusia) peba.}

Dasypus novemcinctus, Linn. Tatu nocemcinctus, Blumenb. Dasypus longicaudus, Max. Prinz von Neu-Wied. Das schwarze Gürtelthier. (BunmenBACH, Abbildungen naturhistorischer Gegenstände. Taf. 83.)

Neun knöcherne Biıden über den Rücken. Die dreiseitigen Schilder der Gürtel liaben konvexe Ränder. Der Schwanz fast von der Länge des Leibes mit dem Kopf, mit zwölf bis vierzehen beweglichen Gürteh. Gegen das Ende hin aber sind die Knochentäfelchen nicht melı in Ringe angeordnet. Vier Zehen an den vordern Füssen. Die knöcherne Haut mit schwärzlicher Epidernis ${ }^{1}$ ).

Einen und einen halben Fuss lang ohne den Schwanz. Wir besitzen ein männliches schwarzes Gürtelthier aus Surinam, das 1 Fuss 9 Zoll (par. M.) lang ist, ohne den Schwanz. Länge des Schwanzes 1 Fuss 4 Zoll. Der Schädel hat eine Länge von 5 Zoll. Die Zahl der knöchernen Gürtel ist bei derselben Species nicht ganz beständig, bei unserem grossen Exemplar finden sich nur sieben bewegliche Knochengürtel des Rückens. Bei diesem alten Thier sind an der vordern Seite des Unterschenkels drei sehr grosse, in eine Querreihe gestellte, längliche, weisse Schuppen, welche frei hervorragen und den Klauen gleichen.

In Guiana, Brasilien, Peru.

\section{Dasypus (Tatusia) urocevas, Lund.}

Acht bewegliche Gürtel. Der Schwanz kürzer als der Leib, an der Spitze in eine hornartige Scheide eingeschlossen.

In Brasilien und Paraguay.

1) Ueber diese und die folgende Art von Dasypus vergl. Burmeister, in D'Alton und Bunmeister, Zeitung für Zoologie. Erster Band. S. 199. 


\section{$-9-$ \\ 4. Dasypus (Tatusia) tricinctus, Linn.}

Drei knōcherne Binden über den Rücken, der Schwanz sehr kurz. In den Pampas von Buenos Ayres.

\section{Dasypus (Tatusia) hybridus, Desm.}

(Schreber, t. 72. 76.)

Sechs bis sieben bewegliche Ḱnochengürtel über den Rücken, der Schwanz halb so lang als der Leib. Die Oberhaut schwärzlich. Die Knochentafeln des Schulterpanzers und des Hüftpanzers sind rundlich und bilden hervorragende Warzen oder Kuoten, um jede der grössern Warzen liegen im Kreise kleinere, weniger hervorragende Knochenkörner. Länge des Leibes von der Nasenspitze an (ohne den Schwanz) 13 Zoll 3 Liniell. Länge des Schwanzes 6 Zoll 9 Linien ${ }^{1}$ ).

In Paraguay.

\section{Dasypus (Tatusia) gymmurus, Illig.}

(Gứrin, Iconogr. Mammif. 34. 2.)

Zwölf bewegliche Knochengürtel über den Rücken, der Schwanz halb so lang als der Leib, nur mit einzelnen, llachen, glatten, knorplichen Warzen besetzt. Die knocherne Bedecknng mit einer schwarzen Oberhant. Die Ohren sehr breit, am ganzen Rande gekerbl. Fünf Zehen an den vordern Füssen, die Nägel an den vorderı Füssen sehr lang.

Es scheinen zwei Arten unter der Benennung Dasypus gymmurus begriffen zu sein 2), eine Art mit ganz nacktem Schwanz, nur das Schwanzende ist an der untern Seite nit einigen eiförmigen Sehuppen versehen ${ }^{3}$ ). Beide Formen sind bei SEba abgebildet (Tab. 30). Das voll mir untersuchte Thier, dessen Scliwanz überall mit glatten, flachen, elliptischen, zerstreuten Warzen oder Knorpelscheibchen versehen ist, wurde von Herrn Kappler aus Surinam geschickt. Am Schädel sind alle Suturen verschwunden; es scheint ein sehr altes Thier zu sein, es ist männlichen Geschlechts. Seine Länge beträgt olne den Schwanz 141/2 par. Zoll.

In Brasilien, Peru, Paraguay, Guiana.

1) Martin, Proceedings of the zoological Socicty of London. 1837. p. 13.

2) A. Wagner, Schrebers Säugthiere. Supplementband. 1844. S. 171.

3) Rexgger, Säugthiere von Paragnay. S. 291. 


\section{Dasypus (Tatusia) villosus, Desm.}

Sechs bis sieben Knochengürtel über den Rücken. Die Haut mit sehr langen, braunen Haaren bedeckt.

(Grıffitr, Anim. Kingdom; Mammalia Tom. III. p. 292 mit Abbild.)

In Südamerika zwischen dem 35 und 36 Grad südlicher Breite nach D’AzArA.

\section{Dasypus minutus, Desm.}

(Cuvier, Règne animal. Ed. accompagnèe de planches. Mammifères pl. 71.), Fünf Zehen an den vordern Füssen. Der Schwanz nicht ganz von der Häfte der Länge des Leibes. Die Ohren selır kurz. Sechs bis sieben bewegliche Knochengürtel über den Rücken. An der untern Seite des Leibes lange, braune Haare.

Länge des Leibes ohne den Schwanz zehen Zoll.

Im südlichen Amerika, in Paraguay, im südlichen Brasilien und bis zum Rio Negro und noch weiter nach Süden.

\section{Drittes Subgenus: \\ Priodontes, Fr. Cuv.}

Nur Backenzähne. Sie sind seitlich zusammengedrückt, sehr zahlreich.

9. Dasypus (Priodontes) gigas, Cuv.

(Krauss, das Thierreich in Bildern. Taf.)

Zwölf bis dreizehen Knochengürtel über den Rücken; die knöchernen Schuppen des Schwanzes bilden keine Ringe. Der mittlere Nagel an den vordern Füssen sehr gross.

Bei einem erwachsenen, männlichen Riesengïrtelthier fand ich zwölf bewegliche Knochengürtel über den Rücken. An dem Schulterpanzer sind vorne auch drei bewegliche Knochengürtel. Auch an dem unbeweglichen Theil des Rückensehilds liegen die Knochentafeln in Querreihen, sie sind gegen den Umfang hin zahlreicher als in der Mitte, weil einige dieser Reihen gegen den Umfang hin sich spalten. Die obere Seite des Kopfes ist mit unregelmässigen Knoclientafeln bedeckt. Die Knochentafeln der beweglichen Gürtel sind rechtwinkliche Vierecke, etwas länger als breit. Die unbeweglichen Knochentafeln des Schulterpanzers sind zum Theil sechseckig, die des IIüftpanzers von der glei- 
chen Gestalt, aber grösser. Der Schwanz ist durehaus mit Knochentafeln bedeckt, welche in Spiralen angebracht sind, jede einzelne Tafel bildet ein Viereck, wovon eine Spitze vorwärts gerichtet ist. Sie liegen nach Art eines Strassenpflasters (nicht dachziegelförmig). Gegen die Spitze des Schwanzes werden sie kleiner. Der Schwanz ist konisch, rund, die Extremitäten sind mit ziemlich unregelmässigen Knochentafeh bedeckt. Die Haut des Bauchs hat zerstreute, runde, dünne Knochenplatten, jede bestelt aber aus einzelnen, kleinen Knocheuschuppen. Zwischen den Knochentafeln ragen an allen Körpergegenden einzelne, kurze Borstenhaare hervor. Die Olren kurz, breit, stumpf, mit rundlichen, flachen Knochenwärzchen bedeckt. Die Epidermis schwärzlich, mit Ausnalıme des Schwanzes und des Unfangs des Rückenschilds, wo sie gelblichweiss erscheint. Jede Knochentafel wird von einer Epidermisscheibe bedeckt, aber zwischen diesen Scheiben liegt ein schmales Band von Epidermis. Beim Trocknen löst sich die Epidermis leicht ab nnd zerfällt in diese Forment. Die Epidermisscheiben auf dem Rücken lıaben zwei der Länge nach verlaufende längliche Vertiefungen, die an ihrem vordern Ende oft durch eine kurze, querlaufende Furche verbunden sind. Aehnliche Vertiefungen finden sich auch auf den entsprechenden Knochentafeln. An den vordern Füssen fünf Klauen, die mittlere ausserordentlich gross, sichelförmig, spitzig, sie ist so gestellt, dass der konkave Rand auswärts gerichtet ist. An den hintern Füssen fünf kurze, sehr stumpfe, breite Klauen oder Hufe. Alle sind gelblichweiss. Länge des ganzen Thiers mit dem Schwanz 4 Fnss 8 Zoll (par. M.). Länge des Schwanzes 1 Fuss 9 Zoll. Länge der mittleren Klaue an den vordern Füssen $4^{1 / 2}$ Zoll. Länge des Ohrs 2 Zoll.

Nach G. Cuvier ${ }^{1}$ ) würden diesem Gürtelthier im Ganzen 92 Zähne zukommen, nemlich oben auf jeder Seite 24 Zälme, unten 22. Fr. Cuvier nimmt im Ganzen 98 Zälne an. R. Owen ${ }^{2}$ ) gibt all, oben seien 24 bis 26 Zähne auf jeder Seite, aber im Unterkiefer 22 bis 24 auf jeder Seite, im Ganzen 94 bis 100 Zähne.

Ieh fand die Zahl der Zähne viel geringer an drei Schädeln von erwachsenen Thieren, die ich untersuchte; nemlich an einem Schädel oben auf einer Seite 18, auf der andern 17 Zähne, unten auf einer Seite 18, auf der andern

\footnotetext{
1) Cuvier, Oss. fossiles. Tom. V.

2) Owen, Odontography; p. 321.
} 
21 Zähne, zusammen 74 Zähne. An einem andern Schädel, an welchem übrigens die meisten Zähne durch Unvorsichtigkeit beim Präpariren oder durch den Transport verloren gegangen, aber alle Zahnhöhlen vollständig erhalten sind, wodurch über die Zahl der Zähne kein Zweifel bleiben kann, verhält es sich so: Oben auf einer Seite 15, auf der andern 17 Zähne, im Unterkiefer auf einer Seite 19, auf der andern 20 Zähne, zusammen 71. An einem dritten Schädel (wie bei den beiden vorhergehenden mit dem Skelet) sind oben auf jeder Seite 15 Zähne, unten auf der linken Seite 18, auf der reehten 17 Zähne, zusammen 65 Zähne. Mit meinen Untersuchungen stimmt die Angabe von D'Azara ziemlich überein, er fand 17 Backenzähne in jeder Kieferhälfte.

An mehreren der vordern Backenzähne ist dureh eine senkrechte Furche eine Abtheilung in zwei Hälften angedeutet.

Priodontes gigas ist das grösste Gürtelthier, indem die Länge des Leibes ohne den Schwanz 3 Fuss beträgt.

Im nördlichen Theil von Paraguay, in Brasilien, im englischen und holländischen Guiana; aber überall selten. Die Thiere, welche ich untersuchte, erhielt iclı aus Surinam.

Chlamyphorus (Chlamydophorus), Harlan.

Zehen Zähne auf jeder Seite, oben wie unten. An den vordern und an den hintern Füssen fünf Zehen, die Nägel der vordern Füsse sehr gross, zusammengedrückt. Der Rücken ist mit querlaufenden Reihen von lederartigen Platten bedeekt. Kein äusseres Ohr.

Chlamyphorus trumcatus, Harlan.

(Cuvier, Règne animal, nouv. éd. par une réunion d'éléves de Cuvier; Mammifères pl. 71. fig. 2.)

Fünf bis sechs Zoll lang.

In Chili.

Lebt meist unter der Erde.

ORYCTEROPUS, Geoffr.

Nur Backenzälne, die mit senkrechten Röhren durchzogen sind. Die Haut mit Haaren bedeckt. An den vordern Füssen vier Zehen, an den hintern fünf. Die Nägel sind stark und gleichen einem Huf. 


\section{Orycteropus capensis, Geoffr. (Erdferkel.)}

(Erste Tafel.)

Die Kiefer verlängert, die zweite vordere Zehe die längste. Die Gesichtslinie fast gerade. Die Haare borstenartig, die Ohren gross und aufgerichtet, der Schwanz an der Wurzel sehr dick. Der Rücken und die Seiten des Thiers sind gelblichgrau mit etwas Röthlichem; die Wurzel des Schwanzes und die Extremitäten dunkel schwarzbraun.

In der Cap-Colonie und nach Lesson ${ }^{1}$ ) am Senegal. Doch glaubt Lesson, es seiell zwei verschiedene Arten. Die Länge beträgt ohne den Schwanz drei und einen halben Fuss. Der Orycteropus lebt in Höhlen unter der Erde; ist sehr vorsichtig und richtet sich zuweilen auf die lintern Extremitäten auf, wie dieses auch beim grossen Ameisenfresser beobachtet worden ist ${ }^{2}$ ), um zu erforschen, ob ihm keine Gefalır bevorstehe. Nährt sich von Ameisen und Termiten.

\section{Orycteropus aethiopicus, Sundew.}

(Kongl. Vetenskaps-Academiens Handlingar. Stockholm, 1843. Tab. III. fig. 1-5.)

Die Kiefer kürzer, die Stirne erhöht, die erste Zehe an den vordern Füssen die längste. Die Haare kürzer als bei der vorhergehenden Art, der aufsteigende Ast des Unterkiefers schmäler.

Wurde von Hedenborg in Sennaar gefunden.

2) Ohne Zähne.

\section{MYRMECOPHAGA, Linn. (AMEISENFRESSER.)}

Keine Zähne. Die Zunge sehr weit herausstreckbar, wurmförmig, mit sehr kleinen Stacheln besetzt. Die Mundöffnung klein. Die Haut mit Haaren bedeckt. Die Nägel an den Vorderfüssen sind stark, spitzig, gekrümmt, zusammengedrückt.

Diese Thiere nähren sich von Ameisen, Termiten und Insekten-Larven. Sie bringen auf einmal nur Ein Junges zur Welt.

1) Lesson, Species des mammifères, suivi d'un mémoire sur les oryctéropes. Paris et Londres. 1840.

2) Schomburgh, Remarks on the greater Ant-bear. Proceedings of the zoological Socicty of London. 1839. 


\section{Myrmecophaga jubata, Linn. (Der grosse Ameisenfresser.)}

(Cuvier, Règne animal, nouv. éd. par une réunion d'élèves de Cuvier; Mammifères pl. 73. fig. 2.)

Hat an den vordern Füssen vier, an den lintern fünf Nägel. Die Haare sind steif, fast borstenartig. Die Kiefer ausserordentlich verlängert. Ueber den Rücken eine Mälne. Der Schwanz ist mit sehr langen Haaren besetzt. An der Schulter ein schiefer, schwarzer, weisslich eingefasster Streifen.

Das Thier hat olne den Schwanz eine Länge von vier Fuss. Nährt sich von Ameisen und von Raupen. Ich fand in der Speiseröhre und im Magen grosse Raupen.

Lebt in niedrig gelegenen Gegenden, in Brasilien, Guiana, Paraguay.

\section{Plymecopluaga tamamua, Cur. (Dex Tamandua.)}

(Wweite 'l'ufel b.)

Der Sclwanz ist mit kurzen Haaren bedeckt, die gegen die Spitze hin seltener werden; die lintere Hälfte des Schwanzes schuppicht.

Ist um mehr als zwei Drittheile kleiner als die vorhergehende Art. Gelb, mit einem breiten, schwarzen oder schwarzbraunen Streif, der über die Schulter rückwärts geht, an den Seiten sich sehr ausbreitel, und auf dem Rücken vereinigt sich die schwarze Färbung von beiden Seiten, doch wechselt die Färbung. Es gibt ganz schwarze und ganz gelbe. Diess sind junge Thiere, indem sie erst in zweiten oder dritten Jahr die Farbe der Erwachsenen annelmen naeh d’Azara und Revgger ${ }^{1}$ ). Rëppel (Museum Senckenbergianum dritter Band) unterscheidet als Varietät oder vielleicht als eigene Species Myrmecophaga crispa. Der bärenartige Ameisenfresser (Myrmecophaga ursina, GrifFITII, Animal Kingdom Tom. III. Lab.) ist von Myrmecophaga tamandua nicht verschieden. Ich erhielt aus Surinam von Herrn Kappler einen erwachsenen Tamandua, bei dem die schwarze Färbung an der Schulter und an den Seiten des Leibes und auf dem Rücken schwach ausgedrückt ist, die Haare sind nemlich nur an der Basis schwarz, an der Spitze gelb. Die Ohren sind länger und schwarz. Der Schwanz hat fast die Länge des Leibes, den Kopf eingerechnel, bei den andern ist der Schwanz kürzer; aber bei dem Skelet eines

1) Sängthiere von Paraguay. 1830. 
erwachsenen Tamandua, von dem ich aber über das Fell nichts angeben kann, fand ich den Schwanz fast um 3 Zoll länger als den Leib, mit Einschluss des Kopfs.

Diese Art lebt in Guiana, in Brasilien, in Paraguay, in Peru.

\section{Myrmecophaga didactyla, Linn. (Der zweizehige Ameisenfresser.)}

(Buumenbach, Abbildungen naturhistorischer Gegenstände. T. 22.)

Hat an den vordern Füssen zwei Nägel, wovon der äussere sèhr gross, an den hintern Füssen vier Nägel. Das Haar ist weich, seidenartig glänzend, oben gelbgrau, mit einem dunkeln rothbraunen Streif, der nach der Länge des Rückens verlauft. Ein Rollschwanz.

Dieser Ameisenfresser hat etwa die Grösse des gewöhnlichen Eichhorns. Der Schwanz hat die Länge des Leibes. Hält sich, wie die vorhergehende Art, viel auf den Bäumen auf.

In Guiana, in Brasilien, in Peru.

\section{MANIS, Linn. (SCHUPPENTHIER.)}

Keine Zähne. Die Mundöffnung klein. Die Zunge sehr weit herausstreckbar, wurmförmig, mit sehr kleinen, rückwärts gerichteten Spitzen besetzt. Der Leib mit den Extremitäten und dem Schwanz ist mit grossen, hornartigen, dachziegelförmig über einander liegenden Schuppen bedeckt; aueh die untere Seite des Schwanzes ist beschuppt. An den vordern wie an den hintern Füssen fünf Zehen mit langen, starken Nägeln.

Diese Thiere können sich kugelförmig zusammenrollen. Sie nähren sich von Ameisen und Termiten, und graben sich Höhlen in die Erde.

\section{Manis Iongicandata, Shaw.}

Manis africana, Desm. Manis macroura, Erxl.

Der Schwanz fast doppelt so lang als der Leib, die Schuppen des Körpers läıglich, zugespitzt, eilf Reihen bildend.

An der Westküste von Afrika.

\section{Manis tricuspis, Sunder.}

Manis multiscutata, Gray.

(Fraser, Zoologia typica. tab.) 
Der Schwanz um die Hälfte länger als der Leib mit dem Kopf; die Schuppen des Leibes schmal, nach der Länge gestreift, theilweise dreispitzig. Sie liegen in 19 bis 21 Querreihen.

Guinea; Fernando Po.

3. Manis tridentata, Focillon.

('Wweite Tafel a.)

(Revue de zoologie. 1850. pl. 11.)

Hellbraun, der Schwanz um ein Fünftel länger als der Leib mit Einschluss des Kopfs. Alle Schuppen in drei Spitzen geendigt, nach der ganzen Länge stark gestreift. 19 bis 21 Schuppenreihen nach der Länge des Leibes. Keine Borsten zwischen den Schuppen.

Die Länge des ganzen Thiers mit dem Schwanz 201/2 par. Zoll.

Von der Küste von Mozambique.

4. Manis crassicandata, Griffith.

Manis brachyura, Erxl. Manis macroura, Desm. Manis pentadactyla, Linn.

(Cuvier, Règne animal, èd. accompagnée de planches, Mammifères pl. 74.)

Der Schwanz von der Länge des Leibes. Die Schuppen nur an der Basis gestreift, sie sind am Leibe in 11 bis 16 Längsreihen gestellt. Die Schuppen des Rückens des Schwanzes quer abgeschnitten. Zwischen den Schuppen einzelne Borstell.

Diess ist die grösste Art. Die Länge beträgt mit dem Schwanz 4 Fuss.

In Ostindien.

5. Manis javanica, Desm.

(Zweite Tafel a.)

Der Schwanz etwas kürzer als der Leib. Nach der Länge des Leibes 17 bis 19 Reihen von Schuppen. Die Schuppen des Sehwanzes abgerundet, alle der Länge nach gestreift, nur die Spitze ist glatt. Zwischen den Schuppen einzelne Borsten.

In Java, Borneo, Sumatra.

Die Länge des Thiers ohne den Schwanz beträgt 11/2 Fuss. Die Schuppen sind von dunkelbrauner Farbe und an den Seiten des Leibes mit einem Kiel 
versehen. Am Bauche und am. Halse stehen gelbliche, kurze, borstenartige Haare. Der mittlere Nagel ist der grösste.

\section{Manis Guy, Focillon.}

(Revue de zoologie. 1850. pl. 10.)

Hellbraun, der Schwanz kürzer als der Leib mit dem Kopf. 21 Schuppenreihen nach der Länge des Leibes. Das Ende des Schwanzes an der untern Seite nackt. Die Schuppen breit in eine stumpfe Spitze sich endigend, bis zu der Spitze gestreift. Zwischen den Schuppen ragen Borsten hervor.

Afrika.

\section{Manis Temminckii, Sinuts.}

(A. Sirtu, Illustrations of the zoology of South Africa. Nro. IV. Mammalia, pl. 7. Sundevall, Kongl. Vetenskaps-Academiens Handlingar för 1842. Tab. IV. fig. 2.)

Der Kopf kurz. Der Schwanz von der Länge des Leibes, sehr dick. Die Schuppen des Leibes in 14 Reihen und sehr gross. Der Schwanz ist mit fünf Reihen von Schuppen bedeckt, gegen die Spitze hin mit vier, indem die mittlere Reihe aufhört.

Zwei Fuss fünf Zoll lang mit dem Schwanz.

Im Kafferlande, in Sennaar nach Неdenвorg.

\section{Manis aspera, Sundev.}

Die Nägel an den vordern Füssen so lang als an den hintern, gekrümmt. Die Schuppen an der Seite und an den hintern Füssen scharf gekielt. Sie bilden 19 Reihen. Einzelne Borsten zwischen den Schuppen. Der Schwanz von der Länge des Leibes mit dem Kopf.

Von Sumatra.

\section{Manis Dalmanni, Sundev.}

Die Nägel fast gerade, fast dreieckig, die vordern doppelt so lang als die hintern.

Zwei und einen balben Fuss lang mit dem Schwanz. Hat ein äusseres 
Ohr, fast dem menschlichen ähnlich. Die Schuppen braun, gestreift, an der Spitze glatt ${ }^{1}$ ).

In China, bei Canton.

10. Manis Ieptura, Blyth.

Der Schwanz so lang als der Kopf und Leib, die seitlichen Schuppenreihen des Schwanzes sind angedrückt, so dass der Rand desselben nicht gezackt, sondern glatt ist.

Heimath unbekannt.

(Journ. of the asiat. Soc. of Beng. XVI. A. WAGNER, Bericht über die Leistungen in der Naturgeschichte der Süugthiere im Jahr 1849. in Troscher, Archiv für Naturgeschichte.)

1) Kongl. Vetenskaps-Academiens Haudlingar för 1842. S. 256. Stockholm. 


\section{Fossile reste}

von Edentaten sind jetzl in ziemlicher Anzahl gefunden worden, vorzugsweise in Amerika. Die Megatherioiden bilden den Uebergang von den Faulthieren zu den Gürtelthieren. Vom Megatherium wurde in Südamerika in der Gegend von Buenos Ayres im vorigen Jahrhundert ein fast vollständiges Skelet gefunden. Es liat eine Länge von zwölf Fuss. Megralony.r findet sich in fossilen Zustande in verschiedenen Gegenden von Nord- und Südamerika. Megalonyx Jeffersmn; Cuv. hatte die Grösse eines Ochsen. Zu der Familie der Megatherioiden gehört fermer: Mylodon, Owen. Es hat viel Aehnlichkeit mit Wegatherium, unterscheidel sich aber besonders dureh die Zälıne; man kennt von Mylodon drei Arten, deren Kinochen in Amerika gefunden worden sind. Mylodon robustus halte eine Lünge von ungefäln neun Fiss, es befindet sich davon in London ein fast vollständiges Skelet aus der Nähe von Buenos Ayres. Femer: Mylodon Darmin, Owen und Hylodon Iharlani, Owen, oder Arycterotherinm missuriense, Harlan. Die fossilen Knochen davon wurden in einer Höhle in Kenlucky gefunden. Scelidotherium, Owen, hat vicl Aelnlichkeit mil Myloulon; die fossilen Reste finden sich in Südamerika. Noch zwei in diese Familie der fossilen Edentaten gehörige Thiere fand Lund in Brasilien: Caelodon und sphenodon. Platyonix, Lund, hat einige Verwandschaft mit den Fauthieren. Platyonix Curieri ans Brasilien latte die Grösse eines Ochsen ${ }^{1}$ ). Zu den Drsypiden gehört Glyptodon, Owen. Dieses Geschlecht schliesst sich durch den auch den Faulthieren zuliommenden absteigenden Fortsatz des Jochbogens noch an die vorhergehende Familie an. $G l_{y}$ ptodon clavipes wurde in Südamerika gefunden. Owen hat später noch vier andere Arten unterschieden. Hoplophorus, Lund, ist ein fossiles Geschlecht, dessen Reste in den Iöhlen von Brasilien angetroffen werden; Lund unterselieidet

1) Dic Abbildung des vollständigen Schädels von Platyonix Brogniartii siehe Fortsattete Bemärkninger over Brasiliens uddöde Dyrskabning af LuxD. Tab. 28. 
drei Arten; diese Thiere waren wie die Gürtelthiere und wahrscheinlich wie auch Glyptodon, und wie das folgende Genus, mil einem knöchernen Panzer versehen. Chlamydotherium, Lund, unterscheidet sich besonders durch Sehneidezähne; von Chlamydotherium giganteum, Lund, welches die Grösse eines Nashorns hatte, fand Lund die Knochen in Brasilien in Höhlen. Pachytherium, Lund, ist nur durch einige Knochen der Extremitäten bekannt, und seine Verwandtschaft mit den übrigen Edentaten noch nicht genau ermittelt.

Von Dasypus, wovon in Amerika einige fossile Arten vorkommen, trennt Lund Euryodon und Meterodon nach der Beschaffenheit der Zähne ${ }^{1}$ ).

$\mathrm{Zu}$ der Familie der Ameisenfresser gehört ein in Europa gefundenes fossiles Thier: Macrotherium, Lartet. Bei Eppelsheim im Grossherzogthum Hessen fand man nemlich eine sehr grosse Nagelphalanx, die mit diesem Knochen der Schuppenthiere Uebereinstimmung zeigt, aber eine ausserordentliche Grösse besitzt. Nacliher fand Larter einige Phalangen bei Sansan, welche vielleicht zu diesem Thier (Macrotherium) gehören, aber es fanden sich zugleich Zähne, welche ohne Zweifel einem Thier aus der Ordnung der Edentaten angehören, sie gleichen den Zähnen der Faulthiere, und wenn sie von demselben Thier stammen, wie die gespaltenen, fossilen Nagelphalangen, so könnte man die grosse Nagelphalanx von Eppelsheim nicht einem riesenmässigen Manis zuschreiben, LARTET hat desshalb ein Macrotherium giganteum aufgestellt. KAup schrieb die grosse, fossile, gespaltene Nagelphalanx dem Dinotherium zu. Glossotherium wurde von Owen nach dem in Brasilien gefundenen hintern Theil des Schädels eines fossilen Thiers aufgestellt, welches nach OwEv vielleicht Aehnlichkeit mit Orycteropus hatte.

1) Blik paa Brasiliens Dyreverden för sidste Jordomvaeltning. 1841. S. 67 . 


\section{Geographische Verbreitung der Edentaten.}

Die Edentaten wohnen nur unter den wärmeren Himmelsstrichen, keines derselben lebt in Europa, die meisten im wärmeren Amerika, einige in Afrika und in Indien.

Die Faulthiere finden sich ausschliesslich im wärmeren Amerika, in Brasilien, in Guiana, in Peru 1), wo sie in den ausgedehnten, einsamen Wälderu fast beständig auf den Bäumen sich aufhalten. Diese Thiere gehen von dem neunten Grad nördlicher Breite nicht weiter südlich als bis zum vierundzwanzigsten Grad; in Paraguay werden sie weder von D'AzarA $^{2}$ ) noch von RengGer ${ }^{3}$ ) angegeben.

Auch die Ameisenfresser (Myrmecophaga) und das zahlreiche Geschleclit der Gürtelthiere kommen nur in Amerika vor, ausschliesslich in den wärmeren Gegenden, doch einige Gürtelthiere (Dasypus minutus) erstrecken sich weit gegen Süden durch Patagonien. Myrmecopleaga erstreckt sich vom achten Grade nördlicher bis zum sechsunddreissigsten südlicher Breite. Chlamyphorus lebt in Chili. Orycteropus ist über einen grossen Theil von Afrika verbreitet; im südlichen Africa kommt Orycteropus capensis vor, in Sennaar Orycteropus aethiopicus, Sundev, am Senegal ein Orycteropus, von dem noch nicht ausgemacht ist, zu welcher Art er gehört.

Die Schuppenthiere finden sich nur in Afrika und in Asien. Maris macroura, Erx. (Manis africana, Desm.), Manis tricuspis, Sundev, Manis Temminckï, Smuts, Manis tridentata, Focillon, in Afrika; die beiden ersten in Guinea, Manis Temminckii im Kafferlande und in Sennaar (nach Неdenвorg), Manis tridentata in Mozambique, Manis javanica, Manis brachyura, Erxl. (Manis pentadactyla, Linn.), Manis aspera, Sundev, und Manis Dalmani,

1) J. v. Tscuude, Untersuchungen iiber die Fauna Peruana. S. 200. 1844-46.

2) D'AzarA, Essais sur l'hist. nat. des quadrupèdes.

3) RavgGer, Naturgeschichte der Säugthiere von Paraguay. 1830. 
Sudev, leben in Asien; nemlich Manis jaranica auf Java, Borneo, Sumatra ${ }^{1}$ ). Manis brachyura, Erxl., in Ostindien, Manis Dalmanni in China bei Can10n, Manis aspera in Sumatra. In Nenholland leben keine Edentaten, wenn man nicht mit Cuvier die Monotremen mit dieser Ordnung der Säugthiere vereinigen will.

Es geht aus der geographischen Verbreitung der Edentaten hervor, dass diese Thiere den Alten fast unbekannt sein mussten, mit Ausnahme des indischen Schnppenthiers, von dem auch Aelian (Lib. XVI. 6.) unter dem Namen Phattages spricht. Die Angabe ist aber so unvollständig, dass es unentsehieden bleibt, ob nicht ein Thier ans der Klasse der Reptilien gemeint sei ${ }^{2}$ ).

1) Verhand. orer de natumlijke Gesehiedenis. Lciden 18 10.

2) In India nascitur bestia, quae erocodili terreni speeiem similitudinemque gerit, magnifudine est Melitensis catelli; pellis adeo aspero densoque cortice munitur, ut limae usum pracbeat, et vel aes disseetet ae ferrum exedat et conficiat; eam Indi Phattagen vocant. 
A N A TOMISCHES. 



\section{Knochensystem.}

Wirbelsäule. Von der sonst gültigen Regel, dass die Säugthiere allgemein sieben Halswirbel haben, ungeaehtet der so verschiedenen Länge des Halses, macht das dreizehige Faulthier und die ilm nahe stehende Art Bradypus cuculliger eine Ausnahme, indem, der Kürze des Halses ungeachtet, zwei Halswirbel mehr sich finden, als bei den übrigen Säugthieren. Die neun Halswirbel des dreizehigen Faulthiers lassen sich nach Tu. BeLL ${ }^{1}$ ) auf deu gewöhnlichen Typus der Säugthiere reduziren, wemu man den achten und neunten Halswirbel dieses Thiers zu den Brustwirbehn zähllt, wozu man nach BeLL berechtigt ist, da an der Spitze des Querfortsalzes dieser beiden Wirbel ein länglicher Kuochen durch ein Gelenk befestigt ist, der als eine vordere, falsche Rippe, wie sie bei den Vögeln und Reptilien vorkommt, zu betrachten wäre. Gegen diese Dentung erheben sich aber manche Einwürfe. Unter drei Exemplaren des dreizehigen Faulthiers ans Guiana (Bradypus cuculliger, Wagl.), die ich zergliederte, fand ich bei den ältern Thieren keine Spur einer solchen vordern, falsehen Rippe, ungeachtet ich sorgfältig darnach suchte, nur der Querfortsatz des achten und noch melı des nennten Wirbels ist länger als bei den vorhergehenden.

Bei einem unausgewachsenen Thier aber fand ich an der Spitze des Querfortsatzes, aber mur am neunten Halswirbel, einen selur kleinen, rundlichen Knochenkern, der durch eine selr kleine, glatte Gelenksfläche, mit der Spitze des Querfortsatzes in Verbiudung stand. Solche grosse, rippenähnliche Knochen, wie sie BeLl an achten und besonders am neunten Ilalswirbel besehreibt und abbildet, kommen bei diesem Faulthier nicht vor. Vielleicht dass die Bildung, wie sie Beul angibt, einer noch wenig bekanuten Art des Faulthiers zukommt, oder dass individuelle Varietäten in Beziehung auf die Bildung der Halswirbel vorkonmen. Schon Cuvier ${ }^{2}$ ) gibt an, dass die Spilze des Querfortsatzes des

1) Transaetions of the zoologieal Soeiety of London. Vol. I. p. 115.

2) Ossemens fossiles Tom. V. p. 85. Trois. éd. 
neunten Halswirbels bei jungen Individuen nicht mit den übrigen Knochen verschmolzen ist, und vermuthet, es könnte dieses Stück ein Rudiment einer Rippe sein. МескеL ${ }^{1}$ ), wo er von der Entwicklungsweise der Wirbel spricht, führt anch einen Knochenkern an, der bei dem Aï (Bradypus tridactylus) vermittelst eines breiten Knorpels an der Spitze des Qnerfortsatzes des neunten Halswirbels sitze; auch am achten Halswirbel finde sich an derselben Stelle ein viel kleinerer Knochenkern. Meckeu bemerkt, dass dadurch diese beiden Wirbel den Rückenwirbeln ähnlicher werden, und dass dadurch die Ausnahme, welche der Aï (Bradypus tridactylus) von den übrigen Säugthieren macht, sich vermindere. Harlan und B Bainvilue ${ }^{2}$ ) fanden auch nur am neunten Halswirbel einen kleinen, beweglichen Knocheu, der mit dem Querfortsatz in Verbindung stand, und nicht von der Grösse war, wie es BeLL beobachtete. Der kleine Knochen an der Spitze des Querfortsatzes scheint nur eine vorübergehende Bildung zu sein, indem dieser kleine Knochen mit dem Querfortsatz zusammenwächst. Dass der achte und neunte IIalswirbel dieses Faulthiers nicht zu den Brustwirbeln gehöre, geht besonders noch daraus hervor, dass die $\boldsymbol{M}$. M. scaleni sich an die Querfortsätze dieser Wirbel befestigen; ferner fand ich, dass die Spiralnerven, welche zwischen den achten und neunten Halswirbel, und zwischen diesem und dem ersten Brustwirbel hervorkommen, nicht den Dorsal-Nerven, sondern den Cervikal-Nerven angehören; denn das Armgeflecht wird, wie beim Menschen und den andern Säugthieren, aus den vier letzten Cervikal-Nerven (hier dem siebenten, achten, neunten und zehenten) und dem ersten Dorsal-Nerven gebildel. Schon v. Bär hat diesen Umstand geltend gemacht, um über die Deutung der Wirbel beim Faulthier zu entscheiden 5). Das Loch im Querfortsatz findel sich noch im achten Halswirbel, im neunten fehlt es, es fehlt auch den vier obern Halswirbeln. Auch die Gestalt des Querfortsalzes verhindert, diese beiden letzten Halswirbel den Rückenwirbeln zuzuzählen, wie schon Blainvilue bemerkt hat. Am siebenten und achten Halswirbel ist nämlich dieser Fortsatz gabelförmig getheilt, am achten viel stärker als am siebenten; am neunten Halswirbel fehlt diese Theilung. Bei Bra-

1) System der vergleichenden Anatomie. Zweiter Band. S. 294.

2) Ostéographie. Note sur les vertèbres cervieales de l'Aï.

3) Beitrag zur Kemntniss vom Bau des dreizehigen Faulthiers. In Meckels Archiv für die Physiologie. Aehter Band. 
dypus torquatus finden sich acht Halswirbel. Bei einem dreizehigen Faulthier aus Guiana (Bradypus cuculliger, Wagl.) fand ich als eine sehr seltene Ausnahme zehen Halswirbel; ich labe dieses Skelet, an dem die Knochen noch durch ihre natürlichen Bänder mit einander verbunden sind, in der vergleichendanatomischen Sammlung der Universilät aufgestellt. Das zweizehige Faulthier (Choloepus didactylus) hat sieben Halswirbel, wie die übrigen Sängthiere. Die Halswirbel der Gürteldhiere und des Chlamyphorus ${ }^{1}$ ) bieten eine Eigenthümlichkeit dar, die den Gegensatz bildet von der Vermehrung dieser Knochen, wie sie bei den Faulthieren vorkommt. Es ist bei den Gürtelthieren und bei Chlamyphorus eine Neigung zur Verninderung der Zahl der Halswirbel. Bei dem Riesengürlelthier (Dasypus gigas) ist der zweite und dritte Ilalswirbel in Ein Stück verschmolzen; bei dem schwarzen Gürtelthier und bei Chlamyphorus ist der zweite, dritle und vierte Halswirbel in Ein Stück verwachsen; zuweilen sind beim Gürtelthier alle Halswirbel, mit Ausnahme des ersten, in ihrem Bogen und Körper unter einander verwachsen. Das Loch in den Querfortsätzen der Halswirbel fehlt bei Orycteropus capensis nur in siebenten Halswirbel, bei Manis javanica nur in ersten, bei Myrmecophaga tamandua im sechsten und siebenten, bei Myrmecophaga jubata im siebenlen, ebenso bei Dasypus gigas. Der Zahnfortsalz des zweiten Halswirbels ist gross bei den Faulthieren, aber bei dem Riesengürtelthier (Dasypus gigas) reicht er bis zu dem Hinterhauptsheiı und ist mit diesem durch eine überknorpelte Gelenksfläche verbunden; es finden sich somit um das grosse Hinterhauptsloch herun drei Gelenksflächen, die beiden für die Artikulation mit dem Atlas, damn am vordern Rande dieses Lochs eine in die Quere verlängerle, glatte Gelenksfläche für den Zahnfortsatz des zweiten Halswirbels. Bei diesem Thier verbinden sich die Halswirbel unter einander durch fünf Gelenke an der vordern wie an der hintern Seite. Es findet sich nänlich ausser der Verbindung durch den Körper des Wirbels, der ausserordentlich breit und sehr dünn ist, auf der rechten wie auf der linken Seite eine doppelte Gelenksfläche, die eine am schiefen Fortsatz, die andere, weiter aussen liegende, an der Wurzel des Querfortsalzes.

Unter allen Säugthieren hat das zweizehige Faulthier die grösste Zahl der B rustwirbel, nämlich dreiundzwanzig, zuweilen, nach BlalvvilLe, vierundzwanzig. Bradypus cuculliger hat vierzehen Brustwirbel, Orycteropus ca-

1) Yarreld, iiber den Knochenbau des Chlamyphorus truncatus. Isis 1830. 
peusis dreizehen, das scliwarze Gürtelthier (Dasypus peba) zehen, Dasypus sexcinctus eilf, Dasypus gigas und Dasypus gymmurus dreizehen, Chlamyphorus truncatus eilf, Myrmecophaga jubata sechszehen, Myrmecophaga tamandua achtzehen, Myrmecophaga didactyla fünfzehen bis sechszehen, Manis javanica fünfzehen, Manis tridentata vierzehen.

Bei Orycteropus und bei Dasypus zeichnen sich die Dornfortsätze der Brustwirbel durch ihre Länge aus, bei ersterem sind die Dornfortsätze gegen den eilften Brustwirbel rückwärts gerichtet, die Dornfortsätze der folgenden Brustwirbel und der Lendenwirbel sind gegen diesen Wirbel vorwärts gerichtet. Bei Dasypus, Manis, Myrmecophaga sind alle Dornfortsätze rückwärts gerichtet.

Bei den Gürtelthieren sind die vordern Gelenkfortsätze der hintern Rückenwirbel, der Lendenwirbel und der vordern Kreutzwirbel gross, und mit sehr grossen, auswärtssteigenden Fortsätzen versehen (Metaphysis nach 0 wen). Bei Dasypus gigas beginnen vom zehenten Rückenwirbel an diese grossen, aufwärts steigenden Fortsätze und finden sich an den Lendenwirbeln und an den drei vordern Kreutzwirbeln. Diese Fortsätze des ersten und zweiten Kreutzwirbels sind so gross, dass sie den grössten Theil des Iüftbeinkamms bedecken und mit diesem verwachsen sind. Diese aufwärts steigenden Fortsätze der hintern Rückenwirbel, Lendenwirbel und vordern Kreutzwirbel der Gürtelthiere reichen so weit aufwärts, dass sie in eine Ebene mit den Spitzen der Dornfortsätze kounmen. Ohne Zweifel dienen diese grossen Fortsätze zur Unterstützung des knöchernen Rückenpanzers.

Die Zahl der Lendenwirbel ist sehr verschieden bei den verschiedenen Edentaten und wechselt von zwei bis acht. Leztere Zahl findet sich bei Orycteropus capensis. Dasypus gigas hat nur einen Lendenwirbel, Dasypus peba fünf, nach Cuvier sechs, Chlamyphorus drei, Myrmecophaga jubata zwei, Myrmecophaga tamandua fünf, Myrmecophaga didactyla zwei, nach Cuvier drei, Manis javanica und Manis tridentata fünf. Das zweizehige Faulthier hat, wie Bradypus cuculliger, vier Lendenwirbel. Nach Cuvier und A. Wagner ${ }^{1}$ ) hat ersteres drei Lendenwirbel, aber an beiden in unserer Sammlung aufbewahrten Skeleten von Choloepus didactylus finden sich vier Lendenwirbel. An einem

1) Schrebers Säugthiere. Supplementband. 1844. 
Skelet von einem ausgewachsenen Thier hat der erste Lendenwirbel einen grössern Querfortsatz als die folgenden. Eigenthümlich ist die Verbindung der letzten Rückenwirbel und der Lendenwirbel bei den Gürtelthieren und bei den Ameisenfressern. Die Zahl der Gelenksflächen ist vermelıt; es findet sich auf jeder Seite an der Wurzel des Dornfortsatzes eine fast senkrecht stehende Gelenksfläche und zwei fast horizontale Gelenksflächen weiler aussen liegend, an der hintern Seite des Wirbels eine obere und eine untere; diese werden aufgenommen in eine aus zwei Gelenksflächen gebildete Vertiefung des folgenden Wirbels. Dieser Theil der Wirbelsäule erhält durch diese Gelenksverbindung eine ansserordentliche Festigkeit.

Kreutzwirbel. Bradypus cuculliger und Choloepus didactylus haben sieben Kreutzwirbel, Orycteropus capensis sechs, Dasypus peba neun, nach Cuvier acht, dagegen zählt el einen Lendenwirbel meln, das Riesengürtelthier (Dasypus gigas) hat zwölf Krentzwirbel, Chlamyphorus drei, Myrmecophaga tamandua fünf, Myrmecophaga didactyla vier, ebenso Manis javanica, Manis tridentata drei. Bei den pflanzenfressenden Edentaten und bei Dasypus und Myyrmecophaga jubata und tamandua ist auch das Sitzbein verwachsen mit dem Rande des Kreutzbeins, wodurch der Sitzbein-Ausschnitt am Becken in ein Loch verwandelt wird. Bei Orycteropus cupensis findet diese Verbindung nicht statt, aber der Querfortsatz des letzten Krentzwirbels erreicht fast den Sitzbeinhöcker und ist mit diesem durch kurze Bandmasse verbunden. Uebrigens trennen sich bei Orycteropms die einzelnen falschen Wirbel des Kreutzbeins leicht von einander.

Schwanzwirbel. In der ganzen Klasse der Säugthiere kommt bei den Edentaten die grösste Zahl der Schwanzwirbel vor. Manis macrura, Erx., hat sechsundvierzig Schwanzwirbel, Manis jacanica neunundzwanzig, Manis Temmincki $\ddot{i}$ einundzwanzig $\left.{ }^{1}\right)$, Manis tridentuta, Focillon, viermndvierzig, Myrmecophaga jubata dreissig, Myrmecophaga tamandua und didactyla vierzig, Cuvier gibt für Mlyimecophlaga tamandua nur zweiunddreissig an. Pander und D'Alton dreissig, in der Abbildung (fünfte Tafel) sind es aber mehr ${ }^{2}$ ). Orycteropus capensis hat fünfundzwanzig Schwanzwirbel, Dasypus

1) Smuts, Mammalia capensia. Leidae 1832.

2) Skelete der zahnlosen Thiere. 1825. 
sexcinctus sechszehen nach 0wen, Dasypus peba einunddreissig, nach $\mathrm{Cu}-$ vier nur zweiundzwanzig, Dasypus gigas vierundzwanzig, Chlamyphorus truncatus vierzehen. Die kleinste Zahl der Schwanzwirbel findet sich unter den Edentaten bei den Faulthieren; Bradypus cuculliger hat neun Schwanzwirbel, Choloepus didactylus nur fünf.

Untere Dornen, als eigene Knochen kommen vor an dem Schwanze bei Mamis, Myrmecophaga, Orycteropus und Dasypus, fehlen aber an dem kurzen Schwanze der Faulthiere. Die untern Dornen zeigen bei Dasypus gigas eine eigenthümliche Bildung, sie bestehen nicht blos aus zwei gabelförmigen Aesten, sondern sie gleichen einem Wirbel, sie sind von einem Kanal durchbolırt für die untere Schwanzarterie; sie haben nemlich einen Körper, wie ein Wirbel, und durch diesen Körper artiknliren sie mit der untern Seite der Schwanzwirbel, ron diesem Körper geht auf jeder Seite ein Ast ab, der sich mit dem der andern Seite in der Mittellinie verbindet. Diese Dornen sind mit Querfortsätzen versehen, sie entspringen an der Stelle, wo die beiden Aeste, welche den Kanal einschliessen, mit einander sich verbinden.

Die Querfortsätze der Schwanzwirbel sind selrr gross bei den Schuppenthieren. Bei Myrmecophaga jubata ist der Scliwanz besonders an seinem Ursprung stark von beiden Seiten zusammengedrückt, was bei den beiden andern Ameisenfressern sich nicht so verhält. Der Kanal für das Rückenmark und seine Nerven findet sich nur an der vordern Abtheilung des Schwanzes; dieser Kanal fehlt bei Myrmecophaga jubata in den fünfehen letzten Schwanzwirbeln, bei Dasypus gigas in den siebzehen, bei Orycteropus capensis in den dreizehen letzten Schwanzwirbeln.

Schädel. Der Schädel der insektenfressenden Edentaten ist schmal, sehr niedrig, der Gesichtswinkel sehr spitzig, besonders sind bei Myrmecophaga jubata und in geringerem Grade bei Myrmecophaga tamandua die Kiefer ausserordentlich in die Lünge gezogen, wodurch die Nasenhöhle die Form einer langen Röhre erlält. Die pflanzenfressenden Edentaten unterscheiden sich von den vorhergehenden sehr auffallend durch die Gestalt des Schädels; er ist kurz und abgerundet.

Die Nähte zwischen den Knochen des Kopfs verschwinden sehr frühzeitig bei den Faulthieren, doch bleibt der Zwischenkieferknochen getrennt vom Oberkiefer. 
Der Zwischenkieferknochen der Edentaten ist allgemein, da er keine Zähne trägt, sehr klein. Bei Myrmecophaga erscheint er als ein schmaler Knochensaum am vordern Rande des Oberkiefers, und hängt mit diesem Knochen durch Knorpelmasse zusammen, so dass er einige Beweglichkeit besitzt. Bei Manis, Orycteropus und Dasypus ist der Zwischenkieferknochen grösser und trägt sogar bei Dusypus sexcinctus einen Zalın (dritte Tafel). Bei Manis erstreckt sich ein schnaler, langer Fortsatz vom Gaumentheil des Zwischenkieferkuochens zwischen den Gaumeufortsatz des Oberkieferknochens der rechten und linken Seite. Der Zwischenkieferknochen der Faulthiere ist selır klein, und bleibt bei Bradypus cuculliger, torquutus auch nachdem die übrigen Nähte am Schädel verschwunden sind, getrenut, und besitzt einige Beweglichkeit, wie bei Myrmecophaga, indem er durch eine Knorpellage mit dem Oberkieferknochen zusanmenhängt. Zwwischen dem rechten und linken Zwischenkieferknochen von Bradypus tridactylus und cuculliger bemerkt man keine Grenze, der Knochen erscheint unpaar. Weil dieser Knochen nur durch Knorpel mit dem Oberkieferknochen zusammenhängt, so geht er leicht verloren, und fehlt häufig an den Faulthierschädeln in den anatomischen Sammlungen, daher die Meinung entstanden ist, dieser Knochen verschmelze frühzeitig mit dem Oberkiefer in Ein Stück. Bei Choloepus diductylus ist der Zwischenkieferknochen grösser, mit dem der andern Seite nicht verschmolzen, hat aber doch auch keinen aufsteigenden Fortsatz, hängt übrigens fest mit dem Oberkieferknochen zusammen.

Der Oberkieferknochen der insektenfressenden Edentaten zeichıet sich durch seine verlängerte Form aus, besonder's bei Myrmecophaga jubata. Die lange Röhre, in welche bei diesem Thier der Kopf vorne ausgezogen ist, wird hauptsächlich von dem Oberkieferbein und den sehr verlängerten Nasenbeinen gebildet. Im jugendlichen Alter sind bei diesem Thier die Kiefer verhältnissmässig viel kürzer als später. Bei Manis und Myrmecophaga ragt, da die Zälne fehlen, der Rand des Oberkiefers slatt des Alveolarfortsatzes als eine schmale Leiste hervor. Bei deı genannten Thieren trägt der Oberkieferknochen nichts bei zur Bildung der Augenhöhle, nur bei Manis noch durch seinen Jochfortsatz. Bei den Faulthieren erscheint dieser Knochen kurz; das Unteraugenhöhlenloeh ist einfach.

Die Nasenknochen sind verlängert, nur bei den Faulthieren kurz und 
breit. (Die eigenthümliche, vom Nasenbein der Edentaten ausgehende Muschel ist bei den Geruchswerkzeugen beschrieben.)

Beim zwcizehigen Faulthier findet sich ein eigenthümlichcr, kleiner Knochen, der unmittelbar vor dem Nasenknochen liegt auf dcr knorplichen Scheidewand der Nasenhöhle (Os praenasale). Er ist unpaar, vorne zugespitzt (dritte Tafel, zweite und dritte Figur). Meckel betrachtet dicsen Knoehen als den aufsteigenden Ast des Zwischenkieferbeins, dagegen spricht abcr die Lage dieses Knochicns am innern Rande der Nasenbeine. Dagegen spricht auch der Umstand, dass bei Dasiypus ein ähnlicher aber in zwei seitliche Hälften zerfallener Knochen vorkomint, ungeachtet hier der aufsteigende Ast des Zwischenkieferknochens sehr entwickelt ist. Auch mit dem Rüsselknochen des Schweins oder des Maulwurfs kann er nicht verglichen werden. Bei dem dreizchigen Fauthier kommt nach Carus ein ähnlicher kleinerer, in zwei seitliche Hälften zerfallener Knochen vor ${ }^{1}$ ). Anch bei Dasypus liegt auf jeder Seite am Rande der Oeffuung der knöchernen Nasenhöhle ein schmaler, dünner Knochen; er sitzt an dem vordern Rande des aufsteigenden Astes des Zwischenkieferknochens und kommt mit dem gleichen Knochen der entgegengesetzten Seite nicht zusammell.

Das Thräncubein findet sich allgemein mil Ausnahme von Manis, ist aber bei den Faulthieren sehr klein, und eine einfache Oeffnung führt in den Thränenkanal, bei Myrmecophaga jubata und tcumandua ist sie doppelt. Bei Manis javanica und crassicaudata führt statt eines Kanals nur ein grosses, eiförmiges Loch zwischen dem Stirnbein und dem Gaumenbein, da das Thränenbein fehlt, von der Augenhöhle in die Nasenhöhle, und bei Manis tridentata fehlt diese Oeffinung ganz. Das Jochbein erreicht bei mehreren Edentaten nicht den Jochfortsatz des Schläfenbeins, der Jochbogen ist also nicht geschlossen, so bei Myrmecophaga, bei den Schuppenthieren und Faulthieren. Bei Myrmccophaga ist sogar das Jochbein sehr klein und beweglich mit dem Thränenbein und Oberkiefer verbunden, es geht desshalb an den Schädeln in den anatomischen Sammlungen leieht verloren, und wird in den Abbildungen, welehe Wiedemann $^{2}$ ) und Six ${ }^{5}$ ) gegeben haben, vermisst. Bei Manis javanica,

\footnotetext{
1) Carus, Erläuterungstafeln zur vergleiehenden Anatomie. Zweites Heft. Tab. VIII. fig. 8.

2) Archiv fü Zoologie und Zootomie. Dritter Band.

3) SPIx, Cephalogenesis. Tab. VII.
} 
Manis tridentata und Myrmecophaga didactyla fand ich diesen Knochen nicht. Bei einem Manis-Schädel, von welchem nieht zul ermitteln war, welcher Speeies er angehörte, fand Köstuı ${ }^{1}$ ) das Joclıbein als einen kleinen, schmalen Knochen an der hintern Oberkieferspitze. An dem Schädel eines grossen Manis crassicaudata, Griffith, in unserer vergleichend-anatomischen Sammlung ist der sehmichte Streif, welcher an der hintern Spitze des Oberkiefers zum Jochfortsatz geht, vollständig verknöchert, und der Jochbogen erscheint somit vollständig geschlossen. Die Gürtelthiere, Chlamyphorus und Orycteropus, haben einen geschlossenen Jochbogen. Das Jochbein der Faulthiere theilt sich in einen aufsteigenden und absteigenden $A$ st, olme den Jochfortsatz des Schläfenbeins zu erreichen (dritte Tafel). Der knöcherne Gaumen der Edentaten wird von dem Zwischenkieferknochen, dem Oberkieferknochen und dem Gaumenbein gebildet, aber bei Orycteropus kommt beim jungen Thier das Pflugscharbein noch dazu, es ragt als cin schmales Stück zwischen dem vordern Theil des Oberkieferknochens und hinter dem Zwischenkieferknochen herein. Ganz eigentlümlich ist die Bildung und Zusammensetzung des knöchernen Gaumens bei Myrmecophaga jubata und tamandua. Er verlängert sich ausserordentlich, fast bis zum Hinterhauptsloch, und ausser dem Zwischenkieferknochen, Obcrkieferknoehen und Gaumenbein trägt auch das Keilbein bei zu der Bildıng des kıöchernen Gaumens, indem der rechte und linke Flügelfortsatz des Keilbeins in der Mittellinie zusammenstossen, sie legen sich unmiltelbar an den ganzen lintern Rand des Gaumenbeins an (fünfte Tafel, zweite Figur, m.). Eine älnliehe Zusanmensetzung des knöelrernen Ganmens kommt bei den Krokodilen vor. Eine von den andern Ameisenfiessern etwas abweichende Bildung fand ich bei dem kleinen Ameisenfresser (Myrmecophaga didactyla), indem zwar der harte Gaumen sich so weit rückwärts erstreckt, als bei den beiden andern Arten, aber das Keilbein trägt dazu nichts bei, sondern von dem lintern Rand des Gaumenbeiıs an wird der harte Gaumen von einer dicken, fibrosen Haut gebildet. Die hintere Nasenöffnung (Choannen) ist einfach hei den Edentaten, indem die Scheidewand der Nasenhöhle sich nicht so weit rückwärts erstreckt. (Die Nasenmuseheln sind beim Geruchsorgane beschrieben.)

Dic Schädelhöhle ist nicht geräunig und sehr nieder.

1) Köstlin, Der Kopf der Wirbelthiere. S. 108. 
Das Stirnbein der Edentaten wird durch eine Naht in zwei seitliche Hälften getheilt, doch verschwindet bei einigen diese Naht bald. Am Stirnbein von Dasypus sexcinctus bemerkt man eine längliche, abgerundete Hervorragung, deren Höhle theils mit der Schädelhöhle, theils mil der Nasenhöhle in Verbindung steht nach 0 wes ${ }^{1}$ ). Ein ähnlicher Fortsatz findet sich auch bei Chlamyphorus. Unter dem obern Augenhöhlenrande im Stirnbein findet sich bei den Faulthieren, bei Orycteropus, bei Myrmecophaga und bei den Schuppenthieren ein rundes Loch; es führt bei den Faulthieren durch einen Kanal, theils in die Stirnhöhle, theils in die Schädelhöhle, vor die Siebplatte des Siebbeins. Bei Orycteropus fülırt dieses Loch nichıt in die Stirnhöhle, wie Cuvier angibt, sondern der Kanal spaltet sich in zwei Aeste, die in der Diploe des Stirnbeins hinter der Stirnhöhle verlaufen und mit den gleichen Kanälen der entgegengesetzten Seite zusammenfliessen. Es scheinen Kanäle für Blutadern zu sein. Bei Myrmecophaga führt dieses Loch in einen Kanal, der in der Sclıädelhöhle vor der Siebplatte des Siebbeins sich öfnet. (Ueber die Stirnhöhlen siehe Geruchswerkzeuge.) Es findet sich bei den Edentaten auf jeder Seite ein Scheitelbein; nur bei Orycteropus ist dasselbe unpaar. Ein Zwischenscheitelbein (Os interparietate odel os triquetrum) habe ich nicht gefunden; doch wurde es in einzelnen Fällen beobachtet bei Faulthieren, bei Dasypus novemcinctus, bei Myrmecophaga didactyla ${ }^{2}$ ).

Die Schuppe des Schläfenbeins ist klein. Der Jochfortsatz dieses Knor chens verbindet sich nur bei Orycteropus, Dasypus und Chlamyphorus mit dem Jochbein. Die Gelenksfläche für die Aufnahme des Gelenkskopfs des Unterkiefers ist sehr flach. Bei dem schwarzen Gürtelthier (Dasıpus peba) verbindet sich der Unterkiefer mit dem Schläfenbein durch eine faseriehte Substanz, ohne dass eine glatte Gelenksfläche vorhanden wäre. Bei Myrmecophaga fehlt in dem Kiefergelenk die freie Knorpelseheibe (Meniscus). (Der Gehörgang und die Gehörknochen sind bei den Gehörorgan beschrieben.)

Das Keilbein ist schmal, vom Türkensattel findet sich beim Gürtelthier eine Audeutung. Bei Choloepus und bei Bradypus torquatus ist der Flügelfortsatz (oder das Flügelbein, os pterygoideum) blasenförmig aufgetrieben,

1) Proceedings of the zoologieal Society of London. 1852. p. 15\%.

2) Otro, De rarioribus quibusdam seeleti humani cum animalium sceleto analogiis. Vratislaviae. 1859. Stanxius, Lehrbuch der vergleichenden Anatomie der Wirbelthiere S. 363. 
und die Höhle mündet in die Keilbeinhöhle. Die Siebplatte des Siebbeins besitzt eine ausserordentliche Ausdehnung und bildet am vordern Theil der Schädelhöhle eine geräumige Aushöhlung. Beim Gürtelthier nimmt diese Platte etwa den dritten Theil der Schädelhöhle ein; bei Orycteropus und Dasypus gigas ist nicht nur der horizontale und der vordere, senkrechte Theil der höhlenförmigen Siebplatte, sondern anch der obere Theil von Löchern durchbohrt (siche Geruchswerkzeuge).

Am II interhauptsbein finden sich die gewölmlichen zwei Gelenksfortsätze und vor jedem derselben ein Foramen condyloideum. Zu den beiden Gelenksfortsätzen komml bei Dasypus gigas eine dritte querverlängerte GeIenksfläche am vordern Rande des grossen Hinterhauptloches, sie dient zur Artikulation mit dem Zahnfortsatz des zweiten Halswirbels. Auch Dresypus gymmurus hat eine Gelenksfläche am vordern Rande des grossen Iinterhauplloches, sie ist aber nicht so ausgedehnt als beim Riesengürtelthier. Das IInterhauptloch der Edentaten steht fast senkreclıt, und der grösste Durchmesser geht in die Quere. Beim schwarzen Gürtelthier bildet die Schuppe des Hinterhauptbeins drei stumpfe, neben einander liegende Hervorragungen, denen in der Schädehöhle Vertiefungen entsprechen. Ein knöchernes Gehirnzelt findet sich bei Manis und Orycteropus; bei Dasypus steigt ein querlaufender Knochenfortsatz von dem hintern Rande der Seitenwandbeine herunter in der Schädelhöhle und bildet so ein unvollkommenes, knöchernes Gehimzelt, so bei $\boldsymbol{D} \boldsymbol{\alpha}$ sypus gigas, bei andem, wie bei Dasypus pebn, ist das knöeherne Grehirnzelt mehr ausgebildet, indem von dem erwähnten Knochenfortsatz eine Knochenleiste heruntersteigt bis zum Felsenbein.

$\mathrm{Z}$ wickelbeine kommen als individnelle Abweichungen zuweilen vor; ich fand zwei bei Myrmecophaga tamandua zwischen beiden Scheitelbeinen, PAnder und D'Altor fanden eines bei einem jungen Bradypus didactylus zwisehen der Stirnnaht, Kronemaht und Pfeilnaht; Leuckart fand einen solchen Knoehen bei Manis jaramica mid Dasypus gigas ${ }^{1}$ ).

Der Unterkiefer der Edentaten ist schwach, md die beiden seitlichen Hälften bleiben das ganze Leben ïber nur durch Knorpelmasse in der Mittellinie vereinigt. Nur die Fanthiere, da sie stärkere Zähne haben, sind mit einem dicken, hohen Unterkiefer versehen, und die beiden seitlichen Hälften

1) Zoologische Bruchstiicke. Zweites Heft. S. 54. 
desselben vereinigen sich frühzeitig vollständig mit einander. Beim zweizehigen Faulthier bildet dieser Knochen vorne eine fast lıorizontale, schnabelförmige Verlängerung. Besonders schwach ist der Unterkiefer bei denen, welche gar keine Zähne liaben, wie Myrmecophaga, Manis. Bei Orycteropus ist der aufsteigende Ast gross, und der Kronenfortsatz höher als der Gelenkfortsatz, so auch bei Dasypus sexcinctus und peba, bei Dasypus gymnurus ist der Kronenfortsatz niedriger als der Gelenkfortsatz, bei Priodontes gigas steht der Gelenkfortsatz mit dem Kronenfortsatz fast in gleicher Höhe. Bei Myrmecophaga fehlt der Kronenfortsatz ganz, nur bei Myrmecophaga didactyla hat der Unterkiefer vor dem Gelenkfortsatz eine spitzige Hervorragung. Die Gelenksfläche ist wenig konvex, ihr grösster Durchmesser geht bei Orycteropus und Myrmecophaga nach der Länge, aber bei den Faulthieren und Gürtelthieren ist die Breitendimension vorherrschend. Ein rückwärts geriehteter Fortsatz am untern hintern Theil des Unterkiefers kommt den meisten Edentaten zu, am stärksten zeigt er sich bei den Faulthieren. Nur bei Chlamyphorns wird dieser Fortsatz nach der Darstellung von YarrelL vermisst, auch bei Manis.

Der Kanal im Unterkiefer ist bei den Faulthieren ausserordentlicl kurz, indem er schon am hintersten Backenzahn an der äussern Fläche des Knochens, bei dem zweizehigen Faulthier fast ganz am obern Rande des Knochens sich öfnet, doch lanft ein enger Kanal noch weiter fort, der neben der Mittellinie eine sehr enge Mündung hat. Bei Orycteropus hat dieser Kanal fünf hinter einander liegende Oeffnungen an der äussern Fläche des Unterkiefers. Der Kanal findel sich auch bei denjenigen Edentaten, welchen die Zähne ganz fehlen, und er erstreckt sich bei ihnen fort durch die ganze Länge des Knochens. Bei Manis javanica hat der Unterkiefer an seinem obern Rande vorne einen kleinen, spitzigen, zahnförmigen Fortsatz, der aber bei Manis Temminckii fehlt ${ }^{1}$ ).

Löcher und Spalten des Schädels. Die Zwischenkieferlöcher sind bei den Faulthieren und Gürtelthieren klein, bei den letzteren liegen sie ausschliesslich im Zwischenkieferknochen. Bei Orycteropus sind diese Löcher ziemlich klein, bei Myrmecophaga und Manis sind sie schmal in die Länge gezogen. Der Thränenkanal ist eng bei den Faulthieren und Gürtelthieren; bei Myrmecophaga beginnt er mit einer doppelten Oeffnung; bei Manis tridentata

1) SMuts, Mammalia capensia. Leidae 1832. Tab. III. 
fehlt der Thränenkanal, bei Manis javanica und crassicaudata fehlt zwar auch das Thränenbein, aber ein dem Thränenkanal entsprechendes Loch liegt zwischen dem Stimbein und dem Gaumenhein. (S. Sinnwerkzeuge: Auge.)

Der Unteraugenhöhlenkanal ist sehr kurz und eng bei den Faulthieren, noch am weitesten bei Choloepus. Bei den Gürtelthieren ist dieser Kanal ziemlich lang, bei Manis und Myrmecophaga sehr kurz. Das Sehnervenloch ist für sich bestehend. Das Foramen spheno-orbitale ist bei den Faulthieren, Gürtelthieren für sich bestehend, bei Orycteropus und Manis mit dem runden Loch zusamiuengeflossen. Das eiförmge Loch besteht für sich. Das Foramen pterygopalatinum findet sich bei den Faulthieren, bei den Gürtelthieren ist es zuweilen mit dem Foramen speno-palatinum vereinigt; aber diese Löcher sind getrennt bei den Schuppenthieren und Ameisenfressern. Es findet sich das Foramen jugulare. Das Forumen caroticum ist klein bei den Gürtclthieren, den Schuppenthieren, den letzteren wird er von Turner abgesprochen, aber es ist nicht angegeben, welche Art untersucht wurde ${ }^{4}$ ), bei Manis pentadactyla ist es vorhanden, fehit als eine besondere Ocffnung bei Orycteropus. Das Foramen condyloideum findet sich bei den Edentaten. Die Emissarien sind bei Priodontes gigus und Orycteropes besonders gross und zahlreich am Stirnbein, am Seitenwandbein, am Schläfenbein.

Vom Hinterhauptloch war schon dic Rede beim Hinterhauptbein.

(Die Zähne sind bei den Verdauungswcrkzeugen abgehandelt.)

Rippen. Die Zahl der Rippenpaare ist schon mit der Zahl der Brustwirbel angegeben. Myrmecophaga tamandua hat unter seinen achtzehen Rippenpaaren acht falsche, Myrmecophaga jubatce hat fünf falsche Rippen, Myrmecophaga didactyla noun, Manis jacanica sieben, Manis tridentata sechs, Orycteropus fünf, Dasypus gigas und Dasypus pela vier, bei Dasypus gigas ist aber die letzte Rippe sehr klein. Chlamyphorus hat drei, Bradypus cuculliger fünf, Choloepus didactylus eilf falsche Rippen.

Der kleine Ameisenfresser (Myrmecophaga didactyla) weicht in der Gestalt der Rippen von allen Edentaten, ja von allen Säugthieren ab, indem die Rippen so breit sind, dass die Zwischenrippenräume verschwinden, und die Rippen decken einander dachziegelförmig. In einem geringeren Grade ist

1) Observations relating to some of the foramina at the base of the skull in Mammalia. By Tunser, jun. In Proceedings of the zoolog. Society of London. 1849. 
dieses anch bei Myrmecophaga jubata der Fall, auch die Rippen der Gürtelthiere und Faulthiere sind breit, besonders ist die erste Rippe der Gürtelthiere sehr breit, aber schmal sind diese Knochen bei Orycteropus.

Die Rippenknorpel verknöchern nach und naeh vollständig bei Manis, Myrmecophaga, Dasypus, Chlamyphorus und bei den Faulthieren. Bei Manis wird der Knorpel aus zwei Stücken zusammengesetzt, die unter einem vorwärts gericlteten, spitzigen Winkel unter einander zusammenstossen. Diese getheilte Rippenknorpel findet sich bei Mamis javamica an der siebenten, achten, neunten, zehenten und eilften Rippe. (Dieses Zerfallen des Rippenknorpels in zwWei Stücke kommt wieder bei den Krokodilen vor.) Je zwei Rippenknorpel, die einander auf der rechten und linken Seite entsprechen, grenzen bei Myrmecophaga jubata und tamandua in der Miltellinie an einander, bei den beiden letzten Knorpelı der wahren Rippen ist dieses vollständig der Fall, weniger vollständig bei den vordern. Das Brustbein verlauft in der Brusthöhle hinter dieser Verbindungsstelle. Bei Drasypus gigas verknöchern die Rippenknorpel frühzeitig. Die Knorpel der walıren Rippen zeigen bei diesem Thier nahe an ihrem äussern Ende, mit welchem sie an die Rippen grenzen, sowohl am vordern als am hintern Rande eine überknorpelte Gelenksfläche, durch welche sie unter einander beweglich verbnnden sind.

Das Brustbein besteht aus einer Reile von hinter einander liegenden Knochen, ist sehr schmal und endigt sich mit einem Knorpel, der bei einigen Edentaten eine grosse Ausdehnung erreicht. Er ist gross und scheibenförmig bei Mamis jatranica. Bei Mamis longicaudata spaltet sich nach Mecked ${ }^{1}$ ) das Brustbein hinten in zwei Aeste, von diesen gehen zwei knorplige, dünne Streifen aus, die in der Unterleibswand bis zum Schaambein reichen. Bei Mamis tridentata fand ich folgende Einrichtnng. Der knorplige Schwertfortsatz des Brustbeins spaltet sich nach einem Verlauf von einigen Linien in zwei Aeste, die $3 \frac{1}{2}$ Zoll lang fast parallel laufen, sie biegen sich gegen die rechte Seite des Bauchs und würden, wenn sie einen geraden Verlauf hätten, bis zum Becken reichen. Dieser gabelförmige Forlsatz liegt zwischen den Bauchmuskeln und dem Bauchfell. Ungefähr in der Mitte seines Verlaufs kommt zu diesem knorpligen Fortsatz noch ein langer Knorpel; er liegt zwisehen den beiden Aesten des vorhergehenden und theilt sich nach einem Verlanf von zwei

1) System der vergleichenden Anatomie. Zweiter Bund. S. 321. 
Linien gabelförmig; die beiden Aeste reichen bis zum Ende des schon erwähnten knorpligen Fortsalzes. Die Spilze verliert sich durch eine fibros-zellige Ausbreilung an der äussern Fläche des Periloneums. Dieser bis zu dem Becken reichende komplizirte Schwertfortsalz des Brustbeins bezieht sich auf dic Verrichtungen der Zunge. Bis zu seinem lintern Ende reichl ein langer Muskel, der den grössten Theil der Zunge bildet und am hintern Ende dieses Knorpels sich befestigt. Dieser Muskel kann dic lange, wurnförmige Zunge zurückziehen. Diesen Muskel und seine Verrichtung hat OTro ${ }^{1}$ richtig beschrieben bei Manis macrouru. Bei Myrmecophaga didactyla ist der Schwerlfortsalz des Brustbeins auch sehr lang und schmal, bei Myrmecophaga tumanduc ist er gross und scheibenförmig, kleiner und eine unregelmässige vierseilige Platte darslellend bei Alyrmecophagu jubatu. Auch bei Myrmecophaga didactylu setzt sieh der schmale Zungenbeinzungenmuskel (MLusc. sterno-glossus), nachdem er in der Brusthöhle heruntergestiegen ist hinter dem Brustbein, am Schwertfortsatz des Brustbeins fest. Das oberste Stück des Brustbeins ist bei Myrmecophaga, aber nicht bei Manis, breil und schildförmig.

Die Aehnlichkeit zwischen der Wirbelsäule und dem Brustbein spricht sich besonders bei Myrmecophaga jubata und tomandua aus, indem die einzelnen Stücke in ihrer Gestalt den Wirbeln sich nähern. Man unterscheidet davon eine cylindrische Abtheilung, die in der Brusthölle liegt und eine äussere, zusammengedrückle. Die Verbindung der verknöcherten RippenknorpeIn mit dem Brustbein geschieht so, dass der Knorpel in zwei Köpfe sich theilt, dic an die beiden genannten Theile jedes Brustbeinstücks sich anlegen. Aehnlich verhält sich das Brustbein bei dem Riesengürtelthier, und die verknöclıerten Rippenknorpeln verbinden sich durch glatte Gelenksfläehen sowohl mit dem breiteru, einem Wirbelkörper enlsprechenden Theil des Bruslbeinstücks, als mit dem schmalen, welches einem Dornfortsatz verglichen werden köunte. Bei dell Gürtelthieren ist das vordere Stück des Brustbeins, an welches die erste Rippe sich anlegt, sehr breit und trägt an seinem vordern Rande zwei Stücke, an welche das Sternalende des Schlüsselbeins durch ein Band sich befestigt. Bei dem Riesengürtelthier liegen zwar die einzelnen Stücke des Brustbeins auch in einfacher Reihe, aber vor dem letzlen Stück des Brustbeins, vor dem Schwerl-

1) Oтro, De rarioribus quibusdam sceleti humani cum animalium sceleto analogiis. Vratislaviae. 1839 . 
fortsatz liegen zwei Brustbeinstücke neben einander. Bei diesem Thier sind die einzelnen Stücke, aus welehen das Brustbein besteht, durch glatte Gelenksflächen mil einander verbunden.

Der grossen Zalıl der Bruslwirbel entsprechend besteht bei dem zweizehigen Faulthier auch das Brustbein aus einer grossen Menge von hinter einander liegenden Knochen, nämlich aus dreizehen. Das Brustbein von Bradypus cusulliger wird nur aus acht Stücken zusanmengeselzt. Der Schwertknorpel feht diesen Thieren.

Die Gestalt der Brusthöhle bietet bei den Edentaten einige Eigenthümlichkeilen dar. Bei Myrmecophaga wird die Brusthöhle dadurch verengl, dass das Brustbein bogenförmig sich einwärts krümmt, doch verschwindet dieses Ansehen grösstentheils bei dem getrockneten Skelel. Die Brushlıöhle des zweizehigen Faulthiers ist bei der grossen Zahl der Rippen (auf beiden Seiten zusammen sechsundvier'zig) sehr in dic Länge gezogen.

\section{Vordere Extrenaitiotent.}

Da die Edentaten illrer vorderı Extremitäten zum Graben in der Erde oder zum Klettern sich bedienen, so sollte man ein wohl ausgebildetes Schlüsselbein bei ilnen erwarten; aber bei einigen fehll dieser Knochen, bei andern ist er unvollständig ausgebildel. Das Schlüsselbein fehlt bei Manis. Die verschiedenen Arten von Myrmecophuga stimmen in Bezielung auf diesen Knochen nicht mil einander überein. Bei Myrmecophaga didactyla ist das Schlüsselbein stark; mit dem Brustbein verbindet es sich durch einen Sehnenstrang, aber mit dem Acromiun des Schulterblatts steht es durch ein Gelenk in Verbindung. Das Schlüsselbein wurde bei Myrmecoplaga jubata und tamandua geläugnet; aber bei Myrmecophaga jubata fand ich ein Rudiment eines Sclüsselbeins iı knorplichen Zustande. Es ist eiı längliches Stück, etwa einen Zoll lang, durch eine glatle Gelenksfläche nit dem Acromium des Schulterblatts verbunden, reicht aber nicht bis zum Brustbein. Bei Myrmecophaga tamandua fand ich kein Rudiment des Schlüsselbeins. Bei den Gürtelthieren verbindet sich das Schlüsselbein mil dem Brustbein durch ein kurzes Ligament. Bei Chlamyphorus ist das Schlüsselbein vollständig nach Yarrell. Dem Orycteropus wird das Schlüsselbein von Cuvier mil Unrechl abgesprochen. Das Schlüsselbein von Bradypus cuculliger ist sehr dünn und geht bei der Be- 
reitung der Skelete leicht verloren. Es bielet die Eigenthümlichkeit dar, dass es nicht mil den Acromium, sondern mit dem Theil des Schulterblatts, der dem Rabensclmabelforlsatz entspricht, sich verbindet. Mit dem Brustbein hängt es durch ein langes Ligament zusammen; auch bei Choloepus verbindet sich das Sclı̈üsselbein mil dem Brustbein nur durch ein ziemlich langes Ligament, artikulirl aber mit dem Acrominm.

Das Scluulterblatt zeichuct sich dadurch aus, dass es bei einigen, wie bei den Gürtelthieren und Ameisenfressern, mit einer doppellen Gräte verselıen ist, wodurch die Fossa infraspinata wieder in zwei Abtheilungen, eine obere und untere, zerfäll. Rei dem zweizehigen Ameisenfresser ist diese untere Schulterblatl-Gräle schn schwach. In der Fossa supraspinata findet man bei den Faulthieren und bei Myrmecophaga jubata und tamandua ein rundes Loch, es fohlt bei Myrmecophaga didactyla. Es wird dadurch gebildet, dass der Rabenschnabel-Fortsatz sich mil dem vordern Rande des Schulterblatls brückenarlig verbindel. Bei den Fauldhieren bleibı diese Brücke lange knorplich.

Den Knorpelsaum an innern Rande des Schulterblatts fand ich bei Mamis, Myrmecophaga, Dasypus, Orycteropus, Bradypus; er verknöchert bei einigen frülızeitig.

Die Fauldhiere unterscheiden sich selir auffallend von den übrigen Edentaten, so wie von allen Säughthieren d!nreh die Länge der vordern Extremitälen, besonders ist dieses der Fall hei Bradypus im engern Simu. (Acheus, Fr. Cuv.) Wenı man ein solches Thier in die aufrechte Stellung bringl, so reichen die vordern Extremitälen so weit herunter, dass noch die ganze Hand den Boden berülıri. Die Röhrenknochen der Faulhiere enthalten keine Markhöhle, sondern sind, wie die Knnochen der Cetaceen, ganz mit Diploe erfüllt. Auch bei Myrmecophaga enthält der Oberarnknochen nur eine Andeutung einer Markhöhle. Auch bei den Gürlelthieren scheint die Markhöhle zu felılen; ich fand sie nicht im Schenkelbein eines crwachsenen Riesengürtelthiers.

Der Oberarmknochen der Faullhiere ist sehr lang, dünı, das Loch am innern Condylus felllt bei Bradypus cuculliger, findet sich aber bei Bradypus didactylus, und nach A. WaGNer bei Bradypus torquatus ${ }^{1}$ ).

Bei den Schuppenthieren, Ameisenfressern, Orycteropus, Gürtelthicren,

1) Bemerkungen über den dermaligen Stand unserer Kemtniss der Faulthier-Arten. In den Münchner Gelehrton Anzeigen. Nro 9. 1850. 
Chlamyphorus ist der Oberarmknochen dick und am innern Coudylus mit einem Loch oder kurzen Kanal durchbohrt, zum Durchgang der Gefässe. Bei Myrmecophaga jubata fand ich, dass die Armschlagader durchgeht mit dem Mediamerven und mit der Armvene. Bei dem Riesengürtelthier verbindet sich der Oberarmknochen nicht nur durch seinen glatten Gelenkskopf unit der Cavitas glenoidalis des Schulterblalts, sondern an der untern Fläche des sehr grossen Acromiums des Schulterblatts ist auch eine Gelenksfläche angebracht, welcher eine eigenthünliche Gelenksfläche am Oberarmbein entspricht.

Der Vorderarm besteht bei allen aus der Ellenbogemröhre und der Speiche. Ersterer Knochen ist bei den insektenfressenden Edentaten mit einem starken Olecranon versehen. Bei den Faulthieren sind diese Knochen besonders lang und dünn, bei Bradypus cuculliger mehr als bei Choloepus didactylus, und das Olecranon fehlt fast ganz.

II andwurzel. Die Knochen der Handwurzel liegen in zwei Reihen; das zweizehige Faulhier hat sieben Ilandwurzelknochen, Bradypus cuculliger nur sechs, drei in jeder Reihe, hei ihm fehlt der erbsenförmige Knochen. Sieben Knochen finden sich auch bei den Schuppenthieren, acht bei Orycteropus und bei Myrmecophaga jubata und tamandua.

Mitt elh and. Orycteropus und einige Gürtelthiẹre haben vier Mittelhandknochen, andere Gürlelthiere und Myrmecophaga jubata und tamandua und Mamis liaben fünf Mittelhandknoehen.

Bei dem zweizehigen Faulthier besteht die Mittelland aus zwei vollständigen Mitlelhandknochen, aber sowohl an der äussern als an der innern Seite liegt noch ein unvollständiger Mittelhandknochen, ein os styloideum, das äussere ist kleiner als das innere. Bei Bradypus cuculliger wird die Mittelhand aus drei Knochen zusammengeselzh, die aber frülzeitig unter einander an ihrem hintern Ende verwachsen; an der innern Seite findet sieh noch ein Rudiment eines vierten Mittelhandknochens.

Finger. In der Zalll der Finger kommen bei den Edentaten grosse Verschiedenheiten vor; man findet zwei, drei, vier, fünf Finger.

Unter den insektenfressenden Edentaten findet man bei Myrmecophaga die Zahl der Finger grösser als die Zahl der Nägel; Myrmecophaga didactyla hat zwei Nägel, doch ist die Zahl der Finger, wie bei den andern Arten, fünf; aber nur der Zeigfinger und der Mittelfinger sind vollständig ausgebildet, und wie bei den beiden grössern Arten von Myrmecophaga ist der Mittelfinger durch 
seine Länge und Dicke ausgezeichnet; der Daumen mold der kleine Finger werden jeder nur durch einen dünnen Knochen dargestellt, der erst, wenn man die Ilant entfernt hat, zn unterscheiden ist, und dem Mittelhandknochen und den Phalangen zugleich entspricht; der vierte Finger besteht aus einer Phalanx, die auf einem Mittelhandknochen ruht. Myrmecophaga jubata und tamandua haben an den vordern Füssen vier Nägel, aber am Skelet findet man doch füuf Finger: der fünfte Finger, der äusserste hat keinen Nagel, und besteht nur aus einem Gliede. Der milllere Finger ist der längste und dickste. Der immere, der Daumen hat nur zwei Phalangen. Manis hat fünf Finger, die alle mit einem Nagel versehen sind, anch hier ist der nittlere Finger der längste. Jeder Finger besteht ans drei Phalangen, mit Ausnahme des imnersten, der nur zwei Phalangen hat. Die letzte Phalanx dor Finger zeigt eine gabelförmige Spaltung und der lufförmige Nagel ist im Innern durch eine senkrechte Scheidewand in zwei Fächer getheilt; auch bei Myrmesoplenga jubata und tamandna hat die Nagelphalanx des Mittelfingers an ihrer konvexen Seite eine tiefe Furche. Bei diesen Ameisenfressern ist die Nagelphalanx mil einer starken, knöchernen Scheide zur Aufinahme der Wurzel des Nagels versehen.

Dasypus gigus hat fünf Finger, der mittlere ist sehr gross, besonders ist die Nagelphalanx sehr gross und sichelförmig, aber dieser Finger hat nur zwei Phalangen, ihm gleicht der vierte Finger, ist aber viel kleiner und hat auch nur zwei Phalangen. In der IIandfläche der Gürtellhicre liegt ein grosser, länglicher Knochen, er ist hesonders gross bei Dasypus gigas, und ist hier hinten am dicksten mnd hat an seiner obern Seite zwei Gelenksflichen zur Artiknlation mit dem halbmondförmigen Knochen und dem os pisiforme. Dieser grosse Knochen in der Handfläche ist ein Sehnenknochen in der Sehne des grossen Beugemuskels der Finger.

Orycteropms hat vier Finger, cbenso einige Gürtelthiere. Der Daumen fehlt, da jeder dieser Finger aus drei Phalangen besteht. Chlamyphorus hat fünf Finger. Zwei vollstïndige Finger linden sich bei Choloepus didactylus, die andern Faulthiere haben drei. Ursprünglich besteht jeder aus drei Phalangen, aber bald verwächst die erste, sehr kurze Phalanx mit dem ilır entsprechenden Mittelhandknochen in ein Stück zusammen. Die dritte Phalanx ist länger als die zweite, sehr spitzig und von beiden Seiten zusammengedrïckt. 


\section{Hintere Extrenition.}

Beckell. In Beziehung auf die Bildung des Beckens zerfallen die Edentaten in zwei Abtheilungen, indem bei einigen der Sitzbeinhöcker mit dem seitlichen Theil des Kreutzbeins verwachsen ist, wodurch statt eines Sitzbeinausschnittes ein Loch gebildet wird, so verhält es sich bei den Faulthieren, bei Myrmecophaga jubata und tamandua, bei den Gürtelthieren; aber bei den Schuppenthieren, bei Myrmecophaga didactyla, bei Orycteropus findet diese Verbindung nicht statt, doch näher't sich bei letzterem Thier der Sitzbeinhöcker stark den vordern Schwanzwirbeln, ohne jedoch mit ihnen zu verwachsen. Die Verwandlung des Sitzbeinausschnittes in ein Loch kommt auch allgemein am Becken der Vögel vor, aber die Oeffnung wird hier durch die Vereinigung des Sitzbeins mit dem Hüftbein geschlossen.

Das eiförmige Loch ist bei den Edentaten sehr geräumig. Nach der Angabe von Daubenton soll das Becken des zweizehigen Ameisenfressers (wie beim Maulwurf und bei den Vögeln) nicht geschlossen sein, indem die Schaambeine sich nieht vereinigen; dieser Behauptung widerspricht Mecker 1); ich fand bei einem vollkommen ausgewachsenen weiblichen Thier, dass die beiden Schaambeine durch einen querlaufenden Knorpelstreif verbunden waren, so dass der nicht verkuöcherte, blos knorpliche Zwischenraum drei Linien betrug. Nach YARRELL ist auch bei Chlomyploorus das Becken vorn offen, wie bei den Vögeln. Das Becken der Faulthiere zeichnet sich von dem der übrigen Edentaten noch dadurch aus, dass das Hüftbein sehr breit und niedrig ist; auch sind die Beckendurchmesser ausserordentlich gross. Die Schaambeinverbindung ist selır schmal, und lange werden beide Schaambeine, wie bei dem zweizehigen Ameisenfresser, nur durch einen schmalen Knorpelsireifen mit einander verbundeu. Bei einem fast ausgewaehsenen dreizehigen Faulthier fand ich nämlich beide Schaambeine dureh einen neun Linien breiten Raum getrennt, der nur durch einen bandförmigen Knorpel ausgefüllt war. An dem Skelet eines erwachsenen Thiers fand ich den Knorpel, der die beiden Schaambeine verbindel, vollkommen verknöcher', aber er bildete einen eigenen, unpaaren Knochen, der mit dem horizontalen Ast des Schaambeins nicht verschmolzen war. Bei

1) System der vergleichenden Anatomie. Zweiter Theil, zweite Abtheilung. S. 435. 
Myrmecophaga jubata bleibl zwischen dem Sitzbein und dem Schaambein lange ein knorplicher Zwischenraum.

Schenkelknochen. Er ist bei den insektenfressenden Edentaten stark und besonders bei den Gürtelthieren durch einen starken Fortsatz an der äussern Seile in der Mitle des Knochens ausgezeichnet. Den Faulthieren und den Schuppenthieren fehlt das runde Band (Ligamentum teres). Bei Myrmecophaga jubata zeigt der Schenkelknochen (wie einige andere Röhrenknochen, Oberarm, Ulıa und Radius) eine netzarlige Oberfläche, indem erhabene, lin und her gebogene Linien unter einander sich verbinden. Diese Bildung konmt erst bei ganz ausgewachsenen Thieren zum Vorschein.

Die Kniescheibe findet sich allgemeill. Die beiden Knochen des Unterschenkels sind stark und bei Orycteropus ist das Schienbein mit dem Wadenbein oben vollkommen verwachsen, bei Dasypus ist das Schienbein mit dem Wadenbein sowoll am obern als am untern Eurle vollkominen verschmolzen; es findet sich beim jüngeren Thier eine beiden Knochen gemeinschaftliche Epiphyse. Bei den Faulthieren endigt sich das Wadenbein unten mit einer Verdickung, die hauptsächlich das Gelenk mil dem Sprungbein bildet, sowoll an dessen äusserer als oberer Seite.

Die Zahl der Fusswurzelknochen wechselt bei den verschiedenen Edentaten. Dasypus und Orycteropus haben sieben, die Ameisenfresser acht Fusswurzelknochen, wovon einer an der innern Seite der Fusswurzel mit dem Kahnbein sich verbindet, und bei Myrmecophaga didactyla als ein breiter, fast schaufelförmiger, grosser Knochen nach innen und hinten hervorragt, wodurch die Fusssohle sehr breit wird, bei den beiden andern Ameisenfressern ist dieser Knochen viel kleiner.

Eine unvollkommene, die Beweglichkeil sehr beschränkende Bildung der Fusswurzel komunt bei den Fauthieren vor. Die Fusswurzel des dreizehigen Faulhiers besteht aus dem Fersenbein, dem Sprungbein und zwei Keilbeinen, letzlere verwachsen aber bald unter einander und mit den Mittelfussknochen. Das Sprungbein arlikulirt mit dem Schienbein, dem Wadenbein, dem Fersenbein und dem grossen Keilbein. Zur Verbindung mit dem Wadenbein hat das Sprungbein eine konisch vertiefte Gelenksfläche, in welche eine konische Hervorragung des untern Endes des Wadenbeins aufgenommen wird. Ein Strecken und Beugen des Fusses kann nicht stattinden, sondern nur Abduktion 
und Adduklion. Der Fersenbeinhöcker ist sehr lang und von beiden Seiten stark zusammengedriickt.

Alle Edentaten haben fünf Mittelfusskuoehen; bei den Fanlthieren sind die drei mittleren allein vollständig, der ïusserste und der innerste ist viel kürzer, dümı und verwäclsst bei den dreizehigen Faulthieren sehr früh mit den Fusswurzelknochen, auch die übrigen Mittelfussknochen enchylosiren an ihrem hinteren Ende mit einander, so wie mit der ersten Phalanx der Zehen.

Zehen. Obschon allen Thieren dieser Ordnung fünf Mittelfussknochen zuliommen, so richtet sich doch die Zahl der Zehen nicht immer nach denselben. Die insektenfressenden Edentaten haben fünf mit Nägeln versehene Zehen, Myrmecophaga didlactyla nur vier. Die pflanzenfressenden Edentaten haben drei Zehen.

Die grosse Zehe der Edentaten hat zwei Phalangen, die andern Zehen drei. Bei den Faulthieren fehlt die grosse und die kleine Zehe. Ursprünglich besteht bei diesen jede der drei Zehen aus drei Phalangen, aber die erste schmilzt bald mit dem entsprechenden Miltelfussknochen in ein Stück znsammen. Die Nagelphalanx hat bei den Schıppenthieren, wie dieses auch bei den vordern Extremitäten der Fall ist, eine gabelförmige Spaltung, nicht aber bei den Ameisenfressern, obschon an der Nagelphalanx der vordern Extremitäten an Mittelfinger eine solche Theilung, doch in geringerem Grade, sich findet. Bei Myrmecophaga ist die Nagelphalanx an den hintern Extremitäten kleiner als an den vordern, hat aber anch die knöcherne Scheide zur Anfnahme der Wurzel des Nagels.

Die Nagelphalanx der Faulthiere ist an den hintern Extremitäten likeiner als an den vordern.

In der Fusssolle liegt bei den Gürtelthieren ein grosser Knochen in der Sehne des gemeinschaflichen langen Beugemuskels der Zehen. 


\section{II us k e 1 u.}

Eine vollständige Anatomie der Muskeln der Edentaten habe ich nielıt vorgenommen; ich beschränke mich, die Muskeln an den vordern und hintern Extremitäten der Myrmecophaga tamamdua, die eine ausserordentliche Stärke, besonders in den vordern Extremitäten, besitzt, zu geben.

Der grosse Brustmuskel ist selır stark; statt des kleinen Brustmuskels liegt, von dem vorhergelrenden verborgen, ein kleiner, doch dicker Muskel, der von der äussern Fläche des Brustbeins entspringt, und sich an Tuberculum internum des Oberarmbeins befestigt. MI. deltoilleus ist sehr dick. Die vordere Abtheilung, die bei den mit einen Schlüsselbein versehenen Thieren von diesem Knochen entspringt, kommt hier von den Dornfortsätzen der IJalswirbel. Der breite Rückennruskel ist sehr stark. Die Sehne des grossen runden Muskels verbindet sich mit ihm, ehe er sich am Oberarmbein befestigt.

An das grosse Tuberculum des Oberarmknochens befestigt sich der Obergrätenmuskel, der Untergrätenmuskel und der kleine runde Muskel. Die Fossa supraspinata des Schulterblatts wird vom Obergrätenmuskel ausgefüllt und dieser Muskel ist vom Mönchskappenmuskel bedeckt. Das Schulterblatt hat zwei Gräten, und die Grube zwischen diesen beiden Gräten wird vom Untergrätenmuskel und kleinen runden Muskel ausgefüllt.

Der Unterschulterblatt-Huskel bedeckt die innere Fläche des Schulterblatts und befestigt sich am innern Tuberculum des Oberarmknochens.

Der zweiköpfige Armmuskel ist selır stark, ausser den beiden gewöhnlichen Köpfen, die vom Schulterblatt komnen, erhält er noch einen dritten kurzen Kopf vom Oberarnknochen, wie dieses bei vielen Säugthieren vorkommt. Der lange Kopf dieses Muskels geht mit seiner Sehne dureh das Sehultergelenk durch, und befestigt sich am obern Rande der Gelenksfläche des Sclunlterblatts. Die gemeinschaftliche Selme des kurzen Kopfs und des M. coracobrachialis ist selur lang, und letzterer Muskel befestigt sich selrr weit unten am Oberarmknochen über dem innern Knorren. 
Der innere Armmuskel (M. brachieus internus) fehlt.

Dreiköpfiger-Armmuskel. Der mittlere Kopf kommt vom Schulterblat, wo er über dem untern Winkel entspringt, der äussere Kopf kommt von der Diaphyse des Oberarnbeins, aber der innere ziemlich dünne Kopf kommt vom Schulterblatt, wo er unmiltelbar unter der Gelenksfläche entspringt. Die Befestigung der gemeinschaftlichen Selme ist am Olecranon.

Ausser diesen dreiköpfigen Strecker des Vorderarms findet sich noch ein länglicher Muskel, der aber viel dünner ist, als der vorhergehende, und ihn zum Theil bedecki. Er entspringt vom Schulterblatt gemeinschaflich mit dem grossen runden Muskel, und befesligt sich am Olecranon. Ein Theil seiner Selme geht in die Frascia des Vorderarms über, die er spannen kann.

Voun innern Knorren des Oberarmknochens geht ein kurzer, dicker Muskel herüber zum Olecranon (H. anconacus pareus).

Ein sehr starker Fingerbenger bedeckt unmittelbar die hintere Seite (Extensions-Seite) des ganzen Oberarmbeins, von welchem er entspringt. Er steigt, bedeckt rom dreiköpfigen Oberarmmuskel, bis zu der Ausstrecke-Seite des Ellenbogengelenks herunter, gelit dann zwischen dem innern Oberarmknorren und dem Olecrmon, und an der Beuge-Seite des Vorderarms fort, indem er von der Ulua noch Verstärkungsfasern erhält. Es ist ein gefiederter Muskel. Am Vorderarm wird er von den Muskeln bedeckt, die am innern Knorren entspringen. Wenu er an der Beuge-Seite des Handgelenks angekommen ist, so verbindet sich ein zweiter Muskelbauch mit ihm, der vom grössten Theil der Länge der Speiche entspringt. Die gemeinschafiliche Sehne ist ausserordentlich dick, geht unter dem Ligamentum carpi proprium volare durch, und gibt vier Aeste ab von selır ungleicher Dicke. Die grösste Sehne nämlich geht zum Mittelfinger, eine kleinere zum zweiten Finger, und eine sehr schwache Selme geht zum vierten Finger, und eine ebenfalls schwaehe Sehne zum ersten Finger. Die Befestigung geschieht an der dritten Phalanx der Finger. Mit diesen Sehnen hängen die kleinen, regenwurmförmigen Muskeln zusammen. Ein besonderer, oberflächlicher Beugemuskel der Finger findet sich nicht.

Vom innern Knorren des Oberarms kommt ein $\boldsymbol{M}$. pronator und ein $\boldsymbol{M}$. Alexor carpi radialis.

Unmittelbar über dem Handgelenk liegt der M. pronator quadratus, bedeckt vom grossen Beugemuskel der Finger.

Spannmuskel des Ligamentum ammulare. Vom innern Knorren des 
Oberarmknochens entspringt ein oberflächlich verlaufender, länglieher, ziemlich dünner Muskel, den man beim ersten Anblick für einen $\boldsymbol{M}$. palmaris longus halten könute, er geht aber unter dem Ligamentum carpi volare proprium ảurch, wie unter einer Brücke, und befesligt sich an dem sehr slarken Bande, durch welches die dicke Beuge-Sehne des Mittelfingers an die erste Phalanx angedrückt wird (Ligamentum anmulare). Ehe diese Sehne unter dem Ligamentum carpi volare proprium durchgeht, verbindet sich mit ihr ein anderer Mluskel, der vom Olecranon und dem grössten Theil der Länge der Ulna entspringl.

Vom äussern Winkel des Oberarmknochens kommt der $\mathbb{R}$ I. supinator longus; von dem äusseru Knorren der äussere Speichenmuskel (einfach); der gemeinschaftliche Streckmuskel der Finger spaltet sich in zwei Köpfe, von denen jeder in eine Sehne übergeht, die grössere setzt sich am Mittelfinger fest, die andere, kleinere, geht zu dem vierten Finger. Die Befestigung geschieht an der Ausstrecke-Seile der drilten Phalanx (Nagelphalanx) der Finger. Der äussere Ellenbogenmuskel ist ziemlich dick.

Von der Ulua kommt ein Streckmuskel der Finger, dessen Sehne in drei Aeste sich spaltet, für den ersten, zweiten und dritten Finger, wodurch letzterer von zwei Streckmuskeln eine Sehıe erlält. Mit diesem Streckmuskel der Finger verbunden ist ein $\boldsymbol{M}$. abductor, der sich an der Speichenseite des ersten Mittelhandknochens befestigt.

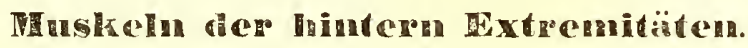

Der grosse Lendenmuskel und der imnere Hüftheinmuskel sind nicht besonders stark. Der schlanke Schenkelmuskel ist selır breit. Der Schneidermuskel schmal. Der vierköpfige Schenkelmuskel besteht aus dem M. vastus extermus, internus, M. rectus, der ein gefiederter Muskel ist, und M. cruralis. M. abductor femoris ist nicht in drei Köpfe getheilt. Der Kamınmuskel ist sehr dick.

Ich fand nur zwei Rollmuskeln des Sehenkels, einen äusseren Hüftbeinlochmuskel und einen, der den Zwillingsmuskeln zu entsprechen scheint.

Der Spannmuskel der Schenkelbinde scheint mit dem grossen Gesässmuskel vereinigt zu sein.

Vom Sitzbein-Höcker kommt ein länglicher Muskel, der sich am innern 
Condylus des Scheukelknochens befestigt, ein adductor des Schenkels. Statt des zweiköpfigen Schenkelmuskels kommt vom Sitzbein-Höcker ein Muskel, der aber keinen Kopf vom Schenkelknochen erlıält. Ferner der halbhäutige und der halbselnige Muskel, sie sind fast durchaus muskulos.

Drei Gesässmuskeln.

An der hintern Seite des Schenkels lauft ein schmaler Muskel herunter, der mit seiner Sehne vom Rande des Kreutzbeins komml, bedeckt vom grossen Gesässmuskel; er scheint hauptsächlich als ein Spannmuskel der fascia des Unterschenkels zu dienen. Unmittelbar am untern Rande des grossen Gesässmuskels verlauft ein riemenförmiger, ziemlich starker Muskel. Er entspringt voin Rande des Kreutzbeins, geht oberflächlich liegend am Oberschenkel ${ }^{-}$herunter und befestigl sich mit einer starken Sehne am innern Rande des Schienbeins. Es ist ein Beugemuskel des Unterschenkels.

An der vordern Seite des Unterschenkels: der vordere Schienbeinmuskel, der lange Ausstreckemuskel der Zehen; seine Sehne spaltet sich in vier Aeste für die vier Zehın von der zweiten an. Der lange Streckmuskel der grossen Zehe entspringt ganz unten von dem Wadenbeil, und seine Sehne spaltet sich in zwei Aeste für die erste und zweite Zehe, letztere erhält aber aneh eine Selıne von dem vorhergehenden Muskel.

Hintere Seite des Unterschenkels: die beiden Köpfe des Zwillings-Wadenmuskels entspringen vom äussern und innern Condylus des Schenkelbeins, und an der vordern Seite legt sich an diesen Muskel der M. soleus an. Die gemeinschafliche Sehne befestigt sich an der Tuberositas calcanei. M. plantaris longus fehlt. Der Kniekehlenmuskel ist gross, indem er bis zu der Mitte des Untersehenkels herunterreicht. Der lange, gemeinschaftliche Beugemuskel der Zehen kommt vom Unterschenkel, seine Sehne ist sehr breit, und wo sie unter dem innern Kü̈ehel durchgeht, um in die Fusssolle zu gelangen, enthält sie einen Knorpel, und in der Fusssohle verbindet sich mit ihr ein kurzer Kopf (Caro quadrata Sylurii). Endlich spaltet sich die Selme des langen gemeinschaftlichen Beugemuskels der Zehen in fünf Aeste, für die fünf Zehen. Bie Befestigung geschieht an der Beugeseite des dritten Zehengliedes. Mit diesen Selmen stehen die regenwurmförmigen Muskeln in Verbindung. Ein besonderer Beugemuskel, der grossen Zehe fehlt. Der hintere Schienbeinmuskel ist doppelt.

An der äusseren Seite des Unterschenkels liegt der lange und der kurze Wadenbeinmuskel. 
Rücken des Fusses. Der knrze gemeinschaftliche Streckmuskel der Zehen ist für alle fünf Zehen bestimmt.

Fusssohle. Der kurze, gemeinschaftliche Bengemuskel der Zehen theilt sich in drei Köpfe, die in drei Sehmen übergehen für die zweite, dritte und vierte Zelı. Diese Sehnen werden von den Sehnen des langen, gemeinschaftlichen Bengemuskels der Zehen micht durchbolirt. Die erste Sehne des kurzen, gemeinsehaftlichen Beugemuskels der Zehen erlıält in der Fusssohle von der innern Seite her einen kurzen Kopf, wie eine Caro quadrata Syluii. Der Abzieher der kleinen Zehe kommt von der Tuberositas calcanei an der äussern Seite des kurzen, gemeinschaftlichen Beugemuskels der Zehen; er geht in eine lange Sehne über, die an der ersten Phalanx der kleinen Zehe sich befestigt. In den Zwischenränmen der Mittelfussknochen liegen die Zwischenknochenmuskelı. 


\section{Ge h i r il.}

Da die Faulthiere in mancher Hinsicht an die Affen sich auschliessen, so möchte eine Vergleichung des Gehirns der Faulthiere mit dem Gelirn der Affen nicht ohne Werth sein.

Das Gehiru des dreizehigen Faulthiers (Bradypus cuculliger, Wagl.) fand ich bei einem noch nicht ganz ausgewachsenen Thier 186 Gran schwer, wälırend der übrige Körper 23 Unzen wog; das Gewicht des Gehirns zum übrigen Körper verhält sich also wie 1:59. Die Hemisphären des grossen Gehirus sind auf ihrer konvexen Seite mit drei Hauptwindungen versehen; die innerste, und die an sie angrenzende laufen nach der Länge der Hemisphären, parallel mit der tiefen Spalte, durch welche die beiden seitliehen Hälften des grossen Gehirns von einander getrennt sind; die äusserste Windung krünmt sich vor dem kleinen Gelirn auf die Grundfläche herunter, und endigt sich dort mit einer starken Verdickung. Die Windungen des Gehirns sind vollkommen symmetrisch. Eine Sylvische Grube, durch welehe das grosse Gehirn an seiner Grundfläche in eiıen vordern und hintern Lappen getrennt würde, findet sich nicht; oder ist vielmehr nur als eine Andentung von der tiefen Grube, wie sie am Gehirn des Menschen und der Affen sich findet, vorhanden.

Das kleine Gehirn wird von dem grossen gar nicht bedeckt, sondern liegt hinter diesen. Eine Abtheilung des kleinen Gehirns in zwei Hemisphären ist durch eine flache Vertiefung auf der obern und untern Seite (oberer und unterer Wurm des klcinen Gehirns) ausgedrückt. Mit dem Gehirn dieses Thiers lhat das Gehirn des zweizehigen Faulthiers sehr grosse Aehnliehkeit ${ }^{1}$ ).

Vom Gehirn der Affen unterscheidet sich das Gehirn der Faulthiere wesentlich dureh die geringe Zalıl der Windungen, durch den Mangel der Sylvischen Grube, besonders aber dadurch, dass das kleme Gehirn gar nicht von den Hemisphären des grossen Gehirns bedeckt wird.

1) Tiedemaxi, Icones cerebri. Tab. IV. 
Das Gehirn der übrigen Edentaten ist wenig untersucht worden. Bei Orycteropus ist das Gehirn nach Levere ') mit Windungen versehen. Bei Dasypus peba sind die IIemisphären des grossen Gelirns glatt, fast ohne Windungen, indem nur an der Seite eine äusserst flache, kurze Furche verlauft. Die Vierhügel sind gross, das hintere Paar etwas breiter als das vordere, so verhält es sich auch bei den Faulthieren. Das kleine Gehirn wird gar nicht vom grossen bedeckt, sondern liegt hinter diesem. Das Gehirn ist sehr klein, indem sein Gewicht nur 114 Gran beträgt ${ }^{2}$ ).

Vom Gehirn des zweizehigen Ameisenfressers hat TIEDEnann eine Abbildung bekannt gemacht 5). Die Hemisphären des grossen Gelirns sind ganz glatt, ohne Windungen, vorne zugespitzt. Das kleine Gehirn wird von dem grossen nicht bedeekt; der obere Wurm ist selir gross.

Ueber das Rückennark der Edentaten sind mir keine Untersuchungen bekannt.

1) Leuret, Anatomie comparée du système nerveux, p. 584.

2) Wriser (Praeside Rapr), Diss. sistens observationcs anatomicas de Tatu novemeincto. Tubing. 1826.

3) Tiedenann, Icones cerebri. 


\section{Sinnwerkzeuge.}

\section{A I $\mathbf{s} e$.}

Die Angenhöhle wird, wie bei den meisten Säugthieren, von der Schläfengrube nicht durch eine knöcherne Scheidewand getrennt; am meisten ist die Augenhöhle bei den Faulthieren nnd bei Orycteropus abgegrenzt von der Schläfengrube durch einen Fortsalz an Oberaugenhöhlenrande des Stirnbeins. Das Selınervenloch ist ziemlich klein; der Unterangenlöhlenkanal sehr kurz.

Das Auge der Edentaten ist Klein; die Hornhant wenig gewölbt, die Sklerotika nicht besonders dick. Die Iris zeigt eine sehr dunkle Färbung und eine runde Pupille. Die Ciliarfortsätze sind kurz, die Aderhaut ist mit einem schwarzen Pigment bedeckt; ich fand bei Bradypus, Dasypus, Myrmecophaga kein Tapetum, wohl aber bei Orycteropus, wo es eine bläulich-weisse Farbe zeigte. Die Krystall-Linse ist ziemlich konvex, besonders bei Choloepus didactylus.

Ansser den vier geraden und den zwei schiefen Augenmuskeln kommt noch, wie bei den meisten Säugthieren, bedeckt von den vier geraden Augenmuskeln der MI. choanoides (M. suspensorius oculi) vor; er ist, als eine Wiederholung der vier geraden Augenmuskeln in vier Abtheilnngen zerfallen.

Ausser der Thränendrüse findet sieh nocl die Harder'sche Drüse, deren Ausführungsgang an der innern Oberfläehe des dritten Augenlieds sich endigt. Das Loch im Thränenbein ist bei Mrymecophaga jubata und tamandua doppelt, bei den übrigen Edentaten einfach; bei Manis fellt das Thränenbein, aber bei Manis javanica, Temminckii und crassicandata fültrt ein grosses, eiförmiges Loch zwischen dem Stirubein und dem Gaumenbein von der Augenhöhle in die Nasenhölle; bei IHanis tridentata felılt auch diese Oeffnung. Der Thränenkanal ist bei den Gürtelthieren und bei Myrmecophaga ausserordentlich lang; vom Thränenbein an erstreckt er sich an der äussern Wand der Nasenhöhle in fast horizontaler Richtung vorwärts, verlauft an der Anlıeftungs- 
linie der untern Muschel und endigt sich am vordern Ende derselben, nahe am Eingang in die Nasenhöhle. Bei Orycteropus reicht dieser Kanal nicht so weil vorwärts.

\section{Gehörwerkzenge.}

Das äussere Ohr fehlt bei Chlamyphorus. Den Schuppenthieren wurde es zwar abgesprochen, aber bei Manis tridentatu fand ich am hintern Rande des zienlich langen knorplichen Gelı̈rganges eine klappenartige Hervorragung, die zun Theil den Eingang in den Gehörgang bedeckt und eine Knorpelscheibe enthält, welche sieh an den Kopf angedrückt weiter ausbreitet unter der Hant über dem Gehörgang.

Bei den Faulthieren er'scheint das äussere Ohr als eine schnale, knorpliche Hervorragung hinter dem Gehörgang; aber bei den Gürtelthieren und besonders bei Orycteropus hat das äussere Ohr eine ausserordentliche Entwicklung erreicht.

Der zweizelige Ameisenfresser wird als das einzige Beispiel angeführt von einem im freien Zustande lebenden Säugthier mit hängenden Ohren, da solche sonst nur bei solchen Sängthieren vorkommen, die in Zustande der Domesticität leben, wie bei einigen Racen der Ziegen, der Hunde. Das Ohr dieses Ameisenfresser's kam aber nicht ganz mil den hängenden Olnen der genannten Thiere verglichen werden. Es bestelıt aus einer dünnen, länglichen, abgestumpften Knorpelplalle, die über und hinter dem äussern Gehörgang befesligt ist. Der freie, stumpfe Rand ist vorwärts gerichtel und so verschliesst das äussere Ohr klappenartig den äussern Gehörgang. Bei den übrigen Arten von Myrmecophaga sind die Ohren ziemlich gross und aufrecht.

Ein knöcherner Gehörgang ist bei den meisten Edentaten wenig ausgebildet. Er fehlt den Schuppenthieren. Bei dem Orycteropus kommt statt desselben und der Knochenblase der Trommellı̈hle nur ein knöcherner Ring vor, der oben nicht geschlossen ist. Sehr kurz ist dieser Gang bei den Ameisenfressern, er wird eigentlich nur dadurch bei ihnen gebildet, dass das Trommelfell etwas einwärts gerückt ist in die Trommelhöhle, bei den Faulchieren ist er selır kurz.

Eigenthümlich und am meisten ausgebildet ist der knöcher'ne Gehörgang bei Chlamyphorus, indem er röhrenförmig vorwärts gekrüunmt ist und über dem Jochbogen vorwärts lauft. 
Die Trommelhöhle wird bei den Edentaten durch die Knochenblase an der Basis des Sclädels vergrössert, doch erreicht sie nicht die Grösse, wie bei einigen fleischfressenden Thieren, und fehlt bei Orycteropus.

Bei einigen Edentaten stehen mit der Trommelhöhle Nebenhöhlen in Verbindung, indem bei dem grössern Ameisenfresser vor der Trommelhöhle eine im Flügelfortsatz des Keilbeins enthaltene Blase liegt, die mit der Trommelhölle in Verbindung steht; auch sind am Körper des Hinterhauptbeins zwei flügelartige Fortsätze, die mit den Flügelfortsälzen des Keilbeins verwachsen und eine IÏ̈hle enthalten, die mit der Trommellıöhle in Verbindung steht ${ }^{1}$ ); bei Manis und bei Orycteropus liegt im Schläfenbein über der Trommelhöhle eine grosse Zelle, welche in diese IIöhle sich öfhet; auch bei den Faulthieren erweitert sich die Trommelhöhle in einen Sinus, der von der Schläfenschuppe gebildet wird und bis in den Joclıfortsatz des Scliafenbeins sich erstreckt; er entwickelt sich früher als die Stirnhöhle, indem ich bei einem niclitausgewachsenen dreizehigen Faulthier diese Höhle im Schläfenbein fand, während noch keine Stirnhöhle vorhanden war. Durch die Euslachische Röhre mündet sich die Trommelhöhle in die Rachenhöhle, meist wird die Eustachische Röhre nur durch eine einfaehe Oeffinung dargestellt, so bei den Ameisenfressern (Myrmecophaga).

Die Gehörknochen (Ossicula auditus) untersuchte ich bei Bradypus, Choloepus, Orycteropus, Dasypus, Myrmecophaga.

Der Ilammer der Faullhiere hat einen sehr plattgedrückten, messerförmigen, spitzigen Stiel; bei Dasypus ist der Hals des Hammers plattgedrückt und der Stiel weicht von ihm fast unter einem rechten Winkel ab; bei Myrmecophaga ist der Kopf des Hammers in die Quere verlängert, fast eiförmig. Der Ambos zeigt die gewöhnliche Gestalt, indem von dem Körper, der die Gelenksfll̈̈che für den Hammer zeigt, zwei divergirende Fortsätze entspringen. Bei Manis sind die beiden Fortsätze kurz, dick und der ganze Knochen stellt ein Viereck vor mil konkaven Rändern ${ }^{2}$ ). So verhält es sich auch bei Choloepus. Der Steigbügel ist bei Bradypus und Choloepus am meisten abweichend, indem bei Bradypus der Zwischenraum zwischen beiden Schenkeln

1) Hyrtu, Vergleichend-anatomische Untersuchungen iiber das Gelörorgan des Menschen und der Sïugethiere. 1845. S. 51.

2) HYrte, Untersuchungen iiber das Gehörorgan. Tab. V. Fig. 7. 
durch ein dünnes Knochenblatt ausgefüllt ist, und bei Choloepus sind die Sclrenkel des Steigbügels so an einander gerückt, dass kein Zwischenraum übrig bleibt. Es ist eine Columella. Bei Manis ist nach Hrrtu der Steigbügel in eine Columella verwandelt, wie bei den Monotremen.

Bei Dasypus hybridus entspringen nach Hyrtr von der Fussplatte des Steigbügels die beiden Sehenkel olne sich mit einander zu vereinigen; der hintere Schenkel ist hakenförmig gekrümmt und arlikulirt mit dem langen Fortsatz des Amboses. Bei Dasypus peba hat der Steigbügel die gewöhnliche, den meisten Säugthieren zukommende Gestalt, ebenso bei den grossen Ameisenfressern, aber bei Myrmecophaga didactyla lassen die beiden Schenkel keinen Zwischenraum. Nach Hyrtu gelit bei Orycteropus und bei Myrmecophaga tamandua durch den Raum, welchen die beiden Schenkel des Steigbügels übrig lassen, eine Arterie, sie kommt durch ein an der hintern Wand der Trommelhöhle befindliches Loch und geht durch die obere Wand der Trommelhöhle zu der Schädelhölle; es scheint ein Ast der Art. maxillaris interna zu sein ${ }^{1}$ ). Am Kopfe des Steigbügels findet sich bei den Faulthieren das kleine, linsenförmige Knöchelchen noch getrenut, selbst wenn die Suturen am Schädel vollkommen verschwunden sind.

Die Muskeln der Gehörknochen habe ich nicht untersucht.

Labyrintl. Bei dem dreizehigen Faulthier sind die drei Bogengänge sehr klein; die Schnecke ist thurmförmig, der gewundene Kanal, durch welchen sie gebildet wird, ist ziemlich dick, und sie besteht ans zwei und einer halben Windung, ebenso bei Myrmecophaga jubata; bei Dasypus peba hat sie zwei Windungen, ebenso bei Orycteropus capensis.

\section{Geruchswerkzenge.}

Unter den Sinuorganen der Edentaten haben die Geruehswerkzeuge die grösste Ausbildung erreicht. Bei Myrmecophaga setzt sich die Nasenhöhle rückwärts fast bis zum Hinterhauptsloch fort, indem der knöcherne Boden der Nasenhöhle hinten durch die Flügelfortsätze des Keilbeins gebildet wird; hei Myrmecophaga didactyla ist der Boden der Nasenhöhle linter dem Gaumenbein nicht knöchern, sondern durch eine fibrose Haut gebildet. Bei Myrme-

1) Hyrtu in den Denkschriften der Kaais. Akademie der Wissenschaften. 1. Band S. 29. 
cophaga jubata ist die Nasenhöhle vorwärts in eine sehr lange, knöcherne Röhre ausgezogen, wodurch der Schädel ein ganz eigenthümliches Ansehen erhält $\left.{ }^{1}\right)$.

Ausser den gewöhnlichen Nasenmuscheln findet sich bei den Edentaten noch eine eigenthümliche Muschel, die der Länge nach an der innern Oberfläche des Nasenbeins entspringt. Sie erscheint als ein auswärts gerolltes Knoehenblatt (die gleiche Einrichtung kommt bei den Hasen vor). Bei Priodontes gigas ragen an der vordern Spitze dieser Musehel knöcherne Blättchen und Streifen hervor, wodurch ein dendritisches Ansehen entsteht.

Die untere Nasenmuschel der Edentaten hat einen Bau, wie bei den Wiederkäuern und dem Schwein, indem sie in zwei Knochenblätler sich spaltet, wovon das eine aufwärts, das andere abwärts gerollt ist, ohne dass eine weitere Theilung in Aeste vorhanden wäre. Bei dem zweizehigen Faulthier bildet sowohl das obere als das untere Blatt der untern Musehel eine mit zahlreichen Löchern siebartig durchbrochene Knochenblase, die im Innern durch einige querlaufende knöcherne Scheidewände abgetheilt ist. Einfacher erscheint dieser Knochen bei den Schuppenthieren, indem er nur ein abwärts steigendes, nach aussen konkaves Blatt darstellt.

Die Siebplatte des Siebbeins der Edentaten ist ausserordentlich gross, mit sehr zahlreichen Löchern durchbrochen, und liegt in einer höhlenartigen Vertiefung, in welche sich die Schädelhöhle vorwärts verlängert für die Aufnahme des Kolbens des Geruchsnervens. Bei Orycteropus und beim Riesengürtelthier ist sogar die obere Wand der höhlenartigen, vertieften Siebplatte mit vielen Löchern durchbohrt. Bei Manis ist die Siebplatte durch einen grossen Hahnenkammfortsatz in zwei seitliche Hälten getheilt; auch die Faulthiere haben diesen Fortsalz; bei Orycteropus wird jede seilliehe Hälfte der Siebplatle durch eine der Länge nach verlaufende Knochenleiste in zwei Abtheilungen getrennt. Die Zellen des Siebbeins sind besonders zahlreich und ausgedehnt bei den Gürtelthieren; auch bei den übrigen Edentaten, sowohl den pflanzenfressenden als insektenfressenden, sind sie sehr ausgebildet. Da bei Orycteropus und beim Riesengürtelthier die Siebplatte des Siebbeins eine Höhle darstellt, die sogar an der obern Wand mit Löchern durchbohrt ist, so entsprechen diesen Löchern

1) Eine schöne Abbildung findet sich in Pander und D'Altox, die Skelete der zahnlosen Thiere. 1825. 
ähnliehe Knochenzellen, wie sie vom Siebbein gebildet werden; sie liegen aber im Stirnbein. Sie stellen nicht die Stirnhöhle dar, denn diese findet sich für sich bestehend bei Orycteropus, und liegt vor diesen Knochenzellen. Bei den Gürtelthieren (Dasypus gigas, Dasypus gymmurus) fehlt die Stirnhölle.

Die Stirnhöhlen sind bei den Faulthieren sehr gross, und verlängern sich bei dem zweizehigen Faulthier durch knöcherne Scheidewände in Fächer getheilt, bis in das Seitenwandbein, auch bei Orycteropus sind die Stirnhöhlen gross. Die hintere Hälfte dieser Höhle liegt im Stirnbein, die vordere Hälfte in der Wurzel des Nasenbeins, übrigens ist die Stirnhöhle niicht durch Scheidewände in Fächer abgetheilt. Diese Höhlen fehlen bei Myrmecophaga und Manis. Die Keilbeinhöhle ist bei dem zweizehigen Faulthier ziemlich gross, und verlängert sich in den blasenartig aufgetriebenen Flügelfortsatz des Keilbeins, scheint aber den übrigen Edentaten, wie die Kieferllölle zu fehlen.

Durch das Jakobson'sche Organ wird bei den pflanzenfressenden und insektenfressenden Edentaten der vordere Theil der Nasenhölle mit der Mundhöhle in Verbindung gesetzt; man kann leicht von dem vordern Theil des Gaumens auf der rechten und linken Seite durch eine Oeffnung eine Borste einbringen, die auf dem Boden der Nasenhöhle wieder zum Vorschein kommt. Das foramen incisivum liegt bei den Faulhieren zwischen dem Zwischenkiefer- und Oberkieferknochen, ebenso bei Myrmecophaga. Bei den Gürtelthieren liegt es ganz im Zwischenkieferknochen und ist hier sehr klein; auch bei Manis liegt es im Zwischenkieferknochen.

\section{z แ $\mathbf{y}$ e.}

Eine der merkwürdigsten Eigenthümlichkeiten im Bau der Edentaten bietet uns die Zunge dar. Bei Manis, bei den Ameisenfressern ist sie selır schmal, ansserordentlich lang, wurmförmig und kann weit herausgestreckt werden. Die Zunge von Myrmecophaga jubata kann beinahe einen und einen halben Fuss weit aus dem Mund herausgestreckt werden ${ }^{1}$ ). Bei den Gürtelthieren hat die Zunge, obgleich sie weit herausgestreekt werden kann, doch keine so ausserordentliche Länge. Sie stellt ein sehr verlängertes Dreieck dar. Bei Orycteropus ist sie zwar sehr lang und schmal, aber nicht wurmförmig, sondern

1) Rexgger, Naturgeschichte der Sängthiere von Paraguay. S. 305. 
glattgedrückt, riemenförmig. Die Zunge derjenigen Edentaten, die von Ameisen und Termiten sich nähren, dient hauptsächlich als Ingestionsorgan. Ihre Oberfläche fand ich bei den Ameisenfressern (Myrmecophaga jubata, tamandua, didactyla) mit sehr spitzigen, lornarligen, kleinen Stacheln bedeckt, deren freies Ende rückwärts gerichtet ist, sie können aber mit dem unbewaffneten Auge nicht deutlich erkannt werden, und finden sich nur gegen den vordern Theil der Zunge zu; bei Myrmecophaga tamandua ist die Zunge etwa 21/2 Zoll weit damil bedeckt (siehe die Abbildung). Der gleiche Uebergang der Zunge findet sich auch bei den Scliuppenthieren.

Die Zungenwarzen verhalten sich so: Es sind nur zwei Papillae vallatae wahrzunehmen, eine auf jeder Seite bei Manis, Myrmecophaga und Dasypus, drei bei Orycteropus; andere Zungenwarzen, (ausser diesen und den genannten kleinen Stacheln) finden sich nicht bei den Ameisenfressern. Auf der Zunge von Manis tridentata fand ich zerstreute, pilzförmige Warzen. Bei Orycteropus und den Gürtelthieren finden sich auch die pilzförmigen Warzen, sie sind klein und zerstreut auf der Oberfläche der Znnge; überdiess ist die Zunge mit dell kleinen, fadenförmigen Warzen bedeckt. Bei den Ameisenfressern ist an der Zungenspitze eine kleine, fast halbkugelförmige, glatte Verdickung angebracht, die vielleicht zum Tasten dient. Die parallellaufenden Spalten am hintern Theil des Zungenrandes ${ }^{1}$ ), die bei vielen Affen, beim Tapir, bei Hyrax, bei manchen Nagthieren sich finden, fehlen bei allen Edentaten. Ein eigenthümliches Organ kommt an der Zunge von Dasypus longicaudus vor. Unmittelbar unter der Zungenspitze ragen zwei sehr kleine, spitzige, hornartige Stacheln hervor, die mit ihrem freien Ende vorwärts und etwas gegen einander gerichtet sind. Sehnenfascrn, die mit dem M. genio-glossus zusammenhängen, gehen an dic Basis dieser beiden Stacheln, die wie MAYER ${ }^{2}$ ) annimint, der sie zuerst beschrieben hat, als eine Zange wirken können, um Insekten, die dem Gürtelthier zur Nahrung dienen, zu ergreifen.

Das Zungenbein ist unter allen Säugthieren bei Manis am einfachsten, indem es nur einen Bogen bildet und keine Hörner hat. Das vordere Horn des Zungenbeins der übrigen zahnlosen Thiere besteht aus zwei durch ein Ge-

1) Rapp, Die Verrichtungen des fünften Tirnnervenpaars. S. 8.

2) Frorieps Notizen. Juni 1842; und MaYer, Neue Untersuchungen aus dem Gebiete der Anatomie und Physiologie. S. 32. Bonn 1842. 
lenk mit einander verbundenen Stücken, wovon das erste viel kleiner ist als das andere. Bei den Gürtelthieren sehickt das Mittelstück einen unpaaren, schmalen Fortsatz rückwärts, der einen Theil der äussern Fläche des Schildknorpels bedeckt. Das hintere Horn des Zungenbeins, das dem grossen Horn beim Menschen entspricht, ist klein, und fehlt ganz oder ist mit dem Zungenbeinkörper in Ein Stück verschmolzen bei Myrmecophaga und Dasypus. Eigenthümlich ist die durch ein Gelenk vermittelte Verbindung der Spitze des hintern Horns, oder wo dieses fehlt, des Zungenbeinkörpers mit dem obern Itorn des Schildknorpels, so bei Orycteropus, Dasypus, Myrmecophaga. Bei Myrmecophaga tamandua verbindet sich das vordere Horn auf eine eigenthünliche Art mit dem Körper des Zungenbeins. Das Horn tritt mit dem Grundstïck des Zungenbeins, von dem das hintere Horn nicht als eigeues Knochenstück getrennt ist, an zwei Stellen zusammen; fast in der Mitte dieses Knochens und wieder an der äussern Spitze dieses Knochens.

Bei den meisten Säugthieren steht die Spitze des vordern Zungenbeinhorns durch einen schmalen, langen Knochen (Os styloideum) mit dem Schädel in Verbindung, aber bei Myrmecophaga eutspringt an der Spitze dieses Zungenbeinhorns ein langer, schmaler Muskel, dem M. stylolyyoidens entsprechend, der sich am Schädel hinter dem äussern Gehörgang befestigt.

Der Zwischenraum zwischen dem ersten Stück des vordern Zungenbeinhorns und dem hintern Horn wird durch einen Muskel ausgefüllt, dureh welchen diese beiden Hörner einander genähert werden kömnen.

Die Muskeln der Zunge der Edentaten zeigen die grösste Aelunlichleit mit den Zungenmuskeln der Echidna ${ }^{1}$ ), die auch eine lange, wurmförmige Zunge hat und von Ameisen sich nälırt.

Bei Myrmecophaga findet sich ein grosser M. genio-glossus und ein M. sterno-glossus. Er bildet als ein ausserordentlich langer, fast cylindrischer Muskel den seitlichen Theil der Zunge, und befestigt sich, nachdem er am Halse heruntergestiegen ist, am Handgriff des Brustbeins. Bei dem kleinen Ameisenfresser (Myrmecophaga didactyla) gelit dieser Muskel an der innern Seite des Brustbeins herunter, und setzt sich an dem langen, schmalen Knochen fest, in welchen das Brustbein hinten ausläuft. Dieser M. sterno-glossus kann die Zunge zurückziehen in die Mundhölle und sie verkürzen. Vom Zungenbein

1) Duvervoy, Mém. de la société d'hist. nat. de Strasbourg. V. I. 
geht nur ein selir schwacher Muskel zu der Wurzel der Zunge. Kein M. styloglossus. In der Zunge finden sich aber, mit Ausnahme des hintern Theils derselben, ringförmige Muskelfasern; durch sie kann die Zunge verlängert und wurmförmig hin und her bewegt werden. (Ueber die Zunge und die Befestigung des M. sterno-glossus von Manis s. Knochensystem; Brustbein.) Ein spindelförmiger Faserknorpel, wie er an der untern Seite der Zunge der Bären, der Hunde und einiger anderer Thiere angetroffen wird, findet sich nicht, nur in der Zunge von Manis kommt er nach MAYer ${ }^{1}$ ) vor.

Die Zunge der Faulthiere ist verschieden von der Zunge der übrigen Edentaten. Beim dreizehigen Faulthier ist sie diek, schmal, kurz; bei Choloepus didactylus ist sie gegen die Spilze hin breit, spatelförmig; sie hat bei den Faulthieren zwei Papillae vallatae, am Rande unterscheidet man die pilzförmigen Warzen, und die Oberlläche ist mit feinen, fadenförmigen Warzen bedeckt. Der wurmförmige Faserknorpel an der untern Seite der Zunge findet sich nicht.

Nerven der Zunge. Sie sind bei denjenigen Edentaten, bei welchen die Zunge so weit herausgestreckt werden kann, durch ihren sebr geschlängelten Verlauf ausgezeichnet, damit sie bei der grossen Ausdehnbarkeit der Zunge nachgeben können. Die Zunge erhält bei Myrmecophaga einen Zweig vom dritten Ast des $N$. trigeminus und einen Zweig vom $N$. hypoglossus. Den Zungenast des $\boldsymbol{N}$. glossopharyngeus fand ich nicht, sondern der Nerv gieng, in viele $Z_{w}$ eige getheilt, in den Schlundkopf.

1) Ueber die Zunge der Vermilinguia. In Fronieps Notizen. Juni 1842. 


\section{Allgemeine Bedeckungen. Krallen.}

Unter den Edentaten kommen einige eigenthüınliche Bildungen der allgemeinen Bedeckungen vor, wovon sonst in der Klasse der Säugthiere kein Beispiel angetroffen wird, so ist die Itaut bei Manis mit liornartigen Schuppen bedeckt, bei den Gürtelthieren enthält sie regelnnässige Knochentafeln.

Sowohl bei den Fauthieren als bei den Ameisenfressern und besonder's bei Orycteropus ist die Lederhaut ausserordentlich dick. Bei den Gürtelthieren liegen in ihr, mit Ausnahme der untern Seite des Leibes, regelmässige Knochentafeln. Diese sind sowohl an ihrer innern als äussern Fläche von einer Lage der Lederhaut bedeckt, die äussere Lage ist aber sehr dünn; sie zeigen den eigenthümlichen Bau der Knochen, man erkennt in ihnen die Knochenkörperchen mit ihren fadenförmigen Fortsätzen. In der Mitte dieser Knochentafeln erkennt man an der innern Fläche eine Oeffinung, oft sind es zwei, dureh welche Nerven und Blutgefässe eindringen ${ }^{1}$ ); die äussere Fläche dieser Tafeln ist wieder mit einer sehr dümmen Lage der Lederhaut bedeckt, mit dem Malpighischen Netz und der Oberhaut; sie hat die Zusammensetzung des Pflasterepitheliums, die Zellen enthalten einen grossen Kern. Die Oberhaut zeigt bei einigen Arten von Dasypus eine schwarze Farbe. Man erkennt in den Epitheliumzellen durch Hülfe des Mikroskops das Pigment als Körnchen ${ }^{2}$ ), welche um den Kern herum liegen. An den nicht verknöcherten Stellen hat die Haut borstenartige Haare, auch finden sich zerstreute Iaare, welche in Vertiefungen der Kuochenplättchen stecken. Chlamyphorus hat in den allgemeinen Bedeckungen viel Aehnlichkeit mit den Gürtelthieren, doch sind sie mehr lederartig und biegsamer.

1) Alessandrini, Structura integunentorum armadilli. In Novi eommentarii aeademiae scientiarum instituti Bononiensis. Bononiae 1849.

2) H. Merer, Ueber den Bau der Haut des Gürtelthiers in MüLlens Archiv für Anatomie und Physiologie. Jahrgang 1848. 
Bei Manis ist die Haut mit grossen, dachziegelförmig über einander liegenden, dicken, hornartigen Schuppen bedeckt, zwischen welchen bei einigen Arten kurze Haare hervorragen. Bei Myrmecophaga tamandua, Cuv., ist der Schwanz, besonders gegen sein Ende hin, mit kleinell, breiten Schuppen bedeckt, wie bei einigen Nagethieren und einigen Beutelthieren. Bei dem zweizehigen Ameisenfresser ist der Schwanz gegen die Spitze hin, über ein Dritttheil seiner Länge an der untern Seite unbelıart, aber nicht schuppicht.

Die Haare der pflanzenfressenden Edentaten haben ein dürres, glanzloses Ansehen, sind aber doch ziemlich weich, und legen sich nicht glatt an; beim zweizeligen Faulthier sind sie durch ihre Länge ausgezeichnet. Unter den insektenfressenden Edentaten hat der grosse Ameisenfresser (Myrmecophaga jubata) die längsten Haare, besonders ist der Schwanz und ein Kamm, der sich nach der Läıge des Rückens erstreckt, dadurch ausgezeichnet. Diese Haare sind über einen Fuss lang, dick, fast borstenartig, dagegen hat der zweizehige Ameisenfresser kurze, selr weiche, seidenartige Haare. Die Haare des Orycteropus sind steif, ziemlich lang und an die Haut angedrückt. Die langen, beweglichen Bartborsten, die sehr vielen Säugthieren an der Oberlippe zukommen, und als Tastwerkzeuge dienen, fellen den Edentaten, nur bei Orycteropus steht um die Nasenlöcher herum ein Büschel von vorwärts gerichteten langen Haaren.

Sowohl bei den Faulthieren als bei den Ameisenfressern (Myrmecophaga) und bei Orycteropus sind die Haare plattgedrückt, und bei Myrmecophaga jubata verlauft der Länge nach eine kleine Rinne. Die Rindensubstanz des Haars ist bei diesem Thier durch ilre Derbheit ausgezeichnet und mit Scheidewänden versehen nach ERDL. Die Markröhre wird durch eine undurchsichtige, feinzellige Masse ausgefüllt. Die Haare des zweizehigen Faulthiers sind auf ihrer Oberfläche mit feinen, der Länge nach verlaufenden Furchen durehzogen.

Die Schweissdrüsen konıte ich nicht untersuchen, weil die Haut nicht in einem dazu tạuglichen Zusland sich befand.

Die Schuppenthiere und Dasypus tricinctus können sich zusammenrollen, wie ein Igel. Bei diesen Edentaten zeigt der Hautmuskel sich sehr entwickelt. Bei Manis erstreckt sich der Hautmuskel von der Schulter zum Becken und breitet sich über den Bauch aas, wo er mit dem Muskel der andern Seite zusammenfliesst, der Rücken ist nicht vom Hautmuskel bedeckt, wohl aber die beiden Seiten des Thiers. 
Den sehr zisammengesetzten Hautmuskel des Dasypus longicuudus (Dasypus novemcinctus, Linn.) hat Alessandrini ausführlich beschrieben und abgebildet $\left.{ }^{1}\right)$. Einige dieser Muskeln kommen von benachbarten Theilen und gehen zu den knöchernen allgemeinen Bedeckungen, andere Muskeln gehen von einem Theil der knöchernen allgemeinen Bedecknngen zu einem andern Theil derselben (Musculi loricae intriuseci). Zu den ersteren gehören der untere und der seitliche Hautmuskel am Halse, der seitliche entspringt vom Jochbogen. Beide kiönnen den vordern Rand des Rückenschilds adduciren. Der Schulterblatt-Hautmuskel kommt von einer starken Sehnenhaut, welche die Muskeln des Schulterblatts bedeckt und befestigt sich an der innern Fläche der Rückenhaut, etwas hinter der Mitte des Rückens. Die beweglichen Knochengürtel werden durch diesen Muskel einander genöhert.

Der IIautmuskel der Brust bedeckt den grossen Brustmuskel, geht vorwärts und fliesst mil dem untern Ilautmuskel des IIalses zusammen, dessen Wirkung er unterstützt. Der untere Ilantmuskel des Schwanzes entspringt von der äussern Fläche des Schambeins und befestigt sich an dem ersten knöchernen Ring der Haut des Schwanzes. Dieser Muskel zielıt den Schwanz abwärts.

Folgende Muskeln gehen von einem Theil des Rückenschildes zum andem. Der grosse Hautmuskel bedeckt einen grossen Theil der imnern Fläche der IIaut des Rückens, er entspringt an dem mit unbeweglichen Knochentafeln versehenen Theil der Hant, welcher die Schulter bedeckt und geht zu dem illulich gebildeten Theil der Haut über der Lendengegend; er gibt auch Streifen ab an die beweglichen Knochengürtel und der seilliche Theil erstreckt sich zu den weichen allgemeinen Bedeckungen des Baucls; an diesem Theil ist der Muskel besonders dick. Alessandnax sucht durch die Wirkung dieses Muskels besonders das kugelförmige Zusammenrollen dieses Gürtelthiers zu erklären, aber nach dem Prinzen Maximulan von Neuivied lat dieses Thier, wie auch die drei andern von ilmı erwähnten Arten nicht das Vermögen, sich zusammen zu kugeln ${ }^{2}$ ).

Muskeln der beweglichen Knochengürtel. Bedeckt von dem äussern Umfang des vorhergehenden Muskels liegen Muskelstreifen, welche von der innern Fläehe der beweglichen Knochengürtel gegen das äussere Ende derselben

1) N. Comment. acad. scicut. instituti Bononiensis. 1819. Tab. 29. 50.

2) Beiträge zur Naturgeschichte vom Brasilien. Zweiter Band. S. 534. 
entspringen, und sich an dem folgenden Knochengürtel befestigen. Sie können die Knochengürtel einander nähern.

Krallen. Bei den Edentaten wird die Nagelphalanx von der Klaue oder Kralle eingeschlossen, wie von einer Scheide oder hufartig. Bei den Faulthieren sind die Krallen sehr gross, spitzig, sichelförmig gebogen, zum Klettern tauglich, bei Orycteropus sind sie nicht gekrümmt; bei dem Riesengürtelthier ist die Kralle an dem mittlern Finger ausserordentlich gross, gekrümmt, spitzig, bei Manis ist das Innere der Kralle durch eine senkrechte Scheidewand getheilt, entsprechend der gespaltenen Nagelphalanx. Bei Myrmecophaga sind die Krallen spitzig, gekrümmt, an den vordern Füssen länger als an den hintern, Myrmecophaga jubata und tamandua treten mit dem äussern Rande der Handfläche auf beim Gehen und beugen dabei die Krallen gegen die Handfläche, bei Chlamyphorus sind die Krallen an den vordern Füssen zum Graben in der Erde ausserordentlich gross. 


\section{Ke hl kop f.}

Da bei den Edentaten die Stimme sehr schwach ist und einförmig, oder auch ganz fehlt, so lässt sich am Kehlkopf, besonders an seiner innern Oberfläche, ein einfacher Bau erwarten. Membranose Beutel, wie sie am Kehlkopf vieler Affen und einiger anderer Thiere vorkommen, felılen ganz. Die Giessbeckenknorpel sind selı klein, da die Stimmritzenbänder, denen diese Knorpel zur Befestigung dienen, schwach sind oder ganz fehlen. Im Allgemeinen haben diese Thiere einen kleinen Kiehlkopf, doch bei Orycteropus ist er ziemlich gross, und nach Verlältniss zu der Grösse des Thiers auch bei dem zweizehigen Ameisenfiesser.

Der Kehlkopf des Orycteropus capensis ist besonders durch die eigenthümliche Gestalt des Schildknorpels ausgezeichnet; dieser lauft als ein schmaler Streifen zwischen dem Zningenbein und dem vordern Bogen des Ringknorpels herüber; das obere Horn des Schildknorpels ist sehr kurz, und verbindet sich durch ein Gelenk mit der Spitze des hintern Horns des Zungenbeins, das untere Horn des Schildknorpels ist viel länger und plattgedrückt, und sein Ende verbindet sich durch eine Gelenksfläehe mit dem Ringknorpel. Der vordere Bogen des Ringknorpels besteht aus einer sehr dünnen Knorpelplatte, ist aber un das Dreifache breiter als der Schildknorpel. Die Giessbeckenknorpel seliicken einen Fortsatz an der innern Fläche des Ringknorpels herunter. Santorinische Knorpel finden sich nicht. Der Kehldeckel enthält nur an der Basis einen schmalen Knnorpelstreifen, das Uebrige ist blos membranos. Es findet sich kein Einschnitt an ihm. Die Stimmritzenbänder sind schwacl.

Beim sclıwarzen Gürtelthier hat der Rand des Kelldeckels einen tiefen Einschnitt. Die Giessbeckenlknorpel sind sehr klein. Das vordere Horn des Schildknorpels verbindet sich unmittelbar mit der Spitze des lintern Horns des Zungenbeins. Keine Santorinische Knorpel; der vordere Bogen des Ringknorpels ist niedrig. Es finden sich keine Stimmritzenbänder.

Wie Bumanenach und Meckel so fand aneh ich beim zweizehigen Ameisenfresser die Kellkopfsknorpel vollständig verknöchert, mit Ausnahme des Kehldeckels. Bei Myrmecopluaga jubata ist die Gestalt des Kehldeckels verwi- 
ckelter als bei dell andern Säugthieren. An der Basis des Kehldeckels entspringt nämlich vom seitlichen Rande ein Horn, das fast parallel mit dem Stinmritzenbande rückwärts geht, und dann, nachdem es den obern Rand des Giessbeckenknorpels erreicht hat, sich aufwärts krümmt und konisch zugespitzt sich endigt. Den Schildknorpel fand ich bei diesen Thier vollständig, den Ringknorpel grösstentheils verknöchert. Das obere Horn des Schildknorpels ist sehr kurz und durch ein Gelenk mit der Spitze des hintern Horns des Zungenbeins in unmittelbarer Verbindung. Eine Falte der Schleimhaut erstreckt sich vom seitlichen Rande des Kehldeckels an um den Eingang in den Kellkopf hinter der Stimmritze herum. Diese Falte ragt etwa einen halben Zoll weil hervor. Bei Hyrmecophaga tamandua fand ich den Schildknorpel fast ganz verknöchert, sehr gross. Sein vorderes Horn verbindet sich mit dem Zungenbein wie bei der vorhergehenden Art. Der hintere Bogen des Ringknorpels ist viel höher als der vordere. Die Giessbeckenknorpel sind selr klein. Santorinische Knorpel finden sich nicht. Statt der Stimmritzenbänder ragen in die Höhle des Kehlkopfs einige von der Schleimhaut überzogene Muskelbündel des M. thyreoarytaenoideus herein.

Bei dem dreizehigen Faulthier hat der Kehldeckel in der Mitte seines freien Randes eine Einkerbung, und es finden sich keine Stimmritzenbänder.

Bei mehreren Edentaten ist die Schilddrüse in zwei vollständig getrennte Lappen, einen rechten und einen linken, zerfallen, so bei Bradypus, Dasypus, Manis, Orycteropus. In der unter meinem Präsidium erschienenen Dissertation von JüGer (Ueber den Orycteropus) ist angegeben, wir hälten die Schilddrüse nicht gefunden, bei einer spätern Untersuchung fand ich dieses Organ, es ist aber sehr schmal in die Lünge gezogen. Das Zerfallen der Schilddrüse in zwei vollkommen getrennte Hälften komnt bei Thieren aus verschiedenen Ordnungen vor, z. B. bei der Hyäne, bei der Fischotter, bei dem Elephanten, dem Hirsch, dem Schnabelthier.

Bei einigen Edentaten ist die Schilddrüse einfach, indem sie sich vor der Luftröhre von einer Seite auf die andere erstreckt, so bei Choloepus, wo die selır schmale, in die Länge gezogene Schilddrüse an ihrem untern Ende von beiden Seiten vereinigt ist. Auch bei Myrmecophaga ist die Schilddrüse einfach, bei dem zweizehigen Ameisenfresser liegt sie sehr tief, und wird vom Handgriff des Brustheins bedeckt. Bei Myrmecoplaga jubata fand ich in einem Fall, dass die rechte und linke Hälfte der Schilddrüse nicht mit einander verbunden waren. 


\section{Verdinung:s - Werkzenge.}

Durch die Einrichtmng der Verdaungswerkzeuge theilen sich die Edentaten in zwei Familien; da die Fantlhiere, die blos von Baumblättern leben, viel zusammengesetztere Verdaunngsorgane, namentlich einen viel zusammengesetzteren Mlagen haben, als die übrigen Edentaten, die von Ameisen, Termiten und ander'n Insekten sich nähren.

Zähne. Diese Organe wurden in der Zoologie hauptsächlich berïcksichtigt bei der Bildung der Ordnung der Edentaten. Es fehlen die Schneidezähne, den meisten fehlen anch die Eckzähne, und bei Myprmecophaga und Mamis fehlen die Zähne ganz. Bei den verschiedenen Gürtelthieren bieten die Zälne grosse Verschiedenheiten dar, und Fr. Cuvisn hat auf diesen Grund das Geschlecht Dasypus getheilt in Dasypus, Tatusia, Priodontes.

Dasypus enthält nach dieser Eintheilung mur Eine Art, Dasypus sexcinctus, Lim. (Dasypus setosus, Max. Prinz vox Neuwied), und unterscheidet sieh nicht nur von den übrigen Gürtelthieren, sondern auch von den übrigen Edentaten dadurch, dass auf jeder Seite im Zwischenkieferknochen ein Zahn sieh findet, der also nach dieser Befestigung als ein Schneidezahm betrachter werden muss, und ilm entsprechen im Unterkiefer anf jeder Seite zwei Zähne, die also auch als Schneidezühne anzusehen sind, doch stehen sie nicht, wie die Sclmeidezähne anderer Thiere, ganz vorne im Unterkiefer (s. die Abbild.). Tatusia und Priodontes unterscheiden sich durch die Gestalt ihrer Backenzälme; andere Zähne finden sich nielıt. Bei Tatusia (Dasypus peba, Desm., Dasypus noremcinctus, Limn.) sind die Backenzälne walzenförmig, bei Priodontes (Dusypus gigas) von aussen nach innen platgedriickt. Das schwarze Gürtelthier (Dasypus peba) hat oben wie unten auf jeder Seite acht cylindrische Backenzähne. Die Kaufläche ist dachförmig, indem von Aussen nach innen eine Gräle verlauft, von der aus die eine Ilälfte der Kaufläche vorwärts, die andere rückwärts sich neigt. Die dachlörnnige Kaufläche entsteht nach und nach dureh das Abniitzen der Zähne, anfangs sind sowolıl die Milchzähne als 
die bleibenden Zähne, mit Ausnahıne der beiden vordersten, zweispitzige Zähne; es findet sich an ihnen eine äussere und eine innere Spitze. Die Zähne sind sehr weiss. Die angegebene Zahl der Backenzähne fand ich an einem wohlerhaltenen Schädel, diese Zahl gibt auch RevgGer $\left.{ }^{1}\right)$ an; Andere schreiben diesem Gürtelthier oben einen Backenzahn mehr zu. Der hinterste obere Backenzahm ist viel kleiner als die übrigen. Dasypus gymnurus hat oben wie unten auf jeder Seite acht Backenzähne.

Dasypus sexcinctus hat oben neun, unten zehen Zälme auf jeder Seite. Sie sind theilweise mit einer braunen Färbung überzogen, von innen nach aussen etwas plattgedrückt, und gleichen sonst in der Gestalt den Zähnen des Dasypus longicaudus. Priodontes gigas (Dasypus gigas) hat im Ganzen 65 bis 74 Zähne. Die Zähıe sind von innen nach aussen zusammengedrückt, klein. Durch eine senkrechte Furche sind mehrere der vordern Zähne oberflächlich in eine vordere und hintere Abtheilung getheilt. Nach Cuvier wäre die Zahl der Zähne bei diesem Gürtelthier viel grösser, 94 bis $96{ }^{2}$ ). Ich habe die Zahlen angegeben, wie ich es an drei Schädeln von erwachsenen Thieren gefunden habe. (S. Seite 11.) Chlamyphorus hat oben wie unten auf jeder Seite acht cylindrische Backenzähne, andere Zälme finden sich nicht.

Orycteropus hat nur Backenzähne, die sich aber in illrem Gewebe von den Zähnen aller andern Säugthiere wesentlich unterscheiden, nur die Zähne des Schnabelthiers zeigen einen ähnlichen Bau. Wurzel und Krone ist an diesen Zähmen nicht abgetheilt, und sie bestehen aus senkrechten Röhren (s. die Abbild.). Aber nur an der Fläche des Zahns, die im Kiefer steckt, sind diese Röhren offen, an der Kaufläche dagegen ausgefüllt; auch ist diese Fläche viel härter als das Uebrige des Zahns. Bei Orycteropus herrscht in der Zahl der Zälıne wenig Beständigkeit ${ }^{3}$ ). Nach Cuvier finden sich oben vierzehen, unten zwölf Backenzähne, auf beiden Seiten zusammengenommen. Desmarest und Guıfırı nehmen oben wie unten zwölf Backenzähne an. Wir fanden in einem Schädel oben sechszehen, unten zwölf Backenzähne, in einem andern Fall oben wie unten zehen auf beiden Seiten zusammengenommen. Es scheint, dass die

\footnotetext{
1) Säugthiere von Paraguay. S. 296.

2) Cuvier, le règne animal. Nouvelle éd. T. I. p. 229.

5) S. die unter meinem Präsidium erschienene Disscrtation von Hermaxn Jäger: Ueber den Oryeteropus capensis. 1837.
} 
Zahl der Zähne nach der Altersverschiedenheit wechselt. Der Schädel, der die meisten Zähne enthäl, scheint von einem jüngeren Thier zu sein; die vordern, sehr kleinen Backenzähne scheinen bald auszufallen.

Der hinterste Backenzalm oben wie unten ist cylindrisch, die beiden vor ihm stehenden aber, oben wie unten, sind gleichsam aus zwei hinter einander liegenden Cylindern zusammengesetzt; die vordern Backenzähme sind wieder einfache Cylinder, doch etwas von aussen nach innen zusammengedrückt, sie nehmen an Grösse ab, der vorderste ist ausserordentlich klein, und entfernt von den andern. Die Kaufläche der Zähne ist horizontal abgeschnitten, nur bei den vordern, kleinen Backenzähnen findet sich eine dachförmige Kaufläche, doch springt die von aussen nach iunen laufende Gräte nicht so stark hervor, wie bei dem zweizehigen Faulthier und bei dem schwarzen Gürtelthier (Dasypus longicaudus).

Die Zähne der Faulthiere zeigen viel Merkwürdiges. Die Schneidezähne fehlen. Das zweizehige Faulthier (Choloepus) hat oben wie unten auf jeder Seite einen grossen, spitzigen Eckzahn, der viel über die Backenzähne hervorragt; aber die Stellung des obern Eckzahns ist ganz eigenthümlich, indem er vor dem untern Eckzalın heruntersteigt, da bei den übrigen Säugthieren, mit Ausnahme der Maki, der obere Eckzahn linter dem untern sich befindet. Bei den dreizehigen Faulthieren hat man den vordersten Zahn auch als Eckzaln bezeichnet, er ist aber von den folgenden Zähnen wenig verschieden; der obere vorderste Zahn ist unter allen der kleinste und cylindrisch, wie die andern Backenzähne; der untere vorderste Zahn unterscheidet sich von den andern Backenzähnen durch die Gestalt der Kaufläche, indem diese nach hinten sehr schief abgeschnitten ist, wodurch der vordere Rand der Kaufläche scharf liervorragt. Bei Choloepus finden sich auf jeder Seite oben vier, unten drei cylindrische Backenzähne, sie endigen sich durch das gegenseitige Abschleifen dachförmig mit zwei Flächen, wovon die eine vorwärts, die andere rückwärts gerichtet ist, und ein Zahn steht dadurch mit zwei Zähnen des entgegengesetzten Kiefers in Berührung (dritte Tafel). Bei den dreizehigen Faulthieren ist die Kaufläche vertieft und der hintere und der vordere Rand ragen scharf hervor. In die Vertiefung der Kaufläche des einen Zahns passt der hervorragende Rand der Zahnkrone des ihm entgegenstehenden Zahns (s. die dritte Tafel, erste Figur). Uebrigens sind sämmtliche Zähne bei allen Faulthieren auch schon bei ganz jungen Thieren, mit einem schwarzen Ueberzug bedeckt. Die Basis des Zahıs 
ist mit einer konischen Vertiefung versehen für die Aufnahme der Pulpa des Zahms.

Bei der mikroskopischen Untersuchung der Zähne des Faulthiers und des schwarzen Gürtelthiers fand ich, dass die äusserste, dünne Schicht, welche die ganze Länge des Zahns bedeckt, ans Cement besteht, in welchem man die zahlreichen Knochenkörperchen erkennt. Dann folgt eine dicke Lage vom Zahnbein gebildet, ausgezeichnet durch die feinen, gestreckten Fasern (Röhrchen), die fast senkrecht gegen die Oberfläche sich erstreckell. Die innerste Substanz ist bei dem Faulthier (ich untersuchte die Zähne von Choloepus didactylus) von grau-brauner Farbe, und besteht aus sechs bis sieben dicken Scheiben; die über einander liegen, wie die Platten einer Volta'schen Säule; in ihnen verlaufen, wie ein Querdurchschnitt des Zahns zeigt, senkrechte Röhren, sie sind aber kleiner und viel weniger zahlreich, als in den Zähnen des Orycteropus und mit Kinochenerde ausgefüllt. Bei den Gürtelthieren (Dasypus longicandus) besteht die imnerste Substanz aus feinen Fasern, die mit der Achse des Zahns parallel laufen. Die Zülne des Dasypus sexcinctus bestehen nach Erph ganz aus Elfenbein (Zahmbein); aber nach Owes ${ }^{1}$ ) ist der Zahn mit einer Lage von Cement bedeckt; so verhall es sich auch bei Priodontes gigas.

Die mikroskopische Untersuchung der Zähne des Orycteropus gab mir folgendes Resultat. Der Zahn wird aus senkrechten, meist sechsseitigen, doch unregelmässigen Säulen zusammengesetzt. In der Achse jeder Säule verlauft ein Kanal, der aber gegen die Kaulläche hin mit Knochenerde ausgefüllt ist. Die Lage, welche zunächst den Kanal bildet, ist durchsichtig, wie dünne Querscheiben, die man unter das Mikroskop bringt, zeigen. Dann folgt eine dicke Lage, die von undurchsichtigen Fasern gebildet wird, welche von der durchsichtigen Lage ausstrahlen (Dentime). Die Zähne des Orycteropus sind als zusammengesclzle Zähne zu belrachten; jede Röhre schliesst die Pulpa des einzelnen Zahns ein. Von senkrechten Röhren sind anch die Zähne des Schnabelthiers durchzogen, doch in der chemischen Zusanmensetzung findet keine Aehnlichkeit statt zwischen den Zähnen des Schnabelhiers und des Orycteropus; bei letzterem bestehen sie nach Lassaigne aus 27,3 organischer Substanz, 65,9 phosphorsaurem Kalk, 6,8 kohlensaurem Kalk, aber beim Schnabelthier enthalten die Zähne 99,5 einer hornähnlichen Substanz mud nur 0,5 Knochenerde.

1) Odontography. Pl. 85. Fig. 4. 
Da bei den Ameisenfressern die Zähne ganz fehlen, so ist der freie, obere Rand des Unterkiefers mit einem sehr dicken, harten, gelben Pflaster-Epithelium bedeckt.

Speicheldrüsen. Bei keinem Säugthier haben die Speicheldrüsen eine grössere Entwicklung erreicht, als bei einigen Edentaten, besonders zeichnet sich die Unterkieferdrüse durch ihre Grösse aus, ja beim Gürtelthier findet sich sogar das einzige Beispiel, dass eine besondere Speichelblase zur Ansammlung des Speichels dient.

Bei den Ameisenfressern sind die Speicheldrüsen ausserordentlich gross, ungeachtet diese Thiere keine Zähne haben und ihre Nahrung nicht kauen. Die Unterkieferdrüse bei Myrmecophaga tamandua ist ausserordentlich gross, in viele kleine Lappen getheilt, und erstreckt sich am Halse herunter, bis sie das Brustbein erreicht, einen kleinen Theil seiner äussern Fläche bedeckt und an den grossen Brustmuskel grenzt. Sie ist über vier Zoll lang. Ihr Ausführmngsgang hat eine blasenförmige Erweiterung, lauft neben dem Gang der andern Seile auf dem Boden der Mundhöhle vorwärts, und öffnet sich ganz vorne, wie beim Gürtelthier, an der Symphysis des Unterkiefers.

Die Olrspeicheldrüse ist viel kleiner als die Unterkieferdrüse, und hat einell sehr dünnen Ausführungsgang (Stenonschen Gang), der gegen den Mundwinkel verlauft und an der innern Fläche der Wange sich öffnet.

Die Unterzungendrüse ist bei der betrïehtlichen Länge der Mundlıölle sehr in die Länge gezogen, besteht aus vielen länglichen Läppchen und öflnet sich in die Mundhöhle durch sehr zahlreiche kleine Mündungen." Aelınliche Drüsenlïppehen liegen auch an liarten Gaumen. An der innern Fläche der Wangen verlauft zwisehen dem Oberkiefer und Unterkiefer eine schmale Hervorragung, etwas dümner als eine Schreibfeder; sie ist mil vielen spilzigen, borstenartigen Warzen bedeckt, deren freies Ende rückwärts gerichtet ist. Diese Hervorragung wird durch eine längliche, körnige Drüse gebildet, ist von Muskelfasern bedeckt (vom M. buccinator), und hat viele, kurze Ausführungsgänge, die in die Mundlıöhle sich öfnen. Aehnliche, borstenartige Hervorragungen an der innern Fläche der Wangen finden sich auch bei Manis. Sie scheinen in Verhindung mit den Stachelı auf der Zunge zum Verschlucken der Nahrung (der Ameisen und Termiten) behülllich zu sein.

Die grosse, fast halbmondförmige Drüse, die Cuvien bei Myrmecophaga didectyla als eine Speicheldrüse beschreibt, gehört zum Ange; es ist die Har- 
dersche Drüse; sie öffnet sich mit ihrem Ausführungsgang an der innern Fläche des dritten Augenlieds.

Bei dem kleinen Ameisenfresser (Myrmecophaga didactyla) setzt sich in der Richtung des Mundes an der äussern Fläche der Wange eine Furche fort, in welcher auf einen Druck eine gelbe, dicke Flüssigkeit aus mehreren Oeffunngen hervorkommt. Es liegt dort unter der Haut eine körnichte, elliptische, vier Linien lange Drüse mit melreren Oeffnungen. Es ist eine Hautdrüse, wie Tredenanx richtig angegeben hat. Meckel zählt sie zu den Speicheldrüsen, und nennt sie eine Lippendrüse ${ }^{1}$ ). Die Unterkieferdrüse reicht bis an die Brust herunter, und kommt mit der Milchdrüse in Berührung. Drei Speicheldrüsen, nämlieh die Unterkieferdrüse, die Ohrdrüse und die Unterzungendrüse finden sich bei Orycteropus. Sie haben mit den bei Myrmecophaga beschriebenen die grösste $\Lambda$ ehnlichkeit. Man kann die Unterkieferdrüse in zwei Lappen der Länge nach tremnen. Der Ausfülırungsgang kommt am vordern Ende der Drüse hervor, und mündet sich unmittelbar hinter der Unterlippe mit einer feinen Oeffıung anf dem Boden der Mundhöhle. Es findet sich keine Speichelblase, aber doch ist der Ausfülrungsgang in der Drüse, etwas vor der Mitte derselben, durch das Zusammenströmen von mehreren Wurzeln um das Doppelte weiter, als nachdem er aus der Drüse herausgetreten ist. Die Ohrspeicheldrüse dieses Thiers ist klein und düm, viel kleiner als die Unterkieferdrüse. Der Stenonsche Gang öffnet sich an der innern Oberfläche der Wange. Die Unterzungendrüse liegt auf dem Boden der Mundhöhle, nur von der Schleimhaut derselben bedeckt, und erscheint als ein schmaler, körniger Streifen. Sie öffnet sich mit vielen kleinen Mündungen auf dem Boden der Mundhöhle.

Bei Dasypus peba (Dasypus longicaudus, Max. Prinz vox Neuwied, Dasypus novemcinctus, Linn.) fand ich an jeder Seite vier Speicheldrüsen. Die Unterkieferdrüse ist, wie bei den andern Edentaten, ausserordentlich gross, indem sie bis an das Brustbein reicht. Sie hat einen besondern, eiförmigen, etwa haselnussgrossen Behälter für den Speichel (siebente Tafel). Es kommen fünf bis sechs Ausführungsgänge aus dieser Drüse hervor, werden von dem hintern Ende der Speichelblase aufgenommen, und aus dem vordern Ende der Blase entspringt der Ausführungsgang. Diese Blase hat dicke Wandungen, man erkennt daran deutlich eine Muskelhaut und auf der innerı Fläche eine glatte

1) Mecker, vergl. Anatomie. Vierter 'Milil. S. 609. 
Schleinhaut, die durch eine Lage von dichtem Zellgewebe mit der Muskelhaut verbunden wirl. Die Gänge, welche sich in die Blase einmünden, haben viel dünnere Waudungen als die Blase sclbst. Die kleineren Gänge verlaufen eine Strecke weit zwischen den Häuten der Blase, wodurch eine klappenartige Einmündung entsteht. Die Speichelblase dieses Thiers wurde von mir zuerst beschrieben (Winker, Praes. Rapp, Dissert. sistens observationes anatomicas de Tatu novemcincto. Tubing. 1824. p. 10. 11.), nachdem Professor JäGEr in Stuttgart sie schon vorher bemerkt hatte. Sechs Jahre später beschrieb Richard Owen $\left.{ }^{1}\right)$ diese Speichelblase; er fand sie auch bei Dasypus sexcinctus.

Ferner findet sich bei dem Gürtelthier eine kleine Olirspeicheldrüse, ihr Ausführungsgang öffnet sich an der innern Seite der Wange, unmiltelbar hinter dem Mundwinkel. Neben dem Ausführungsgang dieser Drüse liegt cine kleine Parotis accessoria. Die Unterzungendrüse ist sehr schmal, und öfnet sich durch mehrere kleine Mündungen auf dem Boden der Mundhöhle. Auch bei Chlamyphorus truncatus sind die Speicheldrüsen sehr gross ${ }^{2}$ ).

Die Faulthiere unterscheiden sich von den übrigen zahnlosen Thieren durch die Kleinheit der Speicheldrüsen. Nach Hecké ist die Unterkieferdrüse kleiner als die Ohrspeicheldrüse, nach Duverwoy ${ }^{5}$ ) grösser. Da wegen der unregelmăssigen Gestalt der Ohrspeicheldrüse durch den blossen Anblick die verhältnissmässige Grösse nicht mit Gewissheit beurtheilt werden kann, so schnitt ich diese Organe bei dem dreizehigen Faulthier heraus und untersuchte das Gewicht, wobei sich ergab, dass die Ohrspeicheldrüse um ein Sechstel schwerer war als die Unterkieferdrüse. Die Unterznngendrüse ist schr klein.

Der Gaumen ist bald glatt, wie bei Myrmecophaga tamandua, bald mit Querfurchen versehen, so bei Dasypus (Gürtellhier).

Das Gaumensegel (der weiche Gaumen) zeichnet sich bei den Ameisenfressern durch seine Länge aus. Auf diese Weise selzen sich die hintern Nasenlöcher (Choanen) in eine lange, menlbranose Röhre fort, die sich endlich mit der Rachenhöhle vereinigt. Bei Myrmecophaga jubata ist der weiche Gaumen an seinem hintern Ende zugespitzt und reicht bis zum Kehldeckel. Das Zäpfchen fehlt den Edentaten, wic den meisten Thịcren, mit Ausnahme der Affen.

1) Proceedings of the zoological Socicty of Jondon. Part. I. 1830-1831. p. 114.

2) Yarrelu, Ueber den Knochenban des Chlamyphorns. Isis 1830.

3) Leçons d'anat. comparée. Séconde érition. 
Tonsillen. Beim schwarzen Gürtelthier erscheinen die Tonsillen als eine halbkugelförmige Höhle mit runder Oeffnung. Die Höhle hat die Grösse einer Erbse, und auf ilhrer innern Oberfläche ragt eine Falte hervor, die am Eingang der Höhle als eine Warze sich endigt. Die innere Oberfläche dieser Höhle nimmt die Mündungen vieler, körniger Drüsen auf. Bei Myrmecophaga fand ich die Tonsillen in Gestalt einer länglichen Platte, die von vielen Drüsenkörnern gebildet wird; sie hat bei dem grossen Ameisenfresser die Länge eines Zolls. Bei Manis tridentata besteht die Tonsille auf jeder Seite aus einer einfachen, mit dem blinden Ende vorwärts gerichteten Höhle mit einer runden, kleinen Mündung. Bei Orycteropus werden die Mandeln aus kleinen, warzenförmigen Körnern zusammengesetzt, die um eine halbkugelförmige Grube von der Gröss̀e einer Erbse in grosser Anzahl herumliegen. Bei den Faulthieren erscheinen die Tonsillen als eine tiefe Grube, die durch eine runde Oeffnung sich ausmündet.

Beim schwarzen Gürtelthier lauft auf dem Boden der Mundhöhle auf beiden Seiten der Länge nach ein mit Lappen besetzter Hautsaum, wie er auch bei einigen andern Säugthieren, z. B. bei Tragulus, vorkommt.

Die Speiseröhre der Edentaten ist eng. Bei Myrmecophaga jubata liegt unmittelbar über dem Zungenbein ein blasenförmiger Anhang, eine Art von Kropf, wie man ihn bei vielen Vögeln findet. Diese Erweiterung hat beim erwachsenen Thier die Grösse einer Zwetsche, hängt mit dem Schlund durch eine runde Oeffnung zusammen, die weit genug ist, den kleinen Finger aufzunehmen. Die Wandungen dieser Blase sind dünn, durchsichtig.

An der Speiseröhre der Edentaten ist besonders die Muskelhaut sehr dick; man kann sie in zwei Lagen tremnen, die äussere besteht aus Längenfasern, die innere aus Querfasern. Die innere Oberfläche der Speiseröhre ist bei dem schwarzen Gürtelthier (Dasypus peba) nicht glatt, sondern mit Warzen dicht bedeckt, die aber mit unbewaffnetem Auge kaum zu unterscheiden sind.

Am Uebergang der Speiseröhre in den Magen liegt bei den Schuppenthieren eine halbmondförmige Klappe, ihr freier Rand ist gegen die rechte Seite gerichtet ${ }^{1}$ ). Bei Manis tridentata fand ich aber keine Spur einer solchen Klappe.

Magen. Man kann die Edentaten eintheilen in solche, die einen einfa-

1) Carus und Orro, Erläuterungstafeln zur vergl. Anatomie. Viertes Heft. 
chen, und solche, die einen zusammengesetzten Magen laben. Ein einfacher Magen kommt denen zu, welche von thierischen Substanzen sich nähren, ein sehr zusanmengesetzter Magen den blos von Baumblättern lebenden Faulthieren. Aber auch der einfache Magen einiger Edentaten, besonders der Schuppenthiere und Gürtelthiere, zeigt schon Spuren von einem Zerfallen in melrere Mägen.

Bei Manis, Orycteropus, Myrmecophaga und Dasypus ist der Magen einfach und an der linken Seite mit einem blinden Sack versehen. Eigenthümlich ist die Gestalt des Magens bei dem zweizehigen Ameisenfresser, wie es

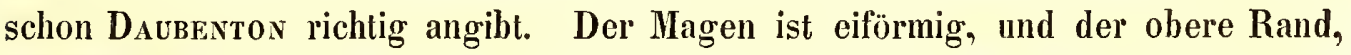
die kleine Curvatur, ist nicht, wie bei andern Thieren konkav, sondern konvex. Fast die gleiche Bildung zeigt der Magen des schwarzen Gürtelthiers, indem die kleine Curvatur nicht konkav erscheint (s. die Abbild.). Die innere Oberfläche des Magens der Edentalen bietet manche Merkwürdigkeit dar. Bei Myrmecophaga ist die innere Oberfläche selır weich und besteht aus einer Drüsenhaut. Man erkennt bei mässiger Vergrösserung unzählige Oeffinungen, es sind die Mündungen von drüsichten Säcken, aus denen diese ziemlich dicke Haut zusammengesetzt wird. Bei Orycteropus bildet die Magenschleimhaut in der rechten Abtheilung viele, netzartig mit einander verbundene Falten, aber in ihrem feineren Bau zeigt sich diese Haut wie bei Myrmecophaga. Es ist ein aus röhrichten Drüsen zusammengeselztes Absonderungswerkzeug. Bei den Schuppenthieren zerfältt der Magen durch seinen Bau in zwei ungleiche IIälften. Zwei Drittheile des Magens sind ziemlich dünnwandig, das dritte Drittheil welches gegen den Pförtner lin liegt, hat sehr dicke Wandungen. Die grössere, linke, dünnwandige Abtheilung des Magens hat ein hartes Epithelium, eine Fortsetzung des Epitheliums der Speiserölre; an der Grenze gegen das rechte Dritheil des Hagens ist es scharf abgeschnitten. Die Verdickung der Wandungen an der rechten Seite des Magens rührt theils von der Muskelliaut, theils von der Schleimhaut her. Nahe am Pförtner ist die Muskelhaut sehr dick, aber die Schleimhaut dünner, weiter entfernt von dem Pförtner ist die Muskelhaut viel dünner als die Schleimhaut. Durch diese Schicht erhält die rechte Abtheilung des Magens eine weiche, innere Oberfläche und diese Lage besteht aus senkrechten Drüsenschläuchen; die Dicke dieser Haut beträgt bei Manis tridentata drei Millimeter. Die Schuppenthiere haben an der rechten Magenhälfte an grossen Bogen ein aus einem Haufen von linsenförmigen Drüsenkörnern zusammengesetztes Absonderungswerkzeug, das durch eine runde Mün- 
dung in die Höhle des Magens sich öffnet, es liegt zwischen der Muskelhaut und der Zellgewebehaut. Bei dem langschwänzigen Schuppenthier ist diese Drüse um die Hälfte kleiner als bei Manis brevicaudata, Griff. ${ }^{1}$ ). Bei Manis tridentata findet sich diese Drüse nicht. Am Pförtner findet sich an der innern Oberfläche des Magens eine halbkugelförmige Hervorragung, welche den Ausgang des Magens verschliessen kann. Diese Hervorragung ist von der Schleimhaut überzogen, wird aber selbst aus einer elastischen, weichen, weissen Masse grebildet.

Die Magenschleimhaut des Gürtelthiers (Dasypus longicaudus) ist zottig, wie die innere Oberfläche des Dünndarms. Unmittelbar vor dem Pförtner befindet sich bei diesem Thier, wie bei Myrmecophaga jubata und tamandua und bei den Schuppenthieren, auf der imnern Oberfläche eine dicke, warzenförmige Hervorragung. Sie dient zur Verschliessung des Pförtners. Ihr Ueberzug hat dieselbe Beschaffenheit, wie die innere Oberfläche des Magens, aber das Immere dieser grossen Warze besteht aus einem weissen, sehr elastischen Gewebe. Bei der mikroskopischen Untersuchung überzeugte ich mich, dass es viele Fettropfen einschliesst. Auch auf der äussern Oberfläche des Magens entspricht dieser Hervorragung eine Erhöhung, was dort von einer Verdickung der Muskelhaut herrührt. Die Muskelhaut des Magens der Edentaten erreicht gegen den Pförtner hin eine ausserordentliche Dicke, wodurch die rechte Magenhälfte $\Lambda$ ehnlichkeit erhält mit dem Magen vieler Vögel; bei Orycteropus fand ich die Muskelhaut gegen das rechte Ende des Magens hin einen halben Zoll dick. Man findet sogar bei einigen, z. B. beim kleinen Ameisenfresser (Myrmecophaga didactyla) und bei Dasypus (s. die Abbild.) auf der Oberfläche dieser dicken Muskelhaut auch einen Selnenstreif. Vom Magen der Vögel findet aber eine wesentliche Verschiedenheit statt, indem die innere Oberfläche des Magens dieser Säugthiere sehr weich ist, ohne jenen harten, hornartigen Ueberzug des Vogelmagens zu besitzen.

Ganz abweiehend von den übrigen Edentaten sind die Faulthiere in Beziehung auf den Bau des Magens, und diese blos von Baumblättern lebenden Thiere zeigen in ihrem Magen manche Aehnlichkeit mit den Wiederkäuern. Obgleich Daubenton, Cuvier, Meckel, Otro den Magen dieser Thiere richtig beschrieben haben, so war doch der feinere Bau bisher weniger bekannt.

1) Cares und Oтто, Erläuterungstafeln. Viertes Heft. S. 19. T. VIII. 
Beim dreizehigen Fauthier aus Guiana (Bradypus cuculliger, Wagl.) ist der erste Magen ausserordentlich geräumig und durch drei muskulose, sehr dicke Falten in drei abgerundete Abtheilungen geschieden, die auf der äussern Fläche durch tiefe Furchen angezeigt sind, es sind nämlich Abtheilungen, wie sie am ersten Magen (Pansen) der Wiederkäuer vorkommen. Dieser Magen hat auf der immern Oberfläche ein dickes Pflaster-Epithelium, aber keine warzenförmigen Hervorragungen. Mit diesem grossen, ersten Magen steht ein schmaler, horuförmiger, langer, zugespitzter Magen in Verbindung, der zwar durch eine weite Mündung mit demselben zusammenhängt, aber in Absicht auf seinen Bau ganz abweicht. Er hat tiefe Höhlen, welche durch breite Hautfalten gebildet werden. Es sind sechs solcher Zellen; ihre Tiefe wechselt von einem halben Zoll bis zu drei Zoll. Eine dieser Taschen ist so tief und weit, dass dieser hornförnige Anhang durch eine der Länge naeh verlaufende Scheidewand in zwei Gänge geschieden wird. An der äussern Fläche des Magens sind sie nicht bemerklich. Sie lıängen unter einander nicht unmittelbar zusammen, sondern nur durch die gemeinschaftliche Magenhölle. Die innere Oberfläche dieses hornförmigen llagens zeigt bei einer mässigen Vergrösserung unzählige Vertiefungen, Gruben, die durch schmale, netzförmige Hervorragungen von einander geschieden sind. Diese Ablheilung des Magens stell ein grosses Absonderungsorgan dar. Mit dem zweiten Magen der Wiederkäuer findet keine Aehnlichkeit statt, wohl aber stimmt dieser horuförmige Magen durch seine Zellen und durch den feinern Bau seiner innern Ifaut mit den sogenannten Wasserzellen im ersten und zweiten Magen des Kamels und des Lamas überein.

Vom Ende der Speiseröhre aus führt eine mit einem dicken Epithelium bedleckte Rimne in einen selı kleinen Magen, dessen Ausgang gegen die rechte Seite hin gerichtet ist. Dieser letzte Magen hängt an der Cardia mit dem grossen Magen (Pansen) zusammen durch eine enge 0effnung, ist hufeisenförmig gekrümmt und wird durch eine Querfalte im Innern in zwei Abtheilungen geschieden, in eine kleinere, mit einer weichen Schleimhant versehene Abtheilung, und in eine grössere, die in den Dünndarm übergeht. Durch die kleinere Abtheilung selzt sich ein schmaler Streifen des dicken Epitheliums von dem ersten Magen fort, und die letzte Magenabtheilung, die in den Dünndarm sich fortsetzt, hat wieder ein sehr dickes, hornartiges Epithelium, auch die Muskelhaut ist sehr dick. In dieses Epithelium erstrecken sich unzählige, fadenförmige 
Verlängerungen. Das dicke, hornartige Epithelium derjenigen Magenabtheilung, die in den Dünndarm übergeht, kommt sonst bei den Säugthieren nicht vor, vielmehr gleicht dieser letzte Magen des Faulthiers durch sein dickes, hornartiges Epithelium und durch seine dicke Muskelhaut, dem Magen der Vögel, und die vorhergehenden Abtheilungen wären dem Kropf und dem Drüsenmagen der Vögel zu vergleichen. Ein Wiederkäuen ist bei den Faulthieren zwar nicht beobachtet worden, doch die Einrichtung des Magens und namentlieh die Schlundrinne könnte darauf hinzuweisen seheinen.

Bei Choloepus ist der erste Magen sehr geräumig, der hornförmige Anllang kurz, stumpf, und er enthält nicht jene Taschen, auch keine Scheidewand, wie bei Bradypus cuculliger. Der erste Magen ist mit einem glatten Epithelium, einer Fortsetzung des Epitheliums der Speiseröhre überzogen, 'aber ein grosser Theil dieses Magens hat eine sehr weiche, aus kleinen Drüsenkörnchen oder Drüsenschläuchen zusammengesetzte Oberfläche. Der folgende Magen ist viel kleiner; etwa ein Drittheil desselben hat eine weiche, aus Drüsenkörnchen gebildete Schleimhaut; gegen den Pförtner hin wird die Muskelhaut ausserordentlich dick. Dieser letzte Magen ist durch eine Einschnürung in zwei Abtheilungen getheilt. Eine Schlundrimne führt von dem Ende der Speiseröhre durch den Pansen durch in den letzten Magen, der aber durch eine Einschnürung in zwei Abtheilungen getheilt ist. Eine Pförtnerklappe findet sich bei den Faulthieren nicht. Bei zwei Choloepus, die ich zergliederte, enthielt der Magen viel verschlıckte Haare dieses Thiers.

Darmkanal. Lie Edentaten, mit Ausschluss der Faulthiere, sollten, da sie in ihrer Nahrung als insektenfressende Thiere mit einander übereinstimmen, keine grosse Verschiedenheit unter einander in Beziehung auf die Länge des Darmkanals erwarten lassen; aber bei Dasypus peba fand ich die Länge des Körpers (von der Spitze der Nase bis zum Aufang des Schwanzes) zu der Länge des Darmkanals wie 1:10 oder 11. Bei Manis tridentata wie 1:81/2. Bei Myrmecophaga tamandua wie 1:7. Bei Myrmecophaga didactyla wie 1:5 [uach Mecher I) ist das Verhältniss wie 1:31/2]. Bei Orycteropus capensis ist das Verhältniss wie 1:16; obgleieh dieses Thier dieselbe Nahrung hat, wie Myrmecophaga und Manis.

1) Anatomie des zweizehigen Ameisenfressers. In Mrekws Arehiv für Physiologie. Fiinfter Band. 
Nach den bisherigen Angaben über die Länge des Darmkanals der Faulthiere würden diese Thiere eine sehr auffallende Ansuahme bilden von dem Gesetz, dass der Darmkanal bei den pflanzenfressenden Thieren länger sei als bei den von animalischer Kost lebenden. Nach Cuvier i) verhält sich bei $\boldsymbol{B r} \boldsymbol{r} \boldsymbol{a}$ dypus tridactylus (Acheus Ai, Cuv.) die Länge des Körpers zu der Länge des Darmkanals wie $1: 3^{1 / 2}$; aber ich fand das Verhältuiss wie 1:6 $1 / 2$. Die Länge des ganzen Darmkanals betrug bei Bradypus cuculligger, welche Art sonst von Bradypus tridactylus nicht als verschieden angesehen wurde, 90 par. Zoll. Auch nach dieser Untersuchung erscheint der Darmkanal immer noch kurz bei einem Thier, das blos von so schwer zu assimilirender Nahrung, von Baumblatteru, lebt. Bei Choloepus verhält sich nach meiner Untersuchung die Länge des Leibes zur Länge des Darmkanals wie 1:81/5.

Die Eintheilung des Darmkanals in den Dünndarm und Dickdarm kommt bei allen Edentaten vor, aber der Dickdarm ist kurz; seine Länge beträgt beim schwarzen Gürtelthier (Dasypus peba) sichen Zoll; der ganze Darm vom Pförtner an hat eine Länge von 111 Zoll. Bei Myrmecophagra tumandua ist der Dickdarm dreizehen Zoll lang, der ganze Darmkanal vom Pför'ner an hundert und vierundvierzig Zoll; beim kleinen Ameisenfresser (Mys'mecophaga didactyla) ist der Dickdarm drei und einen taalhen par. Zoll lang, der ganze Darmkanal siebenunddreissig Zoll. Bei Orycteropus capensis hat der ganze Darmkanal vom Pförtner an eine Länge von vierundvierzig Fuss, wovon acht Fuss anf den Dickdarn kommen. Bei Manis tridentata verhält sich die Länge des Dickdarms zur Länge des ganzen Darmkanals wie 1:8. Bei Choloepus hat der Darmkanal eine Länge ron 177 Zoll, wovon 22 Zoll auf' den Bickdarm kommen.

Der Blind d arm bictet bei den zalnlosen Thieren viele Verschiedenheiten dar; er fehlt ganz bei den Faulthieren und einem Theil der Gürtelthiere; eine kleine, fast halbkngelförmige Hervorragung findet sich bei Myrmecophaga tamandua; cin ziemlich grosser Blinddarm kommt bei Orycteropus vor; der Blinddarm hat nämlich eine Länge von vier und einem halben Zoll; endlich bei dem kleinen Ameisenfresser (Hyrmecophaga diductyla) mud bei Dusypus sexcinctus finden sich zwei einander gegenüber stehende Blinddärme, wie sie bei den Vögeln sehr häufig vorkommen; bei den Säugthieren nur noch

1) Legons l'anatomie comparée. 
bei Hycax, wo sie selir gross, aber nicht am Anfang des Dickdarms, sondern im Verlauf des Colon angebracht sind, ferner unter den Beutelthieren, bei Phascolomys, wo sie ungleich an Grösse sind. Die Blinddärme des genannten Ameisenfressers sind sehr klein, nur zwei Linien lang, schmal und an ihrer Einmündung in dell Darm verengt; an Umfang werden sie von dem Dickdarm vielfach übertroffell. Bei den übrigen Arten von Myrmecophaga findet sich keine Spur dieses doppelten Anhangs. Die beiden Blinddärme des Dasypus sexcinctus sind einen halben $Z$ oll bis einen Zoll lang nach 0 wen ${ }^{1}$ ).

Der Umfang des Dünudarms beträgt bei Dasypus peba einen halben Zoll, der Unfang des Dickdarms 21/4 Zoll, doch in seinem Verlaufe nimmt er an Weite ab, bei den meisten andern Thieren dieser Ordunng erseheint dagegen der Mastdarm an weitesten. Bei Myrmecophaga tamandua hat der Dünndarm einen Umfang von einem Zoll, der Umfang des Dickdarms beträgt das Doppelte; bei Myrmecophaga jubata hat der Dünndarm einen Umfang von $1 \frac{1}{2}$ Z Zoll, der Dickdarm von vier Zoll; bei Orycteropus capensis hat der Dünndarm seimer ausserordentlichen Läuge ungeachtet, den beträchtlichen Umfang von zwei Zoll, der Umfang des Dickdarms beträgt an seinem Anfang vier Zoll, doch wird der Darm in seinem Verlaufe enger, der Mlastdarm ist aber selır weit, indem sein Umfang auf sieben Zoll sich erstreckt; auch bei den Faulthieren ist der Mastdarm ausserordentlich erweitert, sein Umfang beträgt bei Bradypus cuculliger zwei und einen hallsen Zoll, da der übrige Darmkanal kaum einen Zoll im Umfang hat.

Die Schleimhaut des Dümndarms ist nicht bei allen Edentaten mit Flocken bedeckt. Bei Myrmecophaga tamandua und jubata bietet sie ein merkwïrdiges Ausehen dar, sie bildet unzählige feine Falten, welche netzartig unter einander verbunden sind, wodurch schon durch das unbewaffinete Auge wahrnehmbare, tiefe Zellen gebildet werden, welche auch bei der stärksten Ausdehnung der Schleimhaut nicht verschwinden; ganz verschieden ist dagegen die Schleimhaut von Myrmecophaga didactyla, indem sie mit grossen, plattgedrückten, algestumpften und sehr dicht stehenden Flocken bedeckt ist; gegen das untere Ende des Dünndarms nehmen die Zotten an Grösse ab, und zuletzt erscheint die Schleimhaut nur mit kleinen, warzenartigen Hervorragungen bedeckt. Bei Manis tridentata ist die Schleimhaut des Dünndarms eine Sammt-

1) Proceedings of the zoological Society of London. Part I. p. 155. Part II. p. 130. 
haut. Bei Orycteropus zeigl die Schleimhaut des Dünndarms plattgedrückte, schmale Flocken. So anch bei den Faulthieren. Bei Dasypus peba bildet die Schleimhant am Anfang des Dümdarms ein Netz durch sehr feine Falten; in seinem ganzen weitern Verlauf bietet der Dünndarm auf seiner inmern Oberfläche ein eigenthümliches Anschen dar; man bemerkt feine, dichtstehende Kreisfalten, die aber mit den Kerkringischen Kilappen in Darmkanal des Menschen nicht verglichen werden kömen; sie sind klein und kömnen mit blossein Ange nicht dentlich unterschieden werden, nnd man findet in den kleinen Zwischenräumen, die zwvischen diesen Falten übrig bleiben, zarte, netzartige Hervorragungen. Diese Falten entstehen nicht, wie die Kerkringischen Klappen, dadurch, dass dic Schleinhaut in Querfalten gelegt wird, sondern es sind vielmehr Auswüchse der Schlcimhant, wie die Flocken, die im Dünndarm der meisten übrigen Sängthiere sich finden. Dicse Bildung der Darmschleimhant scheint dem Gürtclthier eigenthümlich zu sein, und wurde, so viel mir bekannt ist, noch bei keinem andern Sängthier heobachtet. Die Peyerschen Drüsenhanfen des Dïnndarms finden sich hei Orycteropus, Myrmecophaga, Manis, Dasypus und Choloepus.

Die imnere Oberfläche des Dickdarms erscheint bei allen Edentaten mit kleinen Grübchen bedeckt; es sind kleine, einfache, sehr dicht stehende Drüsen; und zwischen diesen zerstrent kommen noch grössere, einzeln stehende, mit runden Mündungen versehene Schleiml:öllen vor.

Klappen finden sich wenige in Darmkanal dieser Thiere. Die Kerkringischen Klappen (Valvulae connicentes) fehleu. Aın Uebergang des Dünndarms in den Dickdarm fand ich bei Dasypus, Manis tridentata und bei Myrmecophaga didactyla kcine Spur einer Klappe; aber hei Orycteropus, wo ein beträchtlicher Blinddarm sich findet, komm eine fast kreisförmige I'aleula ileacolica vor. Endlich hat der Mastdarm des schwarzen Gürtelhiers Querfalten, welche anch bei der stärksten Ansdehnung' nicht verschwinden.

Der Dickdarm zeigt bei keinem Thier dieser Ordnung, mit Ausnahme der Faulthiere, die blasenartigen Hervorragungen, wie sie am Dickdarm des Menschen, der Affen, des Pferds u. s. f. beobachtet werden.

Die Lage des Magens ist bei den Faulthieren folgende: der erste, grosse, Magen liegt auf der linken Seite, rechts von ihm findet sich der zweite, hornförmige Magen oder Magenanhang; er ist mil der Spitzc abwärts und gegen die linke Seite gerichtet. Der kleine, dickwandige Magen endlich, welcher in 
den Dünndarm übergeht, liegt hinter dem ersten Magen, zwischen ihm und. der Wirbelsäule. An der Konvexilät dieses kleinen Magens ist das grosse Netz befestigt. Die Lage des übrigen Darmkanals fand ich bei allen Edentaten. darin übereinstimmend, dass er an beiden Rändern eines sehr langen, schnalen, fast zungenförmigen Gekröses befestigt ist; sowohl der Dünndarm als der Dickdarm befesligt sich daran. In der Achse dieses Gekröses verlauft die Gekrōsschlagader, und schickt auf beiden Seilen die Zwweige zum Darm. In diesem. Gekröse liegen zahlreiche, zerstreute Gekrösdrüsen; doch bei Mys'mecophaga sind diese lymphatischen Drüsen in eine schmale, durch Einschürungen abgetheilte Hasse vereinigl, welche den Stamn der Art. meseraica superior begleitel. In dem Theil des Gekröses, welcher dem Ende des dünnen Darms und dem Dickdarm entspricht, liegen einzclne, zerstreute meseraische Drüsen. Nur beim Orycteropus, der sich durch die Länge des Darms vor allen Edentaten auszeichmel, findet sich ein Mesocolou transversum, durch welches der Aufang des Jejunum hervorkommt. Bei den Edentaten mit einfachem Magen steigt von der grossen Curvalur desselben das grosse Netz herunter, es enthäl, wie bei delı meisten Thieren, eine Höhle, die mit der Bursa omentalis. posterior zusammenlängl; letztere communizirl mit der grossen Hölle des Bauchfells durch eine weite Oeffinung (Foramen Winslowii) unmittelbar unter dem Stamm der Pfortader, wo diese in die Leber übergeht. Bei den Edentaten mit melrfachem Magen ist das grosse Netz an den letzlen Magen befestigt.

Leber. Die Leber der Edentaten (mil Ausnahme der Faulthiere) ist gross, bedeckt die konkave Fläche des Zwerchfells fast ganz, und ist bei Orycteropus durch tiefe Einschnille in drei, bei den Ameisenfressem in vier, bei Dasypus peba und gymmurus in fünf, bei Manis tridentata in vier Lappen getheilt.

Bei den Ameisenfressern entspricht das Aufhängeband der Leber der Grenze zwischen den beiden mitllern Leberlappen. Die Gallenblase fellt keinem dieser Thiere, mit Ausnahme des dreizehigen Faulhiers, ja bei Orycteropus capensis finden sich an der uniern Fläche des mitllern Leberlappens zwei längliche Gallenblasen, welche aber durch den Perilonalüberzug oberflächlich vereinigt sind, wodurch anf den ersten Blick die Gallenblase einfach erscheint. Jede dieser Gallenblasen setzt sich in einen scllangenförmigen Blasengang fort; beide Gänge vereinigen sich endlich, und unmittelbar nach der Vereinigung münden sich drei Ductus hepatici ein. Der gemeinschafliche Ausfülrungsgang (Ductus choledochus) ist nicht besonders weit, hat ungefähr die Lünge eines Zolls 
und mündet sich in den Zwölflingerdarm, etwa einen Zoll vom Pförtner enlfernt. Da ich nur Ein Thier zur Untersucliung lıatte, jedocl in erwachsenen Zustande, so bleibt die Mögliclıeil, dass die doppelte Gallenblase nur als eine individuelle Varietät anzuselien sei.

Bei den Ameisenfressern liegt die eiförmige Gallenblase an der konkaven Fläche des zweiten Leberlappens, wenn man von der rechten Seite an zälılt. Der Einschnitt zwischen dem zweiten und dritten Leberlappen ist bei Myrmecophaga jubata am wenigsten tief, die Grenze dieser beiden Lappen wird aber hinlänglich durch das Aufhängehand der Leber bezeiclnet. Die innere Oberfläche der Gallenblase zeigt durch viele feine Falten das gewöhnliche, maschenförmige Ansehen. Bei Dasypus ist die Gallenblase gegen den Blasengang: hin spiralförmig gewunden. Die Einmündung des Ductus choledochus in den Dünndarm geschieht bei Orycteropus und beim Gürtelthier gemeinschaftich mit dem Ausfïhrungsgang der Bauchspeicheldrüse.

Die Leber der Faullhiere ist abweichend von den übrigen Edentaten. Sie ist ausserordentlich klein; bei einem erwachsenen dreizehigen Faulthier, das die Grösse einer Katze hatte, fand ich die Leber nur 270 Gran schwer. Sie ist in zwei Lappen von ungleicher Grösse gelıeilt durch einen tiefen Einschnitt, und an der konkaven Fläclı der Leber lıängt hinter der Querfurche ein kleiner, zugespitzter Lappen. Bei dem dreizehigen Faulhier fehl die Gallenblasc, sie findet sich aber bei dem zweizehigen ${ }^{1}$ ).

Die Bauchspeicheldrüse liegt linter dem Magen, kommt gegen die rechte Seite herüber und der Ausfülnungsgang öfhet sich bei Orycteropus, Dasypus, Manis in den Dünndarm gemeinschaftich mit dem Ductus choledochus. Bei Manis tridentata besteht die Bauchspeicheldrüse aus zwei schmalen, langen Aesten, einer davon erstreckt siclı in das grosse Netz und lauft parallel mil der grossen Curvalur des Magens.

Milz. Dieses Organ ist sehr schmal, in die Länge gezogen, indem es bei Orycteropus eine Länge von fünf Zoll erreicht. Die Milz erstreckt sich vom Blindsack des Mageus dem grossen Bogen desselben fast parallel laufend gegen die rechte Seite lıerüber. Beim Faulthier lıt sie dieselbe in die Läıge gezogene Gestalt, und liegt am konkaven Rande der kleinen Magenabtheilung, die in den Dünndarm übergeht. Es findet in dieser Hinsicht lieine Aualogie mit

1) Curifr, Leçous d'anat. comp. Séconde éd. pai M. Duverxoy. Tom. IV. p. 459. 
den Wiederkäuern statt, indem bei ihnen die Milz am ersten Magen (Pansen) angeheftet ist.

Drüsenbälge. Bei vielen Säugthieren öffnen sich am Ende des Mastdarms zwei Drüsenhöllen, eine auf jeder Seite. Unter den Edentaten finden sich diese Organe bei Dasypus, ferner bei Manis und Choloepus. Beim schwarzen Gürtelthier hat diese hohle Drüse etwa die Grösse einer Kirsche und sezernirt eine etwas nach Moschus riechende Materie, in der ich durch Hülfe des Mikroskops viele Epithelium-Zellen erkannte. Diese Drüse ist von einem hantförmigen Muskel bedeckt, durch welchen sie zusammengedrückt werden kann, wodurch sie ihren Iuhalt am Ende des Mastdarms entleerl durch eine ziemlich weite Mündung. Bei Man is tridentata liegt an jeder Seite am Ende des Mastdarms ein Drüsenbeutel von der Grösse einer Bohne; er öffuet sich durch eine enge Mündung an der Seite des Afters. Die innere Oberfläche dieses Beutels ist mit einem dicken Epithelium verselıen, und man erkennt zahlreiche Drüsenkörner, welche eine dicke, gelbe Materie durch eine kleine Oeffnung in die allgemeine Höhle des Drüseubentels schicken. Er ist mit einer Muskellaut versehen, durch welche er zusammengedrückt werden kaun. Bei Choloepus liegt an beiden Seiten des Anus eine Grube, elwa von der Grösse einer Bohne mit selır weiter Mündung. Diese Tasche hat eine Lage von kleinen Drüsenkörnerı. Auf der imuern Oberfläche der Tasche zeigen sich viele Müudungen, und aus jeder ragt ein Haar hervor, aus diesen Mündungen kommt auf einen Druck eine weisse, dicke Materie hervor. Die äussere Lage dieser Tasche ist eine Muskelhaut. Bei Bradypus cuculliger, bei Myrmecophaga und Orycteropus finden sich diese Drüsenbälge uicht.

Zur Eintheilung der Säugthiere bieten uns die Zälne die wichtigsten Merkmale dar, doch bei einigen Ordnungen, wie bei den Pachydermen, den Edentaten, deu Cetaceen liefern die Zälùe weniger allen gemeinschaftliche Kennzeichen, als bei den übrigen Säugthieren. Die verschiedenen Thiere, welche die Ordunng der Edentaten bilden, weichen in den Zühnen selır von einander ab. Bei Myrmecophaga und Manis fellen die Zähne ganz; Orycteropus, obschon er die gleiche Nalırung hat, ist mit zahlreichen Backenzälınen versehen. Bei den verschiedenen Gürtelthieren weichen die Backenzähne in der Gestalt und Zahl sehr von einander ab, und bei einem Gürtelthier (Dasypus 
sexcinctus) kommen sogar Sclmeidezähne vor, die sonst bei den Edentaten felıen. Die Faulthiere haben Backenzähne und Choloepus anch Eckzähne.

Anch im Bau sind die Zälne der verschiedenen Edentaten sehr verschieden, indem sie bei Orycteropus aus dünnen, senkrecht stehenden Röhrchen zusammengesetzt sind, eine Bildnng, die sonst nur noch beim Schnabelthier und bei Stellerus vorkommt. Da die Faulthiere in ihrer Nahrung von den übrigen Edentaten ganz abweichen und ansschliesslich von Baumblättern leben, so finden wir anch den Bau des Magens viel znsammengesetzter als bei den von Insekten sich nährenden übrigen Edentaten. Der selır zosammengesetzte Magen der Faulthiere enthält aber noch keinen Grund, diese Thiere von den übrigen Edentaten ganz zu tremen; anch in andern Ordnungen finden wir Thiere mit einfachem und zusammengesetztem Magen, so bei den Nagthieren, bei den Pachydermen.

Da bei den Schuppenthieren und bei den Ameisenfressern die Zälne ganz fehlen, so betrachtet man die dicke Muskelhaut an der rechten Magenlälfte als einen Ersatz dafür, indem man auf die Analogie mit den Magen der Vögel sich stützt, aber bei Orycteropus, welcher grosse, zahlreiche, mil einer breiten Kaufläche versehene Backenzähne hat, erreicht doch die Muskelhant an der rechten Magenlıäfte eine Dicke von einem halben Zoll. So sehr die Fanlthiere in der Bildung des Magens von den übrigen Edentaten abweichen, so findet man doch noch bei ihnen den Pförtnertheil mit einer sehr dicken Muskelhaut versehen, ja die Aehnlichlkeit mit dem Magen der Vögel ist hier grösser: weil auch der dicke, harte, hornartige Ueberzug der innern Oberfläche nicht vermisst wird.

Die grosse, konische Hervorragung vor dem Pförtner der Ameisenfresser, der Schuppenthiere und der Gürtelthiere ist keine Eigenthümlichkeit dieser Thiere. sondern findet sich auch bei den Kamelen.

Der Darmkanal einiger Edentaten, nämlich der Gürtelthiere und des Myrmecophaga tamandua und jubata bietet uns in Beziehnng auf die Bildung der Schleimhaut eine niedrigere Form dar, und schliesst sich an den Typus vieler kaltblütiger Thiere an; stall der Flocken finden sich nänılich sehr zahlreiche, feine Falten, die von der Oberfläche des Dünudarms sich erheben, wie es bei vielen Reptilien und Fischen vorkommt, obgleich auch in diesen Thierklassen Beispiele genug vou dem sammtartigen Anselıen der Darmschleimhaut vorkommen.

Die Bildung der innern Haut des Dickdarms scheint in der Reile der Säug- 
thiere eine grosse Einförmigkeit darzubieten; es ist eine Drüsenhaut, man erkeunt daran unzählige dichtstehende Grübchen und grössere, zerstreute Schleimhöhlen; die Flocken fehlen.

In Beziehung auf den Blinddarm zeigen die verschiedenen Edentaten viele Verschiedenheiten, sogar die drei Arten von Myrmecophaga stimmen in dieser Abtheilung des Darmkanals nicht mit einander überein. Der zweizehige Ameisenfresser hat zwei einander gegenüber stehende Blinddärme, die aber durch ihren äusserst geringen Umfang in gar keinem Verlältniss stehen mit dem Dickdarm, an den sie befesligt siıd. Man könnte vielleicht diese beiden kleinen Anhänge richtiger für einen doppelten Wurmfortsatz anselıen, der übrigens den andern Edentaten, wie überhaupt den meisten Säugthieren, fehlt. Auffallend ist die grosse Verschiedenheit in der Länge des Darmkanals der verschiedenen Edentateu, und obgleich der Darukanal des dreizehigen Faulthiers viel länger ist, als man gewöhnlich angenommen hat, so kommt doch diesem pflanzenfressenden Thier ein kürzerer Darmkanal zı als den übrigen von Insekten lebenden Edentaten, ja bei Orycteropus hat der Darmkanal eine ausserordentliche Länge, wie er bei einem von thierischer Kost lebenden Säugthier gar nicht erwartel werden sollte; der Darmkanal verlält sich zu der Länge des Thiers wie 1 zu 16.

Die Valculae connicentes fehlen den Edentalen, wie fast allen Sãugthieren; doch kömnen diese Klappen nicht als eine Eigenthümlichkeit des Menscheu betrachtet werdel. Sie kommen nach $\mathrm{S}_{\text {ANDifort }}{ }^{1}$ ) beim Orangutan vor, dem sie sonst abgesprochen wurden, weil man die Untersuchung an jungen Thieren anstellte; aber diese Klappen entstehen erst später, sie fehlen anch bein nengeborenen Kinde.

Die Drïsen, welche in den Darmkanal im weiteren Sinn sich ergiessen, bieten manches Merkwürdige dar hei den Edentaten, besonders rechnen wir hieher die Speichelblase an der grossen Unterkieferdrüse des Gürtelthiers. Auch bei den andern Edentaten zeichnet sich diese Drïse durch ihre Grösse aus; eine unerwartete Erscheinung, da melrere dieser Thiere keine Zähne haben und ihre Nahrung nicht kauen.

Die Leber ist bei den Fanlthieren ausserordentlich klein, und eine Gallenblase fehlt dem dreizehigen Faulthier, kommt aber dem zweizehigen Faulthier

1) Verhandelingen over de naturlijke Gesehicdrnis. Zoolngie. N. '́. 
wie den übrigen Edentaten zu, ja bei Orycteropus capensis finden sich zwei Gallenblasen, die aber äusserlich nicht getrennt erscheinen, da sie einen gemeinschaftlichen Ueberzug vom Bauchfell erhalten; doch kömle diese doppelte Gallenblase eine individuelle Varielät sein, obgleieh bei den Thieren, die im Znstande der Freiheit leben, Bildungsabweichungen viel seltener vorkommen, als bei den Hausthieren und beim Menschen. Uebrigens sind Varietäten in Absicht auf die Gallenblase beobachlet worden, so fand Richard Owes ${ }^{1}$ ) bei zwei Giraffen, die er zergliederte, keine Gallenblase, und bei einer dritten Giraffe war die Gallenblase doppelt.

1) Transactions of the zoological Society of London. Vol. II. p. 228. 


\section{Drgane des Kreislaufs.}

Wie bei den meisten Säugthieren, die sich dadurch vom Menschen unterscheiden, liegt bei den Edentaten das Herz nicht auf dem Zwerchfell auf, und der Herzbeutel ist nicht mit der obern Fläche des Zwerchfells verwachsen.

Bei den Fauthieren und bei Myrmecophaga ist das Herz sehr klein und stumpf. Der olrrörmige Anhang der Herzvorhöfe soll nach Meckel dem Faulthier fehlen; aber dieser Anhang findet sich, wie auch bei den übrigen Edentaten, ist jedoch am Rande nicht mit Einkerbungen versehen, zeigt aber im Innern durch die hervorragenden Muskelbündel das netzartige Ansehen. Wie bei den übrigen Säugthieren findet zwischen der rechten und linken Abtheilung des Herzens keine Kommunikation statt. Zwischen dem linken Vorhof und der linken Herzkammer ist die Valcula mitralis angebracht, zwischen dem rechten Vorlof und der rechten Herzkammer die Valcula tricuspidalis. Am Ursprung der Aorta, so wie am Ursprung der Lungenschlagader liegen die drei halbmondförmigen Klappen. Der Knochen, der bei einigen Säugthieren im Herz vorkommt, findet sich nicht.

Die Aorta bildet einen Bogen, aus dessen Konvexilät dic Arterien für den Kopf, den Hals, für die vordern Extremitälen und für den vordern Theil der Wandungen der Brusthöhle entspringen. Aus dem Bogen der Aorta kommen bei Bradignus cuculliger drei Gefïssstämme; der erste theilt sich in die rechte Scllüsselbeinschlagader und in die rechte Carotis, der zweite Stamm ist die linke Carotis und der dritte die linke Schlüsselbein-Schlagader. Doch fand ich in einem Fall bei Bradypus cuculliger, dass nur zwei Stämme aus dem Bogen der Aorta entspringen, der erste Stamm theilte sich dann in die rechte Schlüsselbein-Schlagader und in die reclite und linke Carotis; die linke Schlüsselbein-Schlagader ist der zweite Stamm, der aus dem Bogen der Aorta entspringt. Bei Choloepus didactylus entspringen nach der gewölnlichen Annalme aus dem Bogen der Aorta drei Gefässstämme; der erste theilt sich in 
die rechte Schlüsselbein-Schlagader und die rechte Carotis; aber die linke Carot is und die linke Schlüsselbein-Schlagader kommen unmiltelbar aus dem Bogen der Aorta. Daubenton 1$)$ gibt an, es entspringen drei Gefässstämme aus dem Bogen der Aorta, aber bei zwei Choloepus didactylus, die ich zergliederte, kamen nur zwei Stämme aus dem Bogen der Aorta, der erste Stamm theilt sich in die rechte Schlüsselbein-Arterie und die rechte und linke Carotis, der zweite Stamm, der aus dem Bogen der Aorta entspringt, ist die linke Schlüsselbeinarterie. So fand ich auch den Ursprung der Gefüsse bei Myrmecophaga jubata und tamandua; aber bei dew zweizehigen Ameisenfresser kommen drei Gefïssstämme aus dem Bogen der Aorta; die Art. anonyma, damn getremnt die linke Carotis und die linke Schlüsselbein-Schlagader. Bei Orycteropus capensis fand ich den Ursprung der grossen Gefässe wie bei dem grossen Ameisenfresser, so verhält es sich auch bei Mamis.

Das Gefässsystem der Edentaten ist wegen der grossen Wundernelze besonders merkwürdig. Bei den dreizehigen Fanthieren und bei Choloepus findet sich ein solches IVundernetz an Hauptstamm der Schlagader der vordern und der hintern Extremitaten; auch die Art. sacralis media und die Art. hypogastrica bildet ein solches Geflecht. Bei Choloepus theilt es sich an Ellenbogengelenk in zwei Aeste, davon geht der grössere (A,t. uluaris) durch den kurzen Kanal am immern Knorren des Oberarmbeins mil dem Nereus mediamus. Die Schlagadern des Vorderarms, so wie auch die Schlagadern des Unterschenkels der Faulthiere sind mit keinem Wundernetz versehen; aber an einigen Zweigen der Carotis kommen Netze vor nach Hуrтt ${ }^{2}$ ), die übrigens nicht so dicht sind, wie die Wimdernetze. Bei Bradypus torquatus beschreibt Hyrtu ein Nelz der tiefen Schläfenarterie, ein Rete ophthalmicum und eines, welches von der Unterangenhöhlen-Arterie im Gesicht gebildet wird; ferner in der Schädelhöhle ein dichteres Netz (Rete mirabile pedunculi), es wird aus Zweigen der Basilararterie gebildet, und ein Netz auf der Siebplatte des Siebbeins (Rete cribrosum). Die Wundernetze der Extremitälen finden sich auch bei Myrmecophaga, sind aber bei Myrmerophaga jubata und tamandua

1) Oeuvres de Burfox, avec les descrip. anat. de Buvbexton. Él. par Desmanest. Mammif. T. VIIr. p. 310.

2) Ueber die Carotiden des Aï (Bradypus torquatus) in den Denkseliriften der kaiserl. Akarlemie der Wissensehaften. Zweite Tafel. Wien 1850. 
viel kleiner als bei den Faulthieren, indem die Armschlagader und die Schenkelschlagader nichts von einem solchen Netze zeigt. Die Armschlagader gibt erst bei ihrem Durchgang durch das Loch am innern Condylus des Oberarmknochens ein Büschel von Zweigen ab, und an den lintern Extremitäten zeigt sich erst an der Kniekelılenschlagader ein Wundernetz, von welchem der Hauptstamm eingeluüllt wird. Ein Theil des Netzes schlägt sich in der Mitle des Schienbeins an dessen innerer Seite herum, um auf die vordere Seite des Unterschenkels zu gelangen, wo es bis zu der Fusswurzel lieruntersteigt.

Bei dem zweizehigen Ameisenfresser bildet schon die Armschlagader und die Schenkelschlagader ein Wundernetz. Auch die Art. sacralis media, die an der untern Seite des Schwanzes verlauft, geschülzt durch die unteren Dornen, bildet bei den Ameisenfressern ein Wundernetz, das aber nicht bis an das Ende des Sclıwanzes sich fortsetzt. Nach Vrouk fehlen die Wundernetze bei Mamis. Ich fand bei Mromis tridentatu weder an der Armarterie noch an der Schenkelarterie ein solches Netz, aber in dem Kanal, welcher durch die untern Dornen der Schwanzwirbel gebildet wirl, findet sich ein arterielles und venoses Wundernetz. Die Arterien kommen aus der Art. candalis, welche aus dem Theilungswinkel der Aorta hervorgeht; diese Arterie kann als die Fortsetzung der Aorta betrachtet werden. Der Stamm löst sich zur Bildung des Wundernetzes nicht in Zweige auf; aus diesem Netz erhalten die Muskeln des Schwanzes Zweige. Die Venen dieses Wundernetzes sammeln sich in einen Stamm, welcher sich in die Vena hypogastrica seiner Seite mündet. Nach Allunan kommen bei Dasypus sexcinctus Wundernetze an den Extremitäten vor. Nach Hyrtr theilen sich bei Dasypus setosus (Dasypus sexcinctus, 'Linn.) Schlagadern am Kopf, Becken, Samensirang, an den Bauchdecken und den Gliedmassen plötzlich in strahlig-divergirende Rölren. Bei einer nicht näher bezeichneten Art von Dasypus findet sich nach Schröper var der KolK und VRouk ${ }^{1}$ ) ein arterielles Geffecht, welches von der Art. iliaca externa entspringt und sich gegen den geraden Bauchmuskel erstreckt; es wird von einem venosen Geflechte begleitet. Ich fand bei Dasypus longicandus (Dusypus noremcinctus, Linn.) Wundernetze an den vordern und hintern Extremitäten. An den hintern Extremitäten ist das Wundernetz schwach und hat Aelnlichkeit

1) Bijdragen tot de Dicrkunde. Ansterana 1848. S. 11. 
mit dem Wundernetz der grossen Ameisenfresser. Die Kniekehlenschlagader ist noch einfach, geht aber in zwei Netze über, das eine steigt an der hintern Seite des Schienbeins herunter, schlägt sich dann an der imnern Seite dieses Knochens herum, das andere Wundernetz entspricht der Wadenbeinarterie. Die Zweige dieser, Netze sind nicht zahllreich und haben einen gestreckten strahligen Verlauf. Auch die Art. sacralis media bildet ein Wundernetz mil gestreckten Zweigen, ebenso die Arteria obturatoria und ischiadica. Die A.t. axillaris und brachialis bildet kein Netz, aber Zweige der Art. arìllaris, wie die Art circumftexa humeri posterior, die Art. circumftexa scapulae mit der Art. angularis scapulae bilden gestreckte Netze oder eigentlich strahlenförmige Gefässbüschel. An der Theilmngsstelle der Armarterie sind wieder Wundernetze. Eines geht durch das Loch an innern Condylus des Oberarmknochens mil dem Ulnarnerven. Dieses Nelz entspricht der Art. uluaris. Ein oberflächliches Netz schlägt sich gegen das Olerranon, ein anderes Netz entspricht der Radialarterie. Es finden sich also beim Gürtelthier die Wundernetze nicht an den Hauptstämmen der Schlagader, sonderu hauptsächlich an den von ihnen abgehenden Aesten.

Man kam bei den Thieren zwei Itauptormen der Wundernetze unterscheiden. Bei der ersten Form löst sich der Gefïssstamm in eine Menge von Zweigen auf, die sich unter einander verbinden, und wieder in einen Stamm zusammenfliessen (amphicentrische Wundernelze nach MüLLEB). Zu dieser Form gehört das Wundernetz an der Carotis ccreliralis der Wiederkäuer und des Schweins, ferner nach MüLuen das Wundernetz an der dirt. coeliuca der Thunfische ${ }^{1}$ ).

Bei der ziveiten Form wird das vaskulose Geflechte von vielen Zwveigen gebildet, die aber nicht wieder in einen Iauptstanm zusammenfliessen (diffuse Wundernetze nach MüLLer). Hieher gehört das Wundernelz an der inneru Oberfläche der Wandung der Brusthöhle der Delphine, dic Wundernetze der Schwimmblase einiger Fische, auch die Wundernetze bei den Fauthieren, bei den Ameisenfressern, Gürtelthieren und hei Stenops. Die diffusen Wundernetze theilen sich wieder in zwei Formen, indem der Hauptstanm entweder in

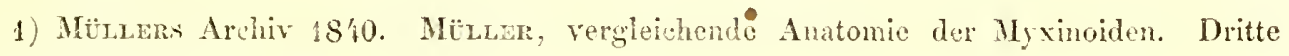
Fortsetzung. 1841. 
kleine Zweige sich auflöst, oder sich erhält, und nur von den kleinen Zweigen, die das Wundernelz bilden, umsponnen wird. Zn der letzten Form gehören die Wundernetze an den Extremitäten von Bradypus und von Stenops, ferner das Wundernetz an der untern Seite des Schwanzes von Manis. Bei ihnen löst sich der Stamm der Armschlagader, der Schenkelschlagader und der Schwanzarterie nicht auf in ein Gefässnetz, sondern vvird nur von kleinen Zweigen umspomnen, and die Zweige vertheilen sich nach und nach zu den Muskeln.

Die Wundernetze, die an den Extrenitäten einiger Edentaten und bei Stenops vorkommen, unterscheiden sich auffallend von dem grossen Wundernetz in der Brusthölle der Delphine durch den Verlauf der Gefässzweige. Sie bilden bei den genannten Cetaceen sehr starke, schlangenförmige Krümmungen und erscheinen in einen Knäuel zusammengewunden, aber bei den Edentaten und bei Stenops sind diese Gefässstänme gestreckt. Bei den Faulthieren sind sie noch am meisten hin und her gewunden. Bei Bradypus, Choloepus, Myrmecophaga und Manis überzeugte ich mich durch die Injektion der Venen, dass das Wundernelz nicht blos aus arteriellen Gefässen gebildet wird, sondern dass eim ähnliches venoses Netz im arteriellen enthalten ist. Den Venen scheinen hier die Klappen zn fellen, denn ich komnte von dem Stamm aus gegen die Peripherie die Venen mit Quecksilber füllen. Auch bei Stenops tardigradus fand ich in den arteriellen Geflechten Venenzweige, und der Stamm der Hauptyene ist selı klein und lauft an der immern Seite des Geflechtes.

Nach Carbisle würde die Ursache der Langsankeit der Faullhiere und der Stenops in dem eigenthümlichen Verlauf der Arterien, die zu den Muskeln der Extrenitäten gehen, begründet sein. Der arterielle Blutstrom muss allerdings in seinem Impuls geschwäclıt werden. Nach Vкоцк würden die Wundernetze zn der anlaltenden Muskelkontraktion fähig machen, welche erforderlich ist, wemn diese Thiere an die Aeste der Bäume, auf denen sie illre Nahrung suchen, sich anliängen. Bei Myrmecophaga jubata finden sich aber die Wundernelze aucl, obgleich dieses Thier nicht anf den Bäumen lebt, auch bei Dasypus.

Die Lungenarterie theill sich in zwei Aeste für die beiden Lungen. Den Ductus arteriosus fand ich in ein Band verwandelt, nur bei Orycteropus capensis war er noch so weit offell, dass man eine gewöhnliche Fischbeinsonde durch ihn von der Lungenschlagader in die Aorta bringen konnte. Uebrigens wurde die Untersuchung an einem erwachsenen, aber doch noch 
jungen Thier, wie aus dem Zustande der Knochen geschlossen werden konnte, indem die Epiphrysen noch niclit erwachsen waren, angestellt. Ohne Zweifel schliesst sich dieser Gang später vollständig.

Ueber den Verlauf der Venen der Edentaten sind nocl keine zusammenhängende Untersuchungen angestellt worden.

Die Blutkörner sind bei dem zweizehigen Faulthier (Choloepus) durch ihre Grösse ausgezeichnet; unter den Säugthieren hat nach Guluver uur der Elephant grössere Blulkörner. Bei andern Edentaten z. B. Dasypus rillosus, Dasypus sexcinctus sind die Blutkörner schon kleiner. 


\section{Arhuningwerkzeuge.}

Luftröhre. Bei allen Edentaten enthält die Luftröhre Knorpelbögen, die niemals ganz geschlossen sind; anch theilt sie sich immer in zwei Aeste, wovon der rechte der weitere ist. Bei dem dreizehigen Faulthier (Bradypus cuculliger) zeichnet sich die Luftröhre durch ihre Länge aus, indem sie, was sonst bei keinem Säughlier beobachtet worden ist, in der Brusthöhle bis nahe an das Zwerchfell heruntersteigt und dann gegen die rechte Seite eine schr starke Krümmung bildet, welche von der rechten Pleura überzogen wird. Der Stamm der Luftrölre wird bei Bradypus cuculliger aus achtzig Knorpelbögen zusammengesetzt, bei Choloepus didactylus aus 32. Sie umgeben die Luftröhre fast vollständig, und es bleibt fast kein membranoser Theil übrig. Die Luftrölure bestelt bei Dasypus longicaudus aus 18 bis 22, bei Orycteropus aus 40, bei Myrmecophaga jubata aus 25, bei Manis crassicaudata, Griff., aus 30, bei Mamis tridentata, Fo cillon, aus 19 Knorpelbögen.

Die Lungen sind bei den pflanzenfressenden Edentaten nicht in Lappen getheilt. Bei den insektenfressenden Edentaten bestättigt sich die allgemeine Regel, dass, wenn eine Theilung der Lungen in Lappen vorkommt, die rechte Lunge melrr Lappen hat als die linke. Bei Dasypus longicandus bestelt die rechte Lunge aus drei, die linke aus zwei Lappen. Bei Myrmecophaga jubata ist die rechte Lunge in vier Lappen getheilt, die linke ist ungetheilt; nach Mecker bestelit sie aus zwei Lappen. Bei Myrmecophaga didactyla hat die reclite Lunge vier Lappen, die linke zwei. Bei Myrmecophaga tamandua ist die Lunge nicht in Lappen getheilt; es finden sich wohl einige Einschnitte, sie gelien aber nicht tief. Bei Manis crassicandata ist die rechte Lunge in fünf Lappen getheilt nach Meckes; bei Manis tridentata hat die rechte Lunge fünf Lappen, die aber durch breite, brückenartige Falten der Pleura zusammenlängen, die linke Lunge ist in zwei Lappen getheilt. Bei den Lungen dieses Thiers hängen die einzelnen Läppchen der Lunge durch selır lockeres, dehnbares Zellgewebe mit einander zusammen. 
Das schwarze Pigment, das in der Lunge des Menschen und einiger Thiere angetroffen wird, felit in der Lunge der Edentaten.

Bei den Faulthieren, Dasypus, Myrmecopllaga fand ich die Lungenzellen sehr gross; es scheint danit eine geringere Eutwicklung von Wärme durch die Respiration gegeben zu sein; diese Thiere leben nur in den heissesten Gegenden, und Scuouburak ') bemerkte, dass eine Myrmecopllaga jubato, die er in ihrem Vaterlande beobachtete, nicht nur an den Extrenitäten, sondern auch am übrigen Körper sich kalt anfühlte; und als die Gesundheit des Thiers leidend wurde, fand man es zuweilen so kalt wie Eis nach dem Ausdruck von Schonburgk.

\section{T In m us.}

Es scheint, dass bei den Edentaten die Thymus sich das ganze Leben über erhält. Ich fand sie bei Bradypus, Orycteropus, Dasypus, Myrmecophaga, Manis. Die herrschende Meinung, dass die Verrichtung der Thymus sich auf die Periode des Fötuslebens beziehe, widerlegt sich 1) dadurch, dass an Ende dieser Lebensperiode die Thymus noch nicht ilır vollständiges Wachsthum erreicht hat, und 2) dadurch, dass bei vielen Säugthieren, besonders bei den Wasserllieren, wie bei der Fischolter, bei dell Robben, den Delphinen, aber anch bei Landthieren, wie beim Dachs, die Thymus gross ist und so das ganze Leben über sich erhält.

1) Proceedings of the zoological Society of London. 185\% p. 25. 


\section{Harnwerkzenge.}

Die Nieren der Edentaten haben olme Ausnahme eine glatte Oberfläche, ohne Abtheilung in Lappen, was damit zusammenlı̈ngt, dass im Nierenbecken nur Eine Nierenpapille hervorragt. Die Gestalt der Nieren ist die gewöhnliche, doch bei den Gürtelthieren erscheint die Niere fast als eine kreisförmige, dicke Scheibe, und beim Faulthier ist sie sehr dick, kurz, eiförmig, und der Ihilus bildet nicht eine schmale Spalte, sondern eine runde Oeffnung.

Bei Manis tridentata fand ich, dass die linke Niere viel tiefer lag als die rechte. Das vordere Ende der linken Niere reichte nicht so weit herauf, um auf gleiche Höhe mit dem hintern Ende der rechten Niere zu kommen. Die linke Niere reichte bis zum Darmbein. Die Nebenniere der linken Seite lag an der Stelle, welche bei einer symmetrischen Lage der Nieren die linke Niere eimnehmen würde. Diese tiefe Lage der linken Niere war vielleicht eine individuelle Anomalie.

Die Nebennieren sind klein, zeigen aber in Beziehung auf ihre Lage eine Merkwürdigkeit, indem sie beim dreizehigen Faulthier (Bradypus cuculliger, Wagl.) weil von der Niere entfernt liegen. Es bleibt ein Zwischenraum fast von der Grösse der Niere. Die Entfernung der Nebenniere von der Niere ist übrigens nicht eine blos dem Faulthier zukommende Eigenthümlichkeit, sondern findel sich auch bei einigen andern Sängthieren, zum Beispiel bei der Hyäne.

Die Harnleiter gehen in die hintere Wand der Blase über in der Nähe des Blasenhalses. Die Ilarnblase ist eiförmig; bei den Faulthieren, wie gewöhnlich bei den pflanzenfressenden 'Thieren, durch ihre Grösse ausgezeichnet.

Der Urachus entspringt nach Owex $^{1}$ ) bei Dasypus sexcinctus nicht an

1) Proceedings of the zoological Society of London. Part I. p. 157. 
der Spitze der Blase, wie bei den übrigen Säugthiereu, sondern von der Mitte der vordern Wand der Blase. Ich untersuchte einen fast reifen Fötus des schwarzen Gürtelthiers (Dasypus longicaudus), fand aber, dass der Urachus an der bei den übrigen Säugthieren gewöhnlichen Stelle an der Spitze oder am Scheitel der Blase entspringt; auch die beiden Umbilikal-Schlagadern verliefen an der Seite der Blase und konvergirten an der Spitze derselben.

Ueber die Primordialnieren (Wolfschen Körper) sind in dieser Ordnung der Säugthiere noch keine Untersuchungen bekannt. 


\section{Fortpflanzungs-Werkzenge.}

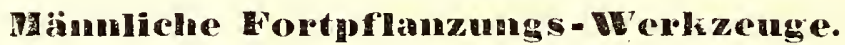

Sowohl bei den Faullhieren als bei Myrmecophaga und bei den Gürtelthieren liegen die Iloden in der Bauchhöhle eingeschlossen. Bei Manis (tridentata) liegen die Testikel ausscrhalh der Bauchhöhle in der Leistengegend an der vordern Mündung des Leistenkanals. Ein Skrotum findet sich nicht. Der Bauchfellkanal, der zu der Tunica raginalis testiculi propria geht, ist bei diesem Thier offen, aber nicht so weit, dass der Testikel in die Bauchhöhle zurückgezogen werden kömmte. Beim Gürtelthier fand ich zwar einen Leistenkanal, der durch einen Fortsalz des Banchfells ausgeklcidet wird, er ist aber so eng, dass er den Hoden nicht aufnehmen kamm, und er endigt sich blind an der äussern Fläche des äussem schiefen Bauchmuskels.

Bei dem zweizehigen Ameisenfresser, bei Choloepus und bei dem drei-. zeligen Faulthier, wo schon Meckes $\left.{ }^{1}\right)$ darauf aufmerksam gemacht hat, haben die Hoden in ihrer Lage die grösste Aehnliclıeit mit den Eierstöcken. Die Hoden liegen nämlich hinter der Blase, vor dem Mastdarm und ctwas zur Seite desselben, sie hängen durch eine Falte des Banchfells, in welcher der Ausführungsgang (Vas deferens) verlauft, mil einander zusammen.

Der Hoden ist rundlich, der Nebenhoden schmal. Der Ausführungsgang (Vas deferens) bildet, wo der Hoden imnerhalb der Bauchhöhle liegt, starke, schlangenförmige Krümmungen. Samenbläschen finden sich bei den Faulthieren, Gürtelthieren, Ameisenfressern. Bei Choloepus didactylus sind die Samenbläschen sehr gross, und bestehen aus dicken, vielfach gewundenen Blinddärmen. Eigentlich würde man dieses Organ richtiger als ein Absonderungswerkzeug bezeichmen, da in Caput gallinaginis zwei Oeffungen auf jeder Seite

1) Beitrag zur Anatomie des Aï. In den Beiträgen zur rergleichenden Anatomie. Zweiter Band. 1811. 
sich finden, die eine davon führt in das Vas deferens, die andere in das 0rgan, das äusserlich den Samenbläschen gleicht. Noch fand ich bei diesem Thier in der Harnröhre auf jeder Seite eine Oeffnung, sie liegt in der Richtming gegen das Ostium cutaneum der Harnröhre und führt in einc buchtige, glatte Höhle, welche viele ganz kur\%e, enge Kanäle aufnimmt. Die Vorsteherdrüse fand ich bei Dasypus longicaudus ans zwei seitlichen, lïnglichen Abtheilungen zusammengesetzt. Die beiden Cowperschen Drüsen haben fast die Grösse einer Bohne. Dic Ruthe ist bci Myrmecophaga stumpf zugespitat, bei Mamis tridentata ist die Eichel fast cylindrisch, stumpf. Bei Dasypus longicaudus bildet die Harnrölıre an ihıcr Mündung eine konische Hervorragung und linter derselben sind zwei knotige, halbkugelförmige Auschwellungen. Die Eichel ist mit einzelnen Härchen besetzl. Der Ruthenzellkörper erscheint bei diesen Thier auf dem Querdurchschnitt halbnondförmig. In der Konkavität verlauft die mit ihrem schwammigen Körper umgebene Harnröhre. Die fibrose Hülle des Ruthenzellkörpers ist schr dick, und nicht durch eine del Länge nach verlanfende Scheidewand in zwei seitliche IIälften getheilt, sondern es finden sich sechs bis sieben fibrose Scheidewände, die der Länge nach verlaufen, und an die fibrose Hülle des Ruthenzellkörpers befestigt sind; eine Bildung, dic bis jetzt bei keinem Thier beobachtet ist. Bei Manis tridentata verlauft im Ruthenzellkörper der Länge nach eine fibrose Scheidewand.

Bei den Faulthieren ist die Ruthe sehr klein, und beim dreizehigen Faulthier an der untern Seite der Länge nach gespalten; es öfnet sich also die Harmröhre an der Wurzel der Ruthe. Bei Choloepus didactylus ist die Eichel in zwei Lippen getheilt, und zwischen beiden Lippen liegt die Mündung der Harnröhre. Der Ruthenzellkörper ist durch eine fibrose Seheidewand in zwei seitliche Hälften getheilt.

Der Ruthenknochen fehlt den Edentaten.

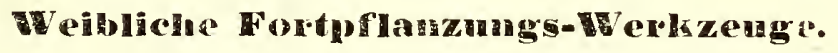

Dic Ovarien sind eiförmig, glatt, ohne Hervorragungen, bei Orycteropus mehr kugelförmig. Die vom Bauchfell gebildete serose Höhle, von wclcher bei manchen Säugthicren der Eierstock wie von einer Scheidenhaut umschlossen 
wird, findet sich bei den Faulthieren und bei Myrmecophaga, steht aber sehr weit offen; bei Dasypus ist diese serose IIöhle mehr abgegrenzt und am Rande von der Fallopischen Röhre eingefasst.

Die Fallopischen Röhren dehnen sich an ilrem freien Ende schnell in eine elliptische Platte aus, die bei Myrmecophaga nicht nur am Rande, sondern auf ilrer ganzen Oberfläche mit hahnenkammförmigen Lappen besetzt ist. Die Fallopischen Röhren bilden schlangenförmige Windungen, ohne zu einem Knäuel aufgerollt zu sein.

Durch die Gestalt der Gebärmutter unterscheiden sich sowohl die pflanzenfressenden als die insektenfressenden Edentaten von den meisten übrigen Säugthieren, und schliessen sich an den Menschen und die Affen an. Die Gebärnutter ist nämlich einfach, nicht in zwei Hörner abgetheilt und ziemlich dickwandig; so verhält es sich bei den Faulthieren, Gürtelthieren, Ameisenfressern, Manis, doch ist die Gebärmutter sehr in die Länge gezogen, und erhält dadurch mehr Aehnlichkeit mit der kindlichen Form des menschlichen Uterus und des Uterus der Affen. Eine Abtheilung in Körper und Hals ist nicht wahrzunehmen. Schon v. Bär und Rudolphi haben gefunden, dass bei dem dreizehigen Faulthier ein doppelter Muttermund, ein reehter und ein linker, vorkomme; so fand ich es auch nicht nur beim dreizehigen Faulthier (Bradypus cuculliger) und bei Choloepus, sondern auch bei allen drei Arten von Myrmecophaga. Die Hölle der Gebärmutter ist einfach.

Bei Myrmecophaga jubata fand ich neben dem selir engen, doppelten Muttermund noch zwei Oeffnungen, welche kaum eine Borste aufnehmen konnten, aber der Zustand der Theile erlaubte mir nicht auszumitteln, wohin diese engen Oeffinungen führen.

Bei Dasypus ist der Muttermund einfach.

Die Gebärmutter des Orycteropus capensis weicht ab von der Bildung, die man bei den übrigen Edentaten antrifft. Es findet sich zwar ein doppelter Muttermund, ein rechter und ein linker, aber jeder Muttermund führt in eine besondere Gebärmutter, wie bei den meisten Nagethieren. Eigentlich fehlt der Körper der Gebärmutter, und jedes Horn öffnet sich für sich in die Scheide. Jedes Horn hat eine Länge von $2 \frac{1}{2}$ Z Zoll. Die innere Oberfläche der Gebärmutter der Edentaten hat starke, dichtstehende Längefalten.

Die sehr kurze Harnröhre der Edentaten öffnet sich unmittelbar vor dem Muttermund, und geht dadurch in einen Kanal über, der zugleich als Scheide 
und als Fortsetzung der Harmöhre betrachtet werden kann. Die innere Oberfläche der Scheide ist glatt. Bei Orycteropus öffnet sich die Harurölre an der äussern Mündung der Scheide, und diese beiden Gänge vereinigen sich in einen selr weiten, gegen vier Zoll langen Kanal, der nach aussen sich öfnet. Zwischen ihm und der Scheide bildet die Schleimhaut eine ringförmige Klappe. Wo dieser weite Kanal (Vestibulum) nach aussen sich öfuet, liegt auf beiden Seiten eine Tasche, welche über einen halben Zoll tief ist. Zwischen diesen beiden Taschen ragl ein breiter Lappen hervor, welcher die Clitoris darstellt. Inı Grunde der Tasche sieht man in Einer Reihe liegend füuf Mündungen von den Ausführungsgängen einer röthlichen, aus zahlreichen Körnern zusammengesetzlen Drüse. Sie hat die Grösse eines Taubeneis nnd wird vou Muskelfasern bedeckt. Sie muss olne Zweifel als die Bartholinische Drüse angesehen werden, welche hier eine ansserordentliche Grösse erreicht hat. Auch bei Myrmecophaga tamandua fand ich zwei Bartholinische Driisen, eine auf jeder Seite. Sie öfhnen sich mil drei bis vier Oeffnungen nahe an äussern Ende des gemeinschaftlichen Ganges, der die Scheide und Harnröhre darstellt, und laben die Grösse einer Erbse.

Bei den Edentaten ist die Mündung der Genitalien getreunt von der Mündung des Mastdarms, jedoch durch einen schmalen Zwischenraum.

Die meisten Edentaten, wie die Faulthiere, Ameisenfresser bringen nur Eìn Junges zur Welt, doch von den Gürtelthieren ist es bekannt, dass sie melrere Junge zugleich werfen, obgleich die Gestalt der Gebärmulter nicht von den übrigen Edentaten abweicht.

Die Hüllen des Fötus sind mir nicht bekannt; bei dem dreizeligen Faulthier sind nach Carrs ${ }^{1}$ ) an dem Chorion mehrere Cotyledonen befestigt, die einen halben Zoll bis einen Zoll im Durchmesser lraben. Die Nabelschnm ist durch ihre Länge ausgezeichnet. Bei dem zweizehigen Ameisenfresser beschreibt Mayer ${ }^{2}$ ) die Placenta als einen dicken, rundlichen Kuchen.

Man kann die Gestalt der Gebärmulter der verschiedenen Säugthiere auf folgende Hauptormeu reduziren:

1. Einfache Gebärmutter mit einfachem Muttermund. Mensch, Affen.

1) Erläuterungstafeh zur vergleichenden Anatomie. Drittes Heft.

2) Analckten zur vergleichenden Anatomie. Zweite Sammlung. S. 54. 
2. Einfache Gebärmutter mit doppeltem (rechten und linken) Muttermund. Faulthiere, Ameisenfresser.

3. Gebärmutter mit zwei Hörnern. Maki (wo die Hörner noch sehr kurz sind), fleischfressende Thiere, Pachydermen, Delphine.

4. Doppelte Gebärmulter, jedes Horn der Gebärmutter öffnet sich durch eine besondere Mündung in die Scheide. Die meisten Nagethiere, die Beutelthiere, Orycteropus.

5. Zwei, gegen ihr inueres Ende erweiterte Röhren münden sich in eine Cloaca. Monotremen.

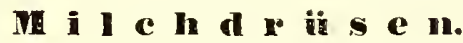

Die meisten Edentaten haben an jeder Seite der Brust eine Miichdrüse, jede ist mit einer Warze versehen. Bei Myrmecophaga didactyla kommt noch eine Milchdrüse an beiden Seiten des Bauchs vor; sie hängl nicht mit der körnigen Drüse an der Brust zusammen und ist viel kleiner als erstere. Die meisten Giirtelthiere haben nach D'Azara zwei Milchdrüsen, eine an jeder Seite der Brust, doch bei dem schwarzen Gürtelthier (Dasypus longicandus) kommt dazu noch eine in der Leistengegend. Die kleine Zahl der Zitzen ist auffallend bei den Gürtelthieren, da die kleinen Arten mehrere Junge (bis zehen) auf einmal zur Welt bringen.

Auch bei Orycteropus finden sich vier Zitzen, zwei am Bauche und zwei zwischen den hintern Füssen. 


\section{Erklärung der Abbildungen.}

Erste Tafel.

Die Zeichnung ist naeh zwei Thicren gemacht, welche Herr Baron v. Ludwig auf dem Cap ausstopfen liess, und an die Königl. Naturalien-Sammlung in Stuttgart schickte. Diese Abbildung wurde sehon in der Dissertation von JüGEr aus Stuttgart, welche unter meinem Präsidium erschien, bekannt gemaeht, ist jedoch hier naeh der Natur in manchen Einzelnheiten verbessert worden. Auch den ausgewachsenen Orycteropus, an welchem die anatomischen Untersuchungen angestellt wurden, wie so viele zoologische und vergleichend-anatomische Gegenstände verdanken wir dem Herrn Baron v. Ludwig.

\section{Zweite Tafel, a. \\ Manis tridentata, Focrllon.}

Das Thier, nach welchem die Abbildung gemacht ist, befindet sich in der zoologisehen Sammlung der Universität Tiibingen.

Manis javanica.

Naeh einem dureh Dr. Kollmans erhaltenen Exemplar.

Zweite Tafel, b.

Myrmecophaga tamandua, Cuv.

Naeh cinem ausgestopften Thier in der zoologischen Sammlung der Universitait Tuibingen. Es wurde aber bei der Abbildung auch ein in Weingeist aufbewahrter, fast reifer Fötus beniitzt. Auf der rechten Seite ist ein Theil des Schwanzes in natiirlieher Grösse dargestellt, um die schuppichte Hant desselben zu zeigen.

\section{Dritte Tafel.}

Erste Figur. Sehädel von Bradypus cuculliger Wagl. in natïrlicher Grösse. Die Suturen sind vollständig versehwunden.

Zweite Figur. Vordere Hälfte des Schädels von Bradypus didactylus von der Seite angesehen, in natïrlicher Grösse mit allen Zähnen. a) Zwischenkieferknochen. b) $O_{s}$ 
praenasale. c) Nasenbein. d) Oberkiefer. e) Thränenbein. f) Joehbein, wovon die hintere Hälfte abgebrochen ist, damit die hintern Backenzähne sichtbar werden. g) Stirnbein. h) Unterkiefer.

Dritte Figur. Schädel von Bradypus didactylus von obcn angesehen, in natürlicher Grösse. b) Os praenasale. c) Nasenbein. d) Stimbein. e) Thränenbein. f) Jochbein. g) Seitenwandbein. h) Hinterhauptsbein.

Vierte Figur. Schädel von Dasypus sexcinctus Limn. (Dasypus setosus, Max. Prinz von Neu-Wied), von der Seite angesehen, in natïlicher Grösse. a) Zwischenkieferknochen, einen Zahn tragend. b) Nasenbcin. c) Oberkiefer. d) Thränenbein. e) Jochbein. f) Stimbein. g) Seitenwandbein. h) Schläfenbcin. i) Hinterhauptsbein. k) Unterkiefer. Fünfte Figur. Sehädel von Dasypus sexcinctus Linn., von unten angesehen, ohne Unterkiefcr. a) Zwischenkieferbein. c) Oberkiefcr. l) Gaumenbein. i) Hinterhauptsbein. k) Knoehenblase des Schläfenbeins. Man erkennt in dieser Abbildung die Gelenksfläche, welche am vordern Rande des grossen Hinterhauptsloches angebracht ist, zur Artikulation mit dem Zahnfortsatz des zweiten Halswirbels. Diese Gelenksfläehe kommt auch dem Riesengürtelthier (Priodontes gigas) zul.

Der Schädel, welcher in der vierten und fünften Figur dargestellt ist, wurde von Rengger aus Paraguay mitgebracht, ist jetzt Eigenthum der anatomischen Sammlung in Zürich, und wurde mir zur Benuitzung für diese Sehrift von Hente in Zürich mitgetheilt.

\section{Vierte Tafel, a.}

Fig. 1. Sehädel von Orycteropus capensis von der Seite, um die Hälfte verkleinert. a) Zwischenkieferknoehen. b) Nasenbein. c) Oberkieferknochen. d) Thrïnenbein. e) Joehbein. f) Stirnbein. g) Seitenwandbein. h) Sehläfenbein. i) Hinterhauptsbein. k) Unterkiefer. Fig. 2. Schädel des Oryctcropus capensis von oben, um die Hälfte des Durchmessers verkleinert. a) Zwischenkieferknochen. b) Nasenbein. e) Oberkieferknoehen. f) Stirnbein. g) Seitenwandbein. h) Schläfenbein. i) Hinterhauptsbein.

Fig. 3. Schädel des Orycteropus capensis von unten, um die Hälfte verkleinert. a) Zwischenkieferbein. b) Ein kleiner Theil des Pflugscharbeins, das am knöehernen Gaumen sichtbar ist. c) Oberkieferknoehen. 1) Gaumenbein. i) Hinterlauptsbein.

Fig. 4. Der vorletzte Backenzalın des Oryctcropus capensis. In natürlicher Grösse.

Fig. 5. Grundfäche des vorletzten Backenzahns von Orycteropus capensis. Um das Doppelte im Durchmesser vergrössert, um die Mündungen der Röhren zu zeigen, aus welehen die Zähne dieses Thiers zusammengesetzt sind.

\section{Vierte Tafel, b.}

Skelet von Myrmecophaga jubata. Ein Fü̈ftheil der natïrlichen Grösse. Aus Surinam. Das Skelet ist in der vergleichend-anatomisehen Sammlung der Universität Tübingen. Skelet 


\section{$-10 \%-$}

von Priodontes gigas (Riesengïrtelthier). Ein Fünftheil der natiirliehen Grösse. Das Skelet, wie aueh die ausgestopfte Haut dieses Thiers ist in der zoologisch-anatomisehen Sammlung der Universitït und wurde dureh Herrn Kapplen in Surinam erhalten.

\section{Fünfte Tafel.}

Fig. 1. Sehädel von Myrmecophaga tamandua Cuv, in natürlieher Grösse, von der Seite. a) Zwisehenkieferknoehen. b) Oberkieferknoehen. e) Nasenbein. d) Thrïnenbein. e) Joel bein. f) Stirnbein. g) Seitenwandbein. h) Sehlafenbein. i) Hinterhauptsbein. 1) Unterkiefer.

Fig. 2. Selı̈̈del von Myrmecophaga tamandua von unten. a) Zwisehenkieferknoelıen. 1) Oberkieferknoehen. e) Joehbein. k) Gaumenbein. m) Keilbein.

Fig. 3. Sehïdel von Myrmecophaga didactyla von der Seite, in natiirlieher Grösse. a) Zwisehenkieferknoehen. b) Oberkieferknoehen. e) Nasenbein. f) Stirnbein. g) Seitenwandbein. i) Minterhauptsbein. 1) Unterkiefer.

Fig. 4. Sehädel von Myrmecophaga didactyla von oben, in natïrlieher Grösse. e) Nasenbein. f) Stirnbein. g) Seitenwandbein. i) Hinterhauptsbein.

Fig. 5. Sehädel von Myrmecophaga didactyla von unten, in natiolieher Grösse. a) Zwisehenkieferknoehen. b) Oberkieferknoehen. k) Gaumenbein. m) Keilbein. i) Hinterhauptsbein.

\section{Sechste Tafel.}

Erste Figur. Sehädel von Manis javanica von der Seite. Natiilliehe Grösse. a) Zwisehenkiefer. b) Nasenbein. c) Oberkieferknoehen. d) Unterangenhöhlenloeh. f) Stirnbein. g) Seitenwandbein. h) Sehläfenbein. i) Hinterhauptsbein. k) Unterkiefer.

Zweite Figur. Sehädel von Manis jacanica von oben. a) Zwisehenkiefer. b) Nasenbein. c) Oberkieferknoelıen. f) Stirnbein. g) Seitenwandbein. Das Original, naelı welehem diese beiden Zeiehnungen gemaeht sind, wurde mir von LeucksrT in Freiburg giitigst mitgetheilt.

Dritte Figur. Querdurehselınitt eines Zalms von Orycteropus capensis, bei 250 faelıer Vergrösserung. Es sind Prismen, in deren Aehse ein Kanal verlauft, der hier sehwarz erseheint.

Vierte Figur. Zunge von Myrmecophage tamandua mit den hormartigen Spitzen. Vergrössert.

\section{Siebente Tafel.}

Speieheldrïsen des sehwarzen Gürtelthiers (Dasypus peba Desm.). In natiirlieher Grösse.

aa) Die Unterkieferdrüse, die sieh bis zu dem grossen Brustmuskel erstreekt.

bb) Die Speielıelblase der Unterkieferdriise mit dem Ausfiulıungsgang. Auf der linken Seite befindet sielı diese Speichelblase und die Drïse, zu welelıer sie gehı̈rt, noeh ganz in der Lage; anf der reelten Seite ist die Unterkieferdrüse etwas von der 
Speichelblase cntfernt worden, um die Ausfiihrungsgänge dicser Speicheldrïse, welche in die Speichelblase sich ergiessen, sichtbar zu machen.

c) Die Ohrspeichcldriise, welche bei dicsem Thier sehr klein ist, mit ihrem Ausführungsgang.

d) Die Unterzungendrüse.

e) Eine kleine acinose Drüse vor der Ohrspeicheldrüse am Ausführungsgang derselben. (Parotis accessoria).

\section{Achte Tafel.}

Erste Figur. Magen von Dasypus peba in natürlicher Grösse. Es ist daran ein breiter Sehnenstreifen zu bemerken, wie am Magen vieler Vögel.

Zwcite Figur. Gehirn von Bradypus cuculliger Wagl. in natiirlicher Grösse.

Dritte Figur. Gehirn von Dasypus peba, von oben angesehen, in natiirlicher Grösse.

Die Hemisphären des grossen Gehirns zeigen keine Windungen. 


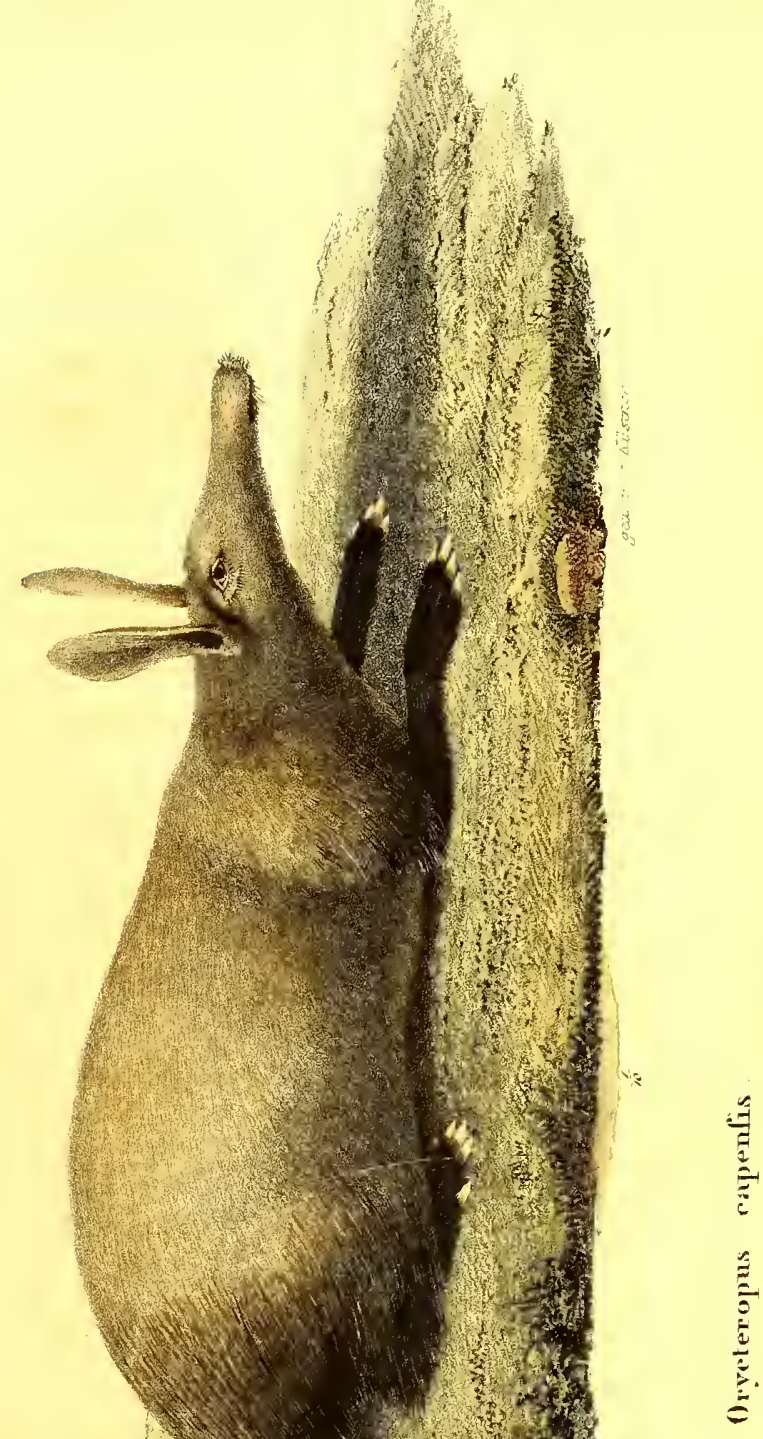





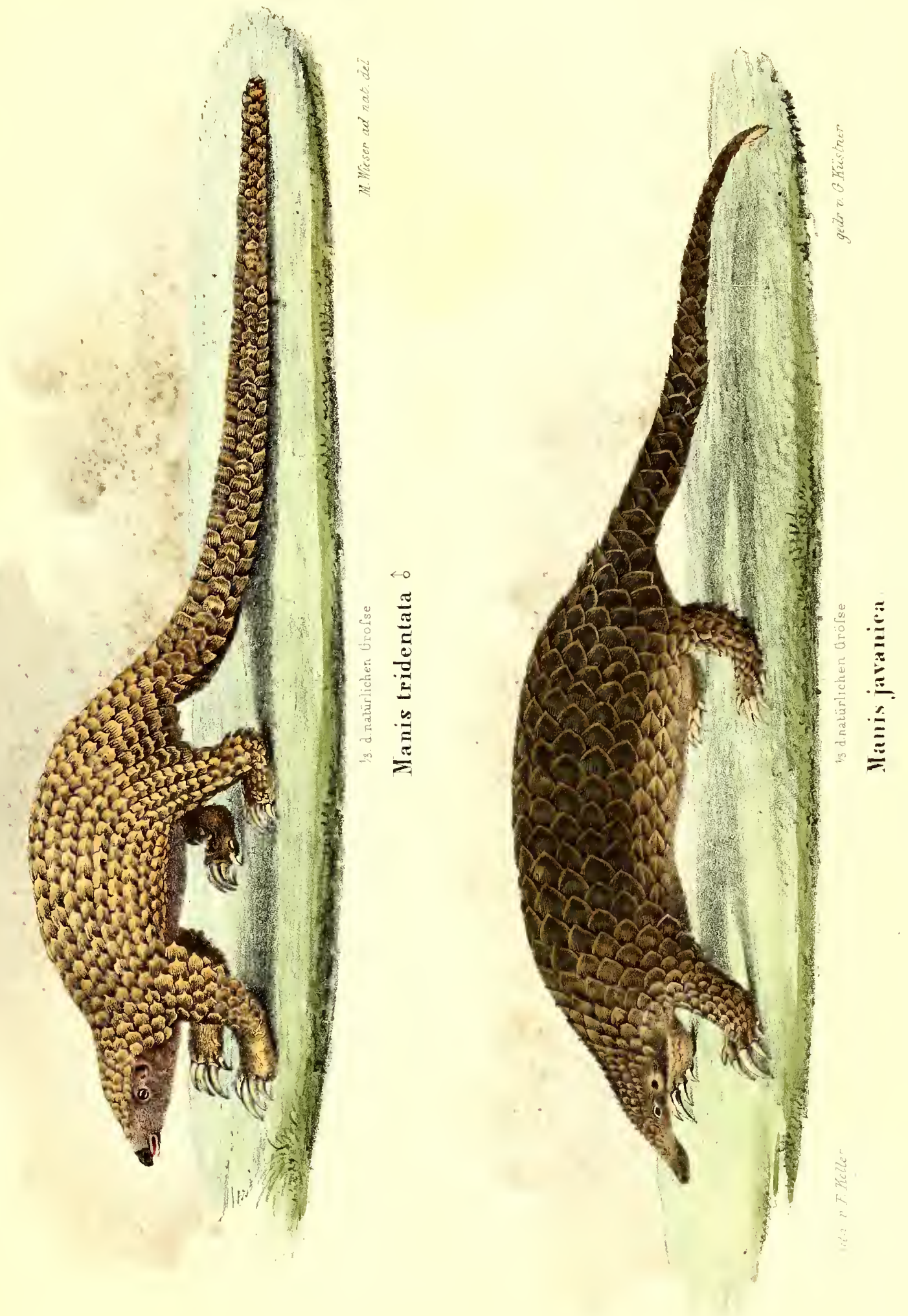





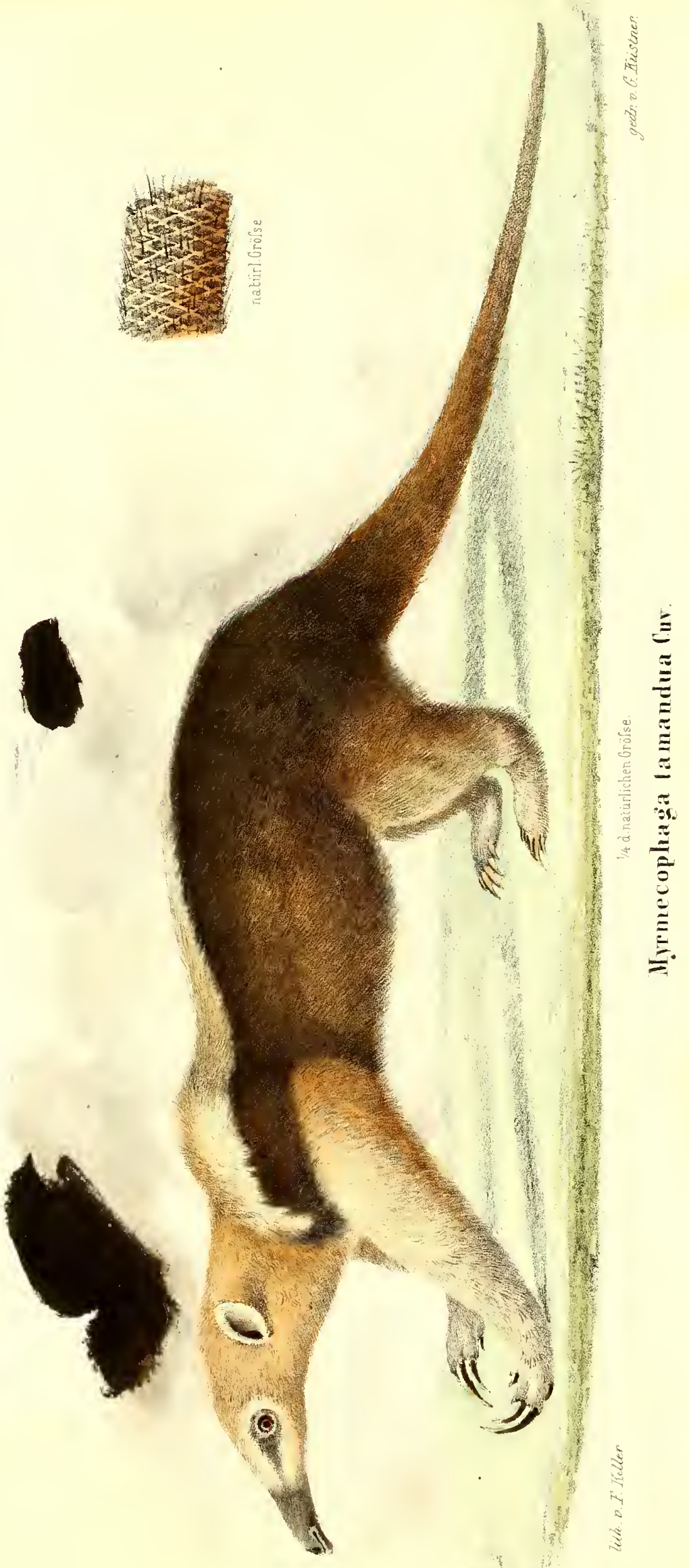


a. 

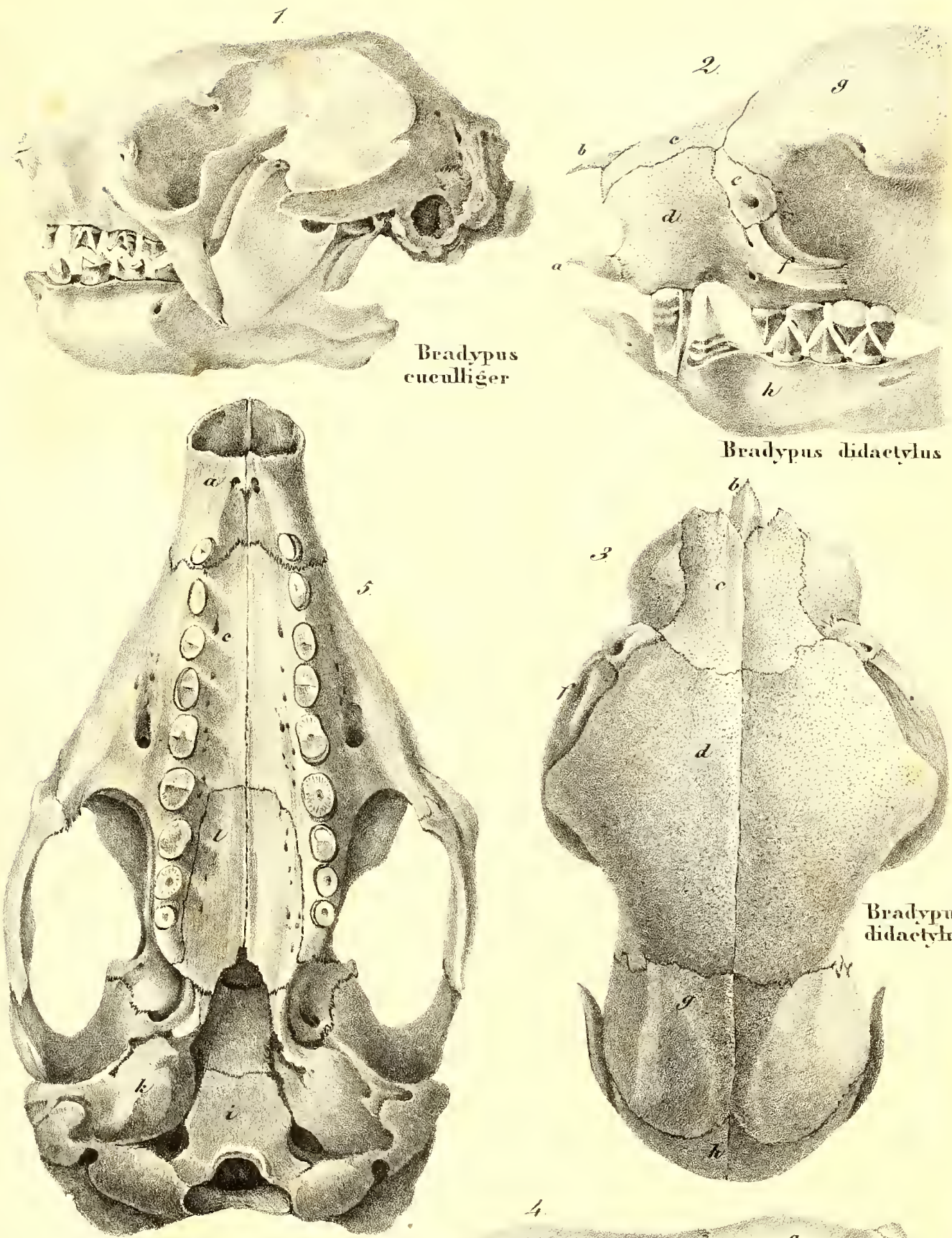

Bradypus didactolus

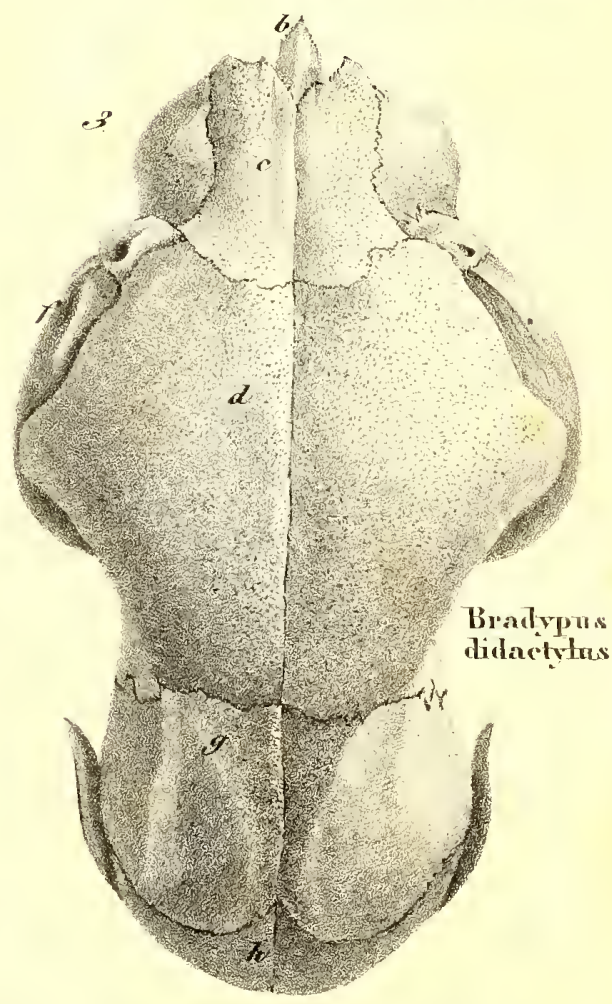

4

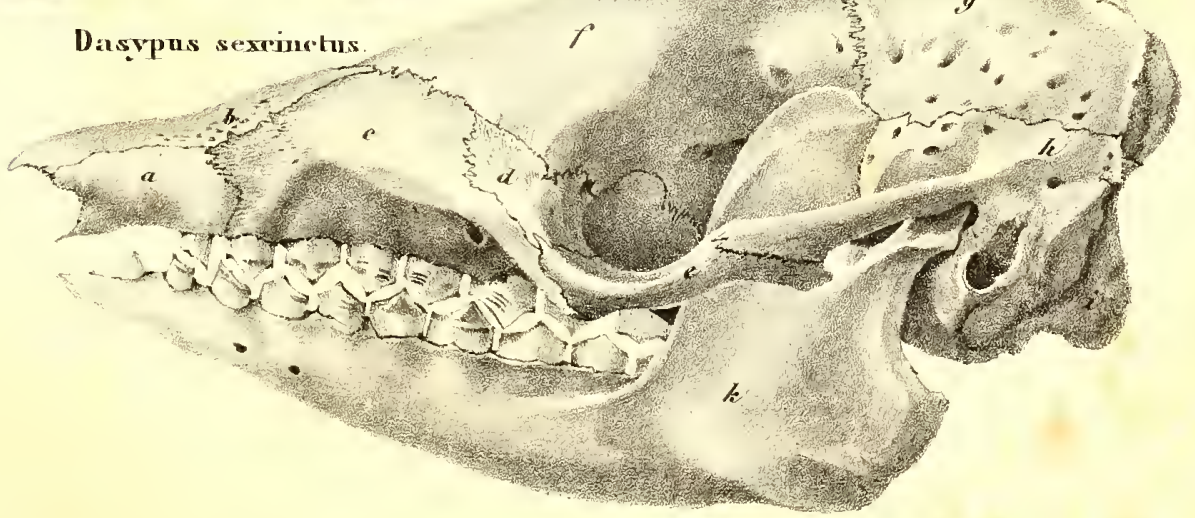


. 

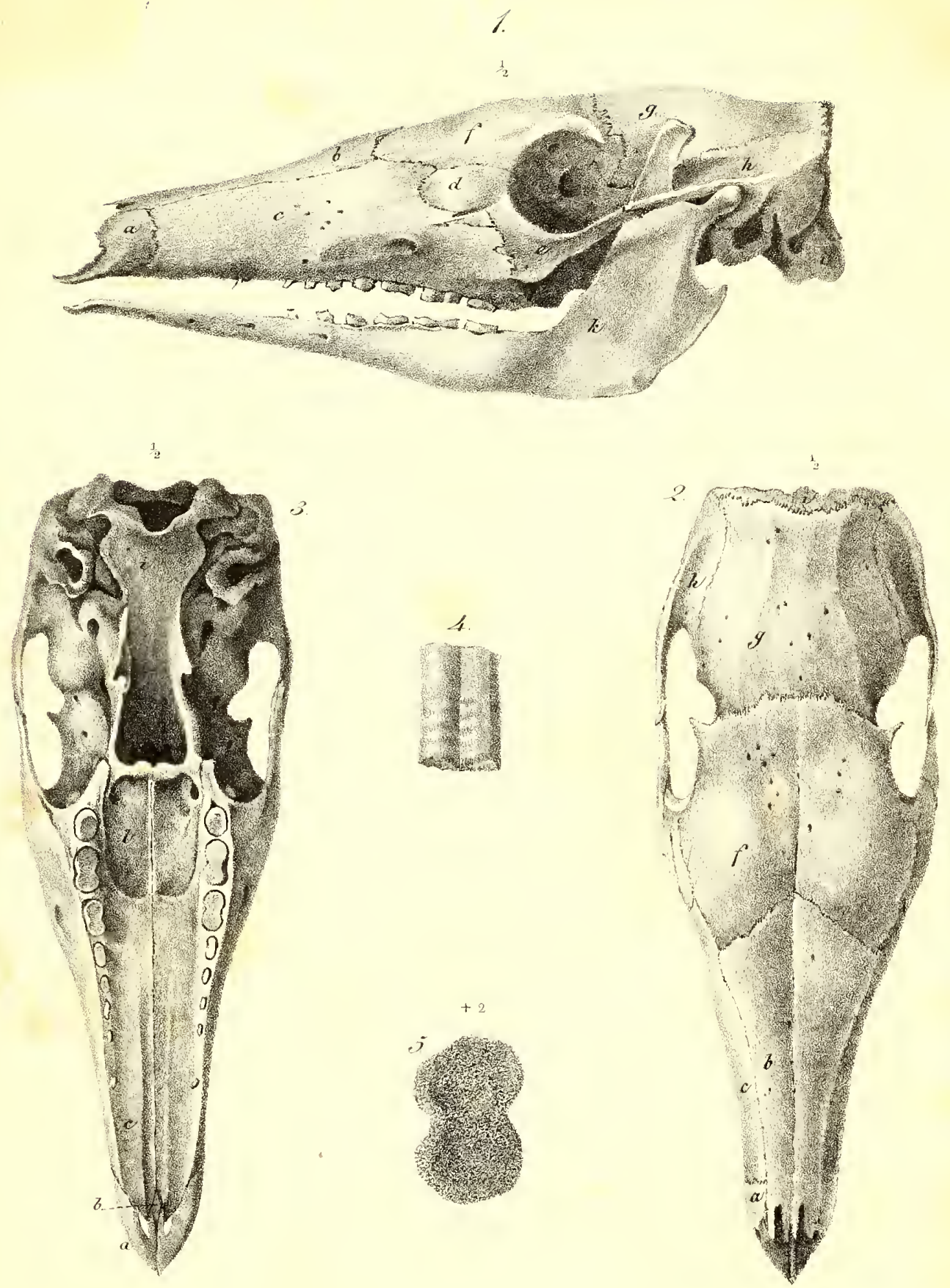

Orycteropus appeusis 
$$
\text { , }
$$ 



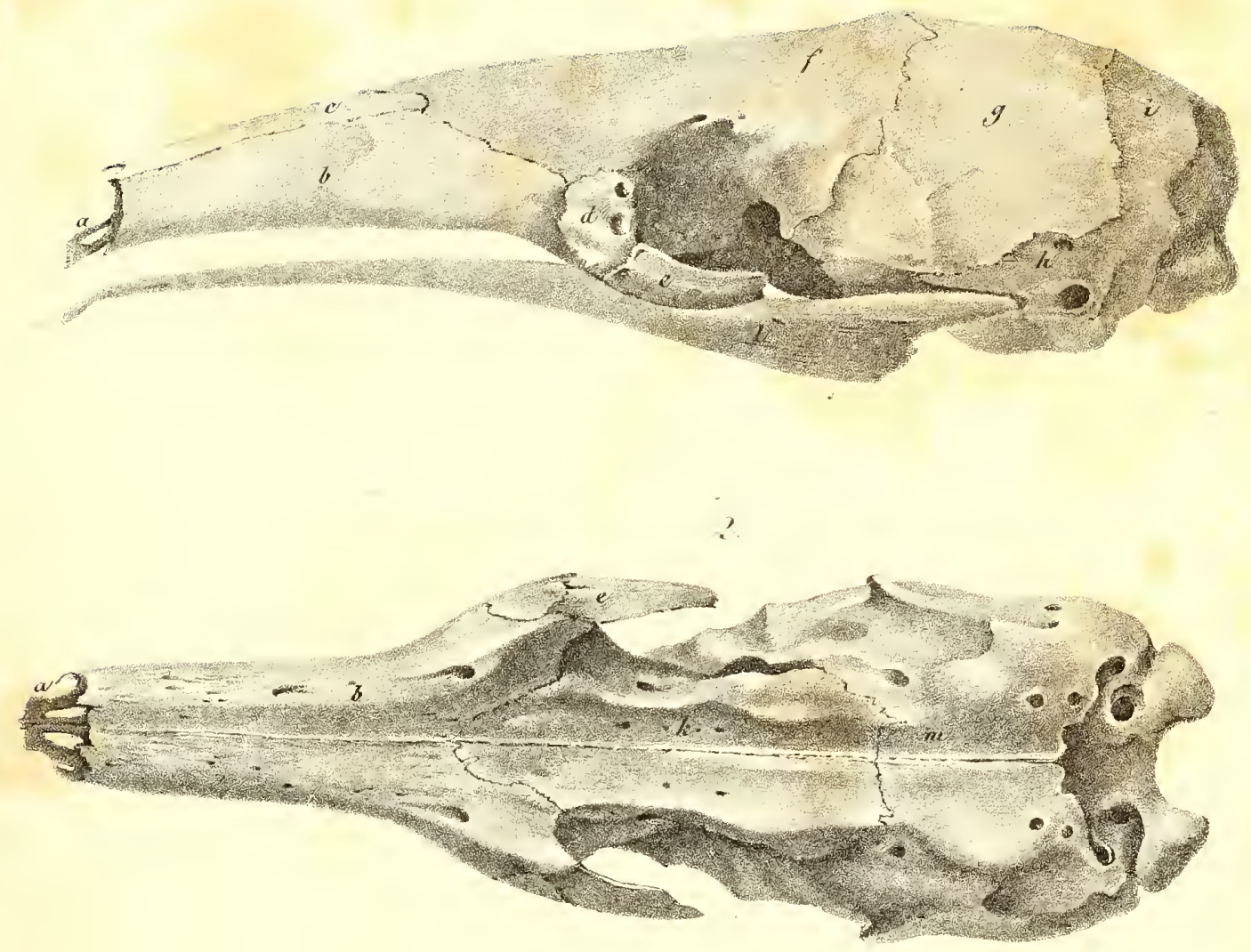

Mrrmecophaga tamandua
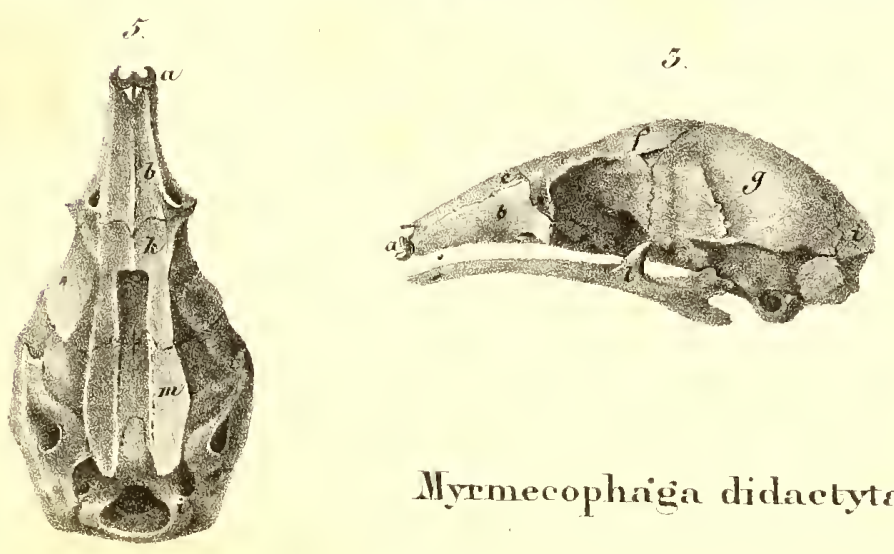

Mysmecophriga didactyta

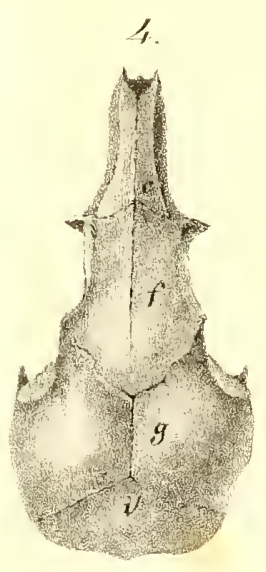



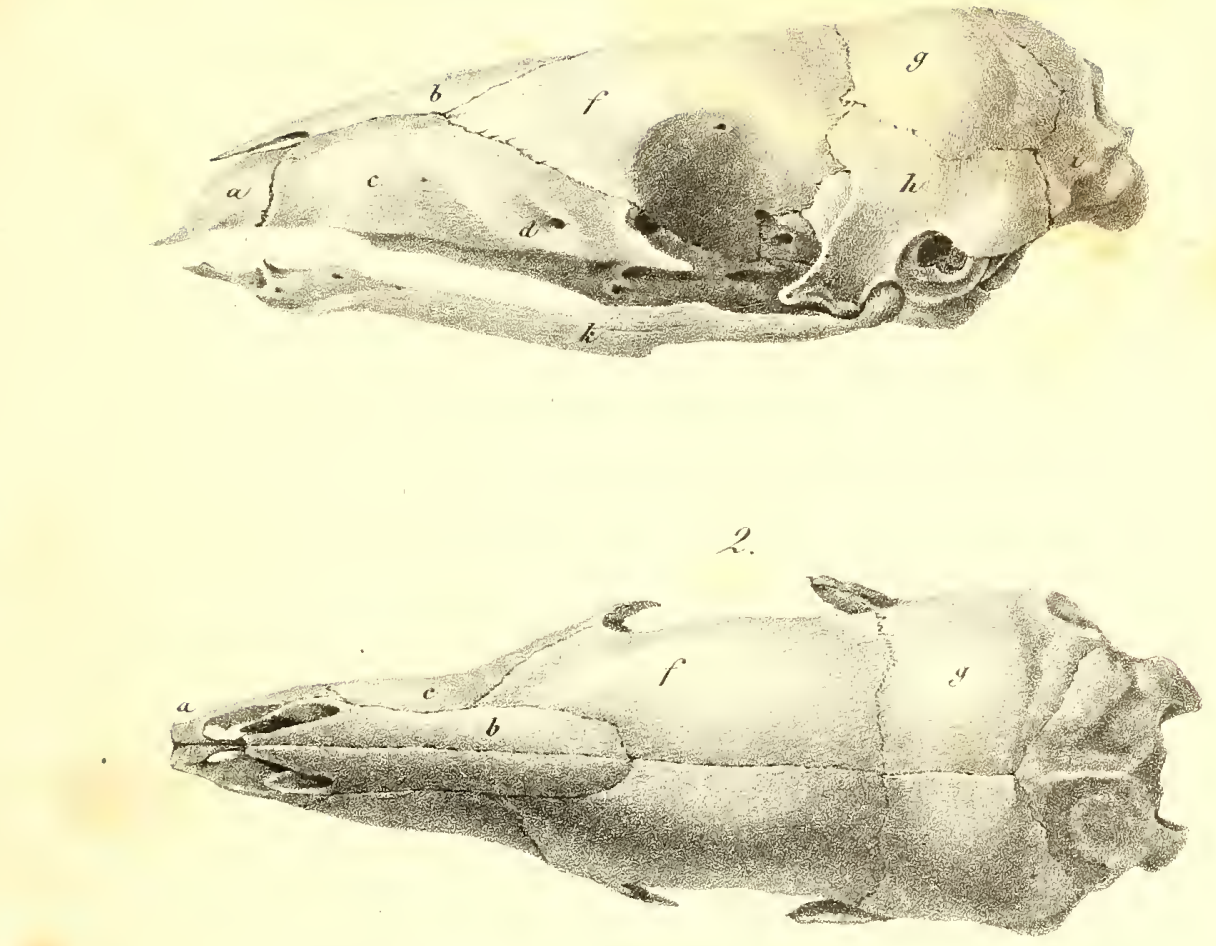

Mamis javanica

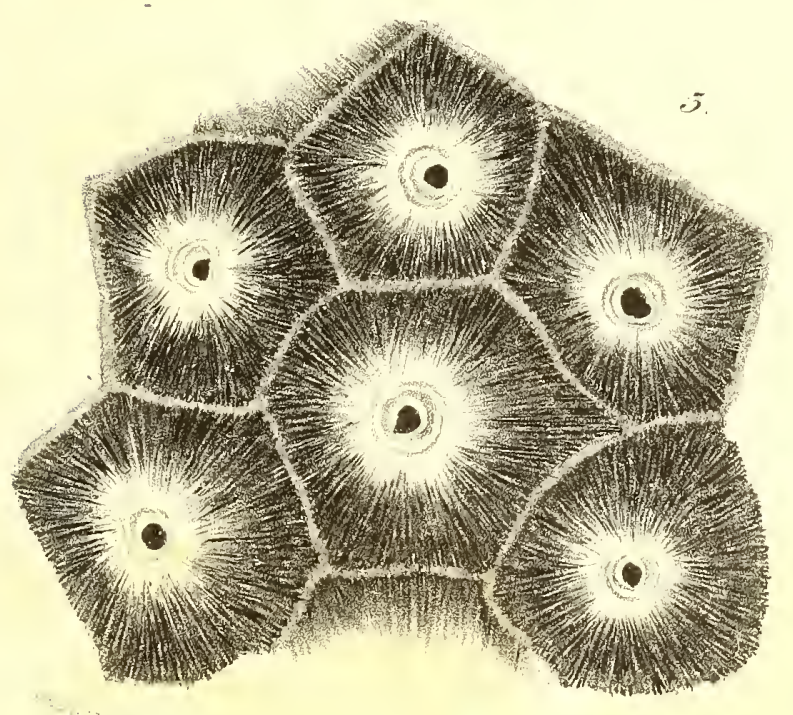

Orycteropus capenfis

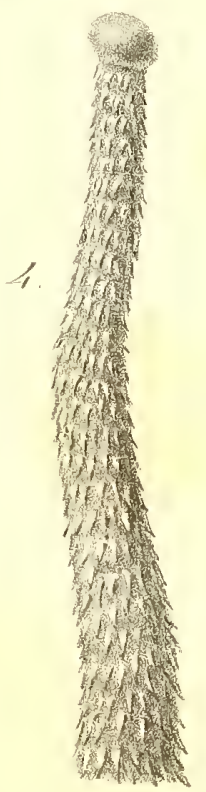

Zunge ron Mrameeoplaga tamandua 
Taf VII

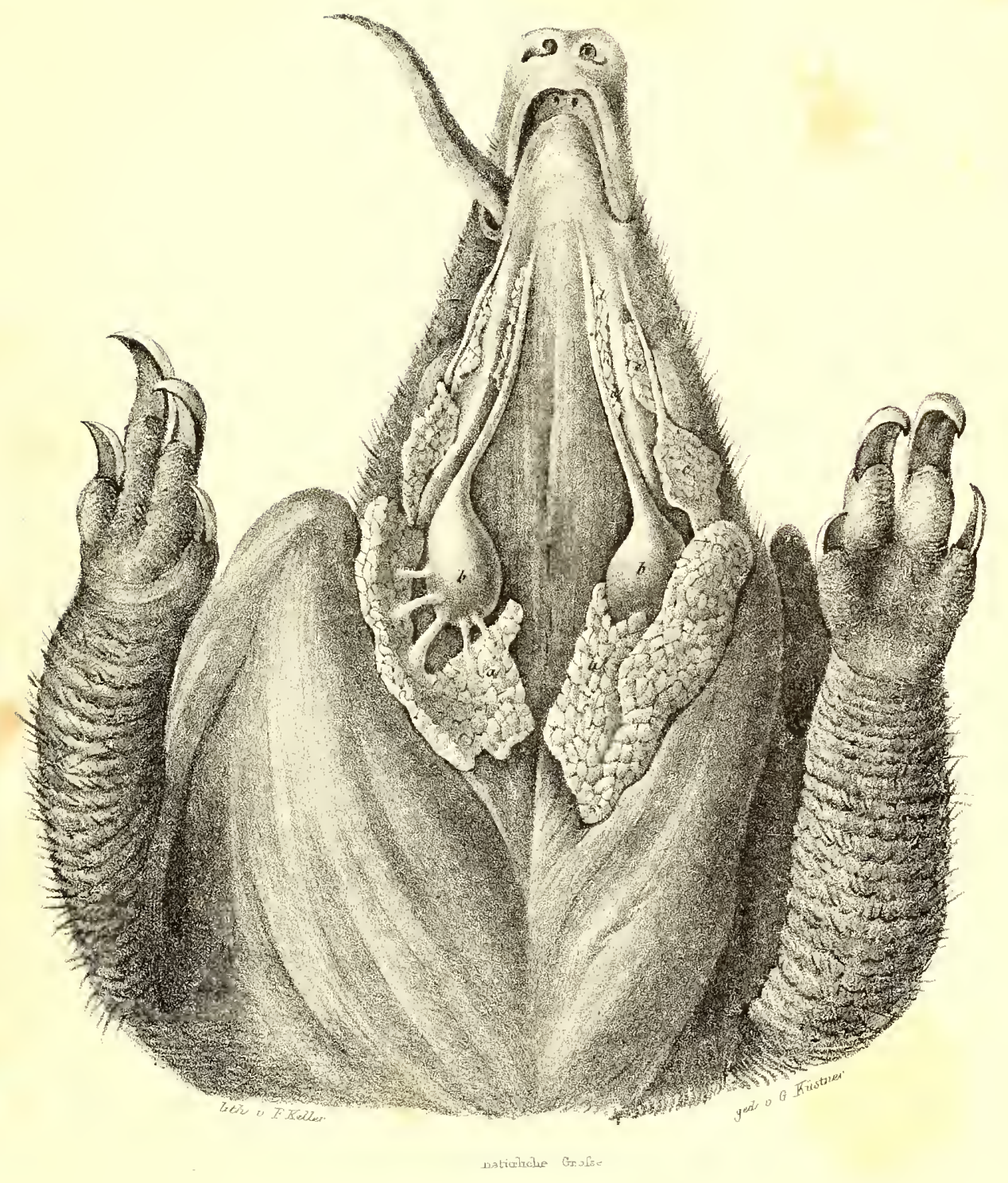

Dasspus peba 
Taf. TIII.

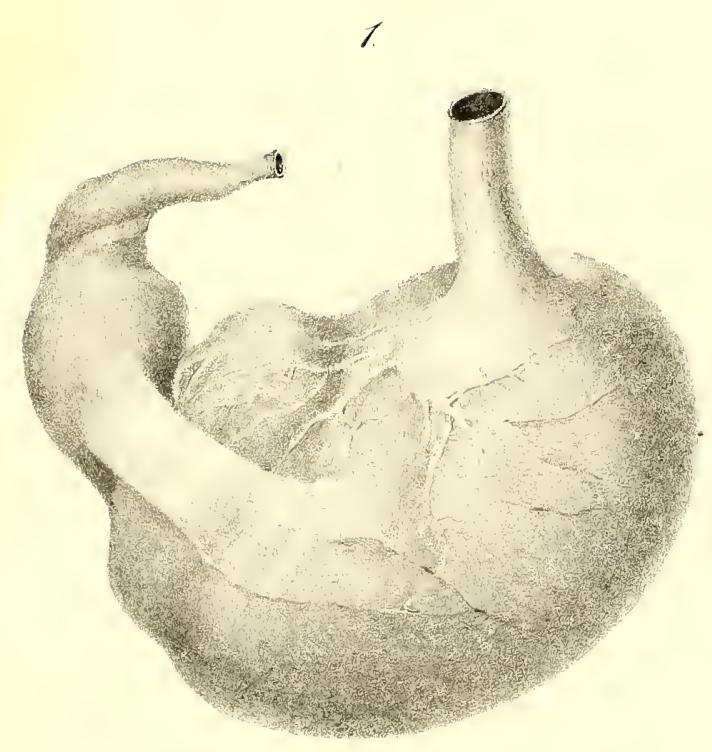

\section{Dasypus pebat}

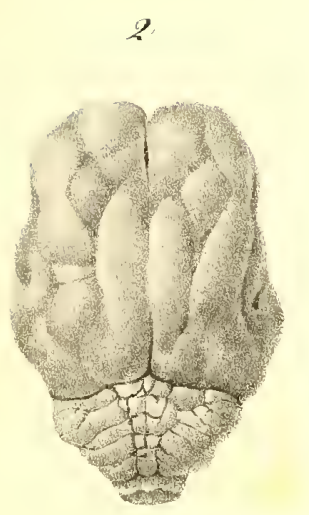

Bradypus rumbliger

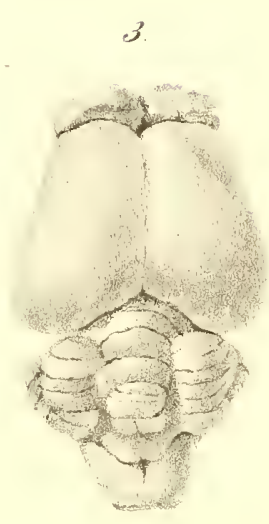

Dasypus peba. 
. 

Bei C. Fr. Fues in Tỉbingen sind erschienen und durch alle Buchhandlungen zu beziehen:

Autenrieth, J. H. F. v., weil. Kanzler und Professor, und H. Fr., Dr. Prof., Gerichtlichlmedicinische Aufsätze und Gutachten, auch u. d. T.: Forensia von H. F. Autenriellı. Eı'ster Theil. gr. 8. 1846. n. 3 fl. $48 \mathrm{kr} \cdot, 2$ Rihle $7^{1 / 2}$ ngr.

In halt. I. Die Entstehung der Strafgesetzgebung aus dem wechselseitigen Einfluss des Racheinstinkts und des geselligen Triebs"des Menschen v. F. A. - Il. Ueber die natïrlichen Grund’lagen des Strafrechts, v. F. A. - III. Begrïndung der Todesstrafe in den natïrlichen Verhältnissen der Sthatsgesellschaft, von F. A. - IV. Zurechnungsfähigkeit betreffende Gutachten. I. Unzurechnungsfahigkeit anssprechende Gutaehten. a) in Hinsielnt der Verwaltung des Vermögens. b) wegen Tüdtung und Versnchs der Tödtung. - II. Gutachten, welehe unter gradwciser Annähermn⿳亠口冋口 bald zum einen, bald zum andern Zustand weder gänzliche Unzurechnungsfühigkeit, noch rolle Zurechnıngsfähigkeit bestimmen. a) wegen Injurien. b) wegen Brandstiftung. e) wegen Versuchs der 'T̈̈̈dtung und vollbrachter 'Tödtung. - III. Zurechnungsfihigkeit crkennende Gntachten. a) weg’en Tüłtung. - V. Gutachten über Fälle, bei welcben Kindsmord constatirt werden soll. a) Tödtung von Neugeborenen betreffend. b) Tödtung nach der Geburt durch Verwahrlosung. - V1. Gutachten ïber Fälle von Körperbeschädigung. a) wegen Dammum permanens. b) wegen tödtlicher Verletzmng. - VII. Ređe über die Bestrafung der Kunstfehler der Aerzte, von F. A.

Antenrieth, J. H. F. v., Rede über das Gedächtniss, gehalten bei der Austheilung der akademischen Preise am 6. Novbr. 1846. gr. 8. gcl.

n. $15 \mathrm{kr}$., 5 ngr.

Moln1, H. v., Dr. Prof., Mikrographic, oder Aulcitung zur Kenutniss und zun Gebrauche des Mlikroskops. Mit 6 lithgr. Tafeln. gr. 8. 1846. gelı. 4 fl. 24 kr., oder 2 Thlr 18 ngr.

Inhalt. Von der Grenze des Sehens mit blossen Ange. - Das cinfache Mikroskop. - 1)as zusammengesetzte Mikroskop. - Das Dissektionsmikroskop. - Das Sommenmikroskop, das Gasmikroskop und das photoelectr. Mikroskop. - Das kadadioptr. Mikroskop. - Dic mikroskop. Beobachtung. Die mikrometr. Messung. - Das Zeichnen mikrosk. Objekte. - Beriehtigung'en. - Erklärung der Tafeln.

DIoln, H. v., Dr. Prof, Vermischte Sclıriften botanischen Inhalts. Mit 13 lithogr. I'afeln. gr. 4. 1846. geh.

5 fl. 24 kr., oder 3 Thli 10 ngr.

Inhalt. I. Untersuchung der Frage: welche Artorität soll den Gattungsnamen der Pflanzen lecigegeben werden? - II. Ueber die Symmetric der Pflanzen. - III. Bcobachtungen iiber die Umwandlung von Antheren in Carpelle. - IV. Ueber die männlichen Blïthen der Coniferen. - V. Ueber die fibrosen Zellen der Antheren. - VI. Einige Bemerkungen über die Entwicklung und den Ban der Sporen der "eryptogamischen Gewächse. - VII. Ueber die Entwicklnng der sporen vou Anthoceros laevis. - VIII. Morphologisclie Betraebtungen ïber das Sporangium der mit Gefissen verselınen Cryptogamen. - IX. Ueber den Bar des Stammes der Bammfarne. - X. Ueber den Bau des stammes von Isoëtes lacustris. - XI. Ueber den Ban des Palmenstanmes. - XII. Untersuchungen ïlser den Mittelstock von Tamus Elephantipes. - XIII. Ueber den Bau des Cyeadecnstamms. - XIV. Entersnehungen iiber die Entwicklung des Korkes und der Burke auf der Rinde der liammartigen Dicotylen. - XV. Sind die Lenticellen als Wurzelknospen zu betrachten? - XVI. Untersuchungen ülser dic Lenticellen. - XVII. Ueber dic Spaltöffnungen auf den Blättern der P'roteaceen. - XVII. Ueber dic Entwicklung der Spaltöttinungen. - XIX. Ueber die Cuticula der Gewäclıse. - XX. Lcber den Ban der grossen getüpfelten Fiefässe von Ephedra. - XXI. Einige Bemerkungen ïber den Bau der getïpfelten Gefässe. - XXII. Leber den Bau der Ringgefässe. - XXIII. Anatomisehe Untersnchungen ï̉ser die poröscu \%ellen von Spagnum. -- XXIV. Ueber den Bau der vegetabilischen Zellmenbran. - XXV. Einige Beobachtumgen iiber die blaue Färbung der vegetabilisehen Zelhmembran durch Jod. - XXVI. Untersuchnmgen ïber die anatomischen Verhuiltnisse des Chorophylls. - XXVIl. Ueber dic Vermelnung der I'flanzenzellen dureh.Theilung. - XXVIII. Ucber die Reitzbarkeit der Blätter von Robinia. - XXIX. Untersuchungen ïber die winterliche Färbung der B]:̈tter. - XXX. Ueber den Einfuss des Borlens auf die Vertheilung der Alpcnpflanzen. - XXXI. Einige Bemerkungen über die Grössenbestimmung mikroskopischer Objekte.

Mohl, H. v., Dr. Prof., Dr. Juslus Liebigs Verhältniss zur Pflanzenphysiologie. gr. 8. 1843. geh.

n. 36 kr., 12 ngr.

Quenstedt, F. A., Prof., Petrefaktenkunde Deutschlands. Mit besonderer Rücksicht auf Würtemberg. 6 Hefte. Text in gr. 8. Allas dazu fol. Auch unter deın Titel: Die Cephalopoden. Mii einem Atlas von 36 Tafeln in folio. 1846-1849.

16 fl. 12 kr., oder 10 'Thlr. 



(1) 1010
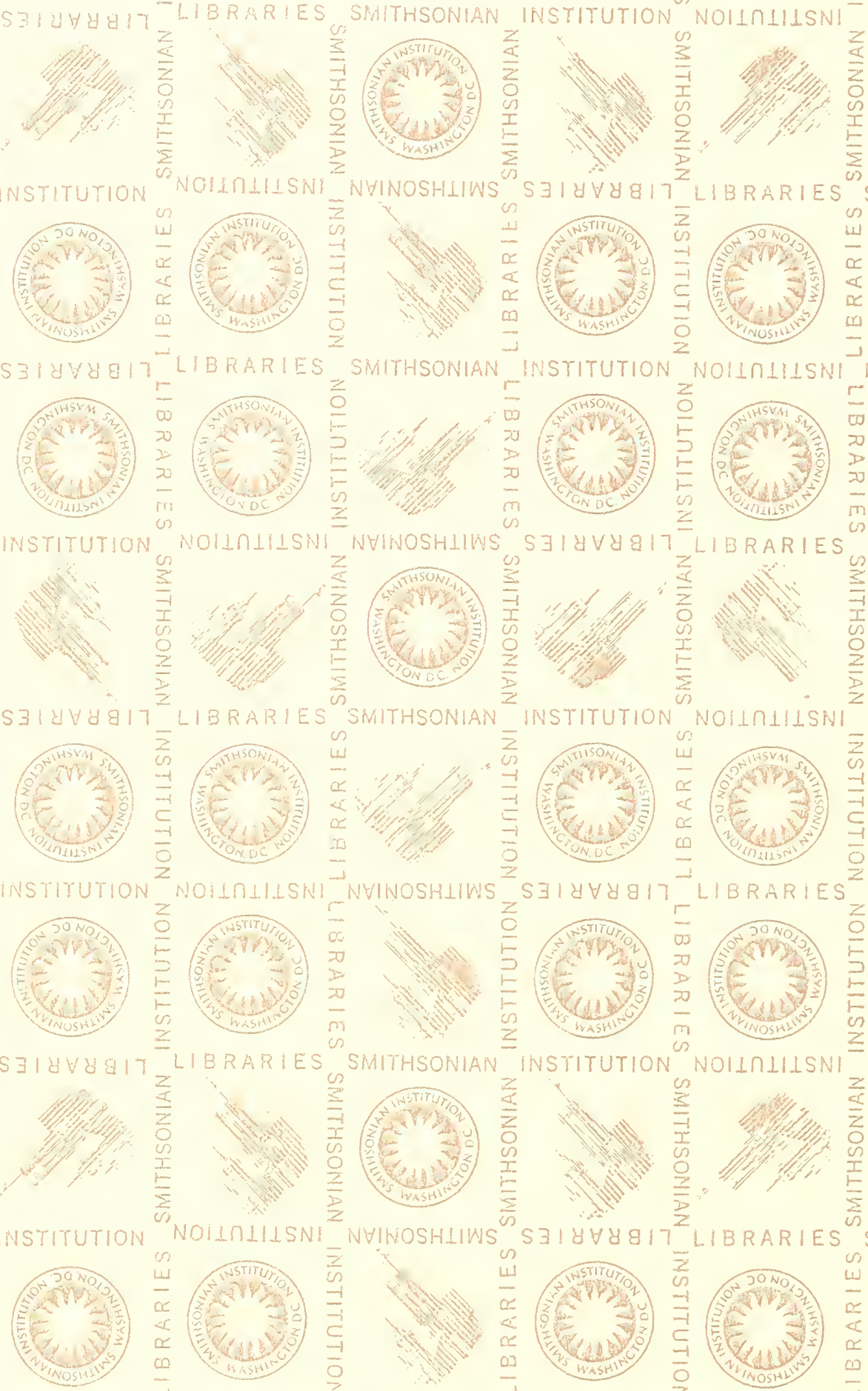
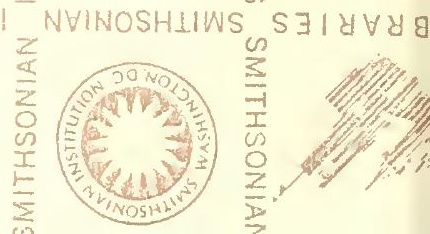

SM
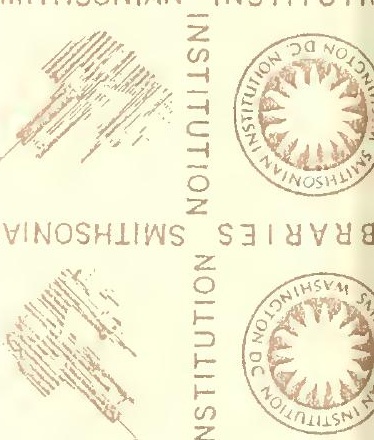

誌
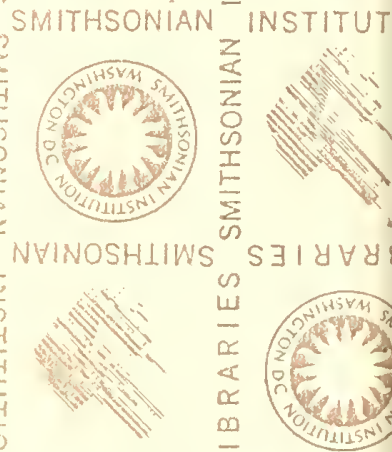

$S \exists 1$ y $\forall 88$
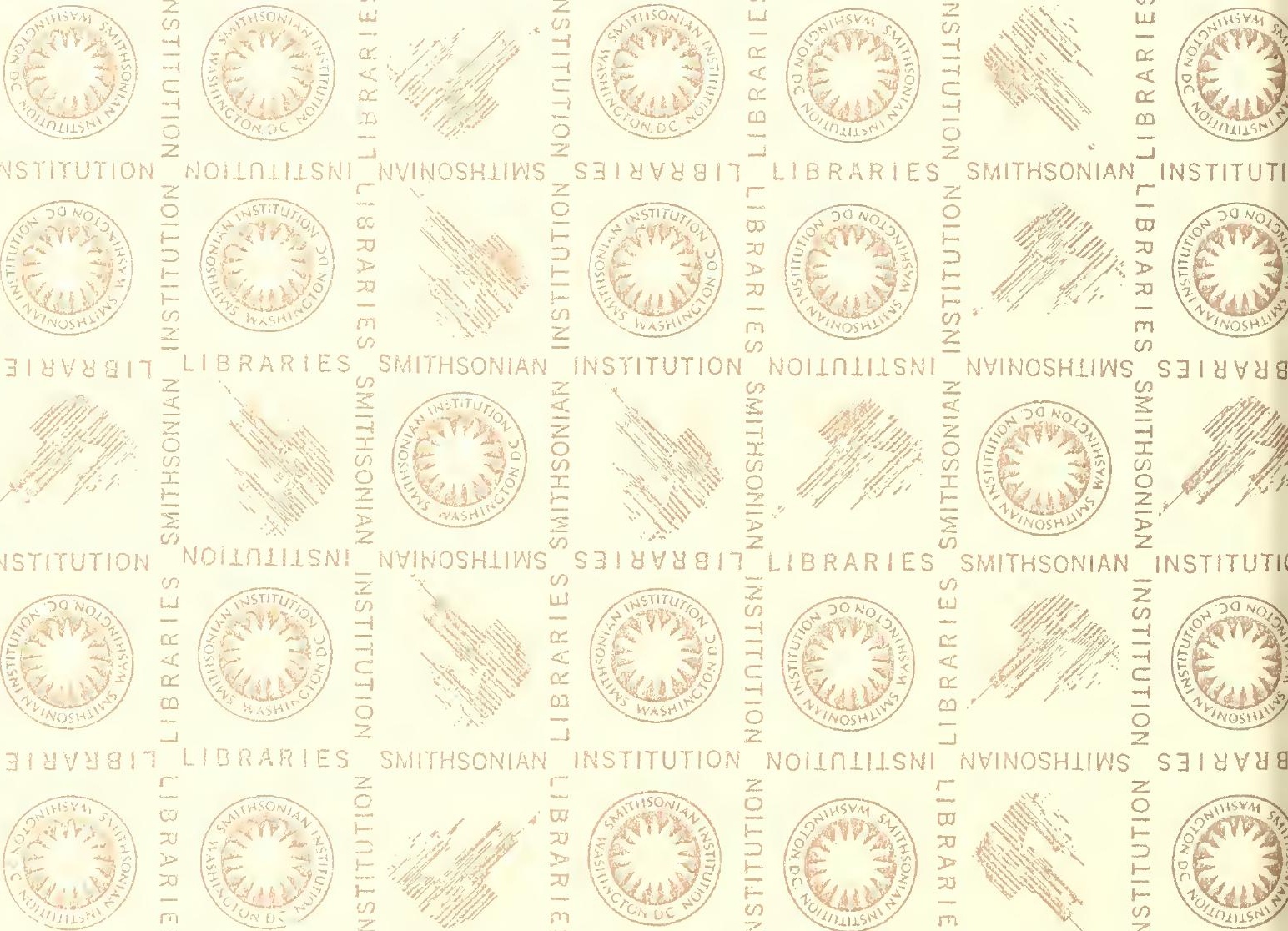

S $\exists I \forall \forall \forall 8$
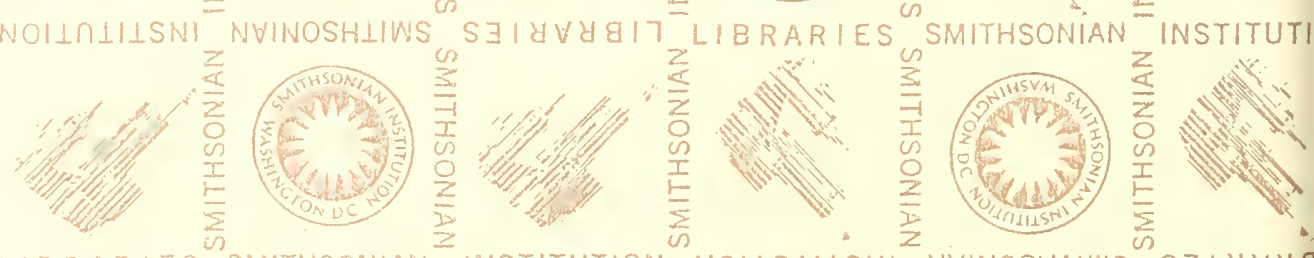
ARIES क $S M I T H S O N I A N$
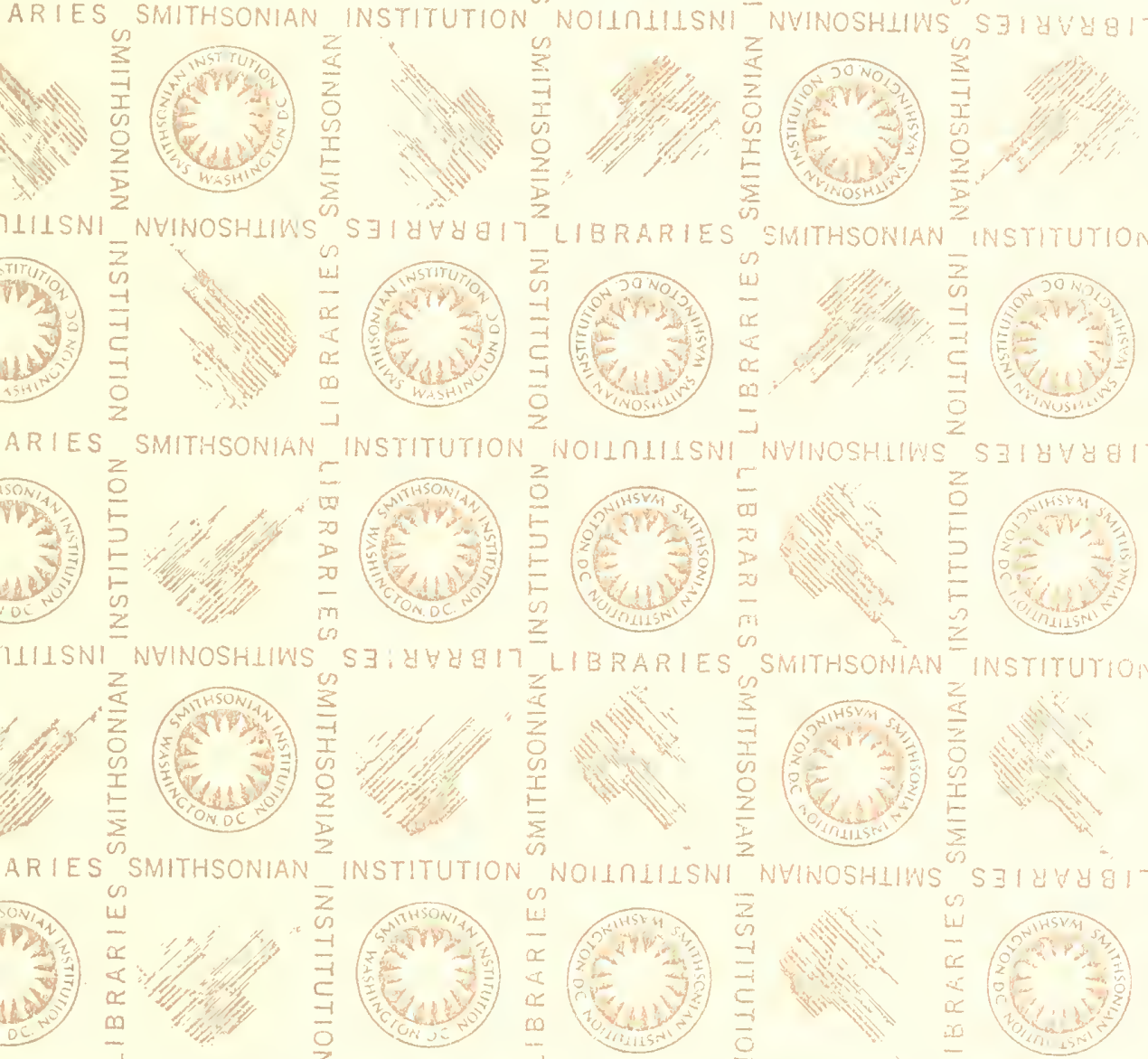

111 SNI NVINOSHLINS
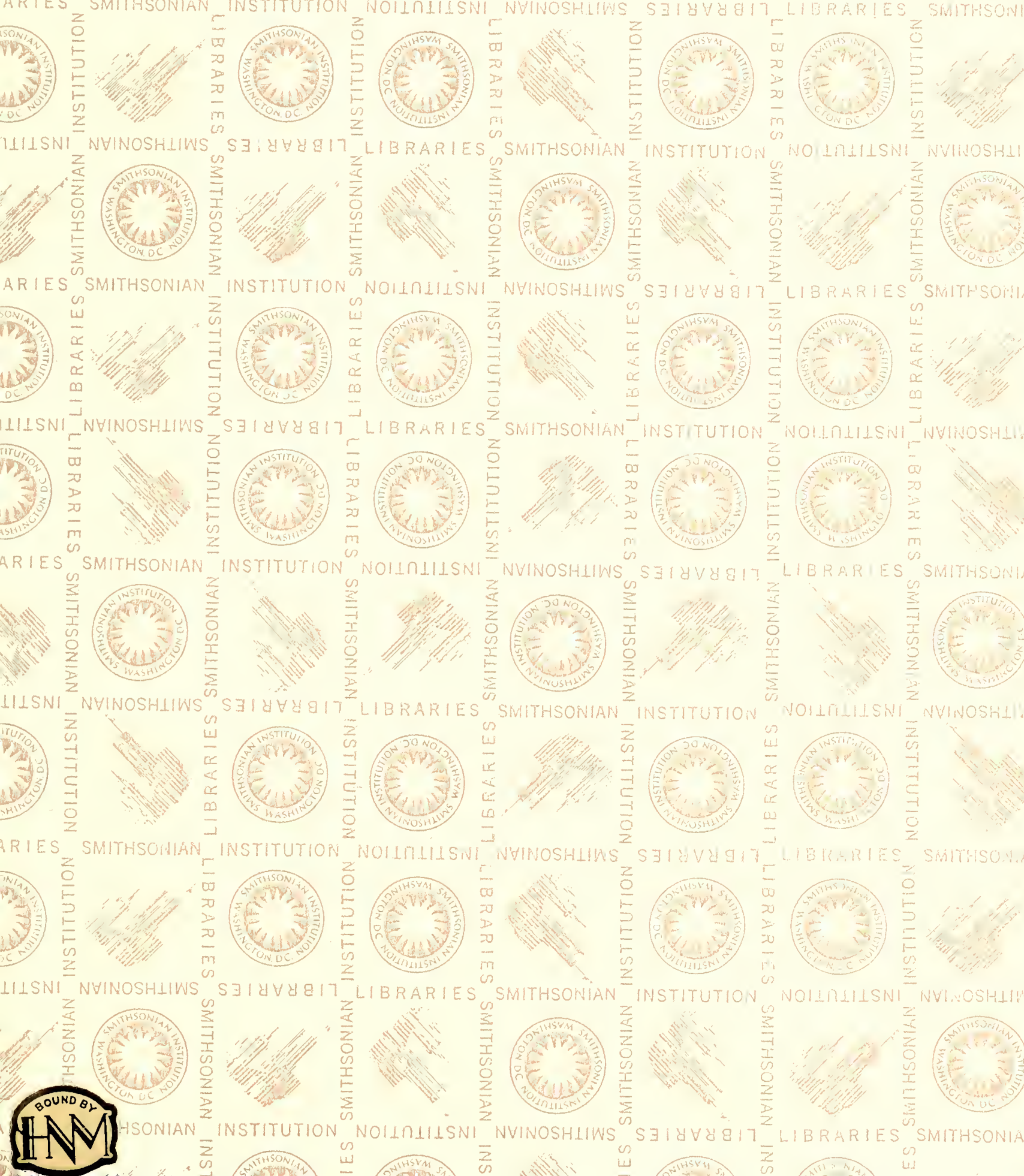
